Florida International University FIU Digital Commons

$3-31-2005$

\title{
On the developmental continuity/discontinuity of early adolescent patterns of racial identity salience : relations with later identities and psychosocial adjustment
}

Anthony L. Burrow

Florida International University

DOI: $10.25148 /$ etd.FI14051892

Follow this and additional works at: https://digitalcommons.fiu.edu/etd

Part of the Psychology Commons

\section{Recommended Citation}

Burrow, Anthony L., "On the developmental continuity/discontinuity of early adolescent patterns of racial identity salience : relations with later identities and psychosocial adjustment" (2005). FIU Electronic Theses and Dissertations. 1869.

https://digitalcommons.fiu.edu/etd/1869 
FLORIDA INTERNATIONAL UNIVERSITY

Miami, Florida

ON THE DEVELOPMENTAL CONTINUITY/DISCONTINUITY OF EARLY

ADOLESCENT PATTERNS OF RACIAL IDENTITY SALIENCE: RELATIONS

WITH LATER IDENTITIES AND PSYCHOSOCIAL ADJUSTMENT

A dissertation submitted in partial fulfillment of the

requirements for the degree of

DOCTOR OF PHILOSOPHY

in

PSYCHOLOGY

by

Anthony L. Burrow

2005 
To: Dean R. Bruce Dunlap

College of Arts and Sciences

This dissertation, written by Anthony L. Burrow, and entitled On the Developmental Continuity/Discontinuity of Early Adolescent Patterns of Racial Identity Salience:

Relations with Later Identities and Psychosocial Adjustment, having been approved in respect to style and intellectual content, is referred to you for judgment.

We have read this dissertation and recommend that it be approved.

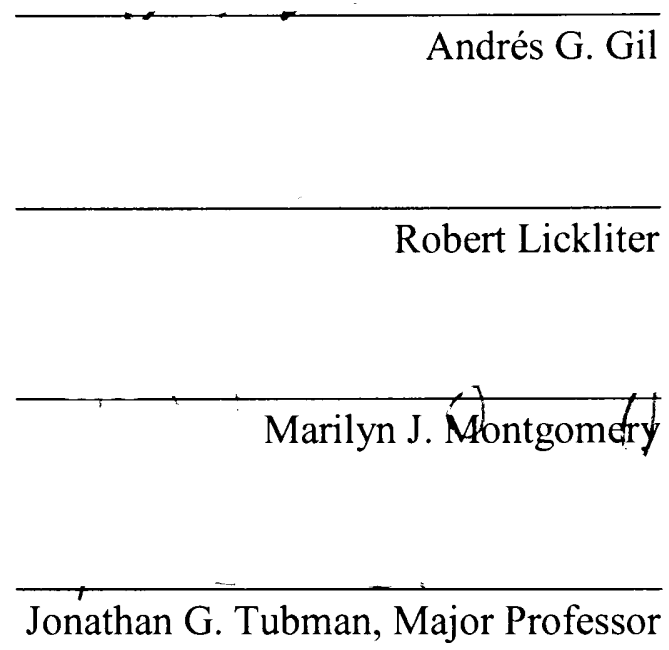

Date of Defense: March 31, 2005

The dissertation of Anthony L. Burrow is approved.
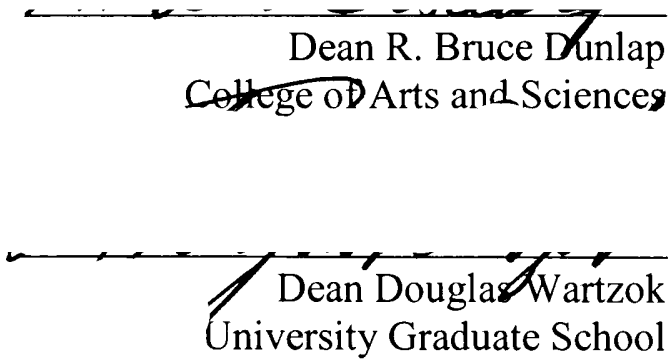

Florida International University, 2005 
(C) Copyright 2005 by Anthony L. Burrow

All rights reserved. 


\section{DEDICATION}

This dissertation is dedicated to those who have helped me to grow. 


\section{ACKNOWLEDGMENTS}

I would like to acknowledge my major professor, Dr. Jonathan Tubman, for his constant encouragement and support of not only this dissertation, but also my personal and professional development. Also, I would like to thank my committee members, Drs. Andrés Gil, Robert Lickliter, and Marilyn Montgomery, for their motivation, mentoring, and insight towards helping me complete this work. Each of these scholars has made this otherwise daunting task seem simple.

In addition, I would like to thank sincerely the Florida Education Fund's McKnight Doctoral Fellowship program and the American Psychological Association's Minority Fellowship program for enabling me to receive my doctoral training. My appreciation for the opportunities afforded to me in this time equals my passion for serving those in the next. 
ABSTRACT OF THE DISSERTATION

ON THE DEVELOPMENTAL CONTINUITY/DISCONTINUITY OF EARLY

ADOLESCENT PATTERNS OF RACIAL IDENTITY SALIENCE: RELATIONS

WITH LATER IDENTITIES AND PSYCHOSOCIAL ADJUSTMENT

by

Anthony L. Burrow

Florida International University, 2005

Miami, Florida

Professor Jonathan G. Tubman, Major Professor

Given the significant amount of attention placed upon race within our society, racial identity long has been nominated as a meaningful influence upon human development (Cross, 1971; Sellers et al., 1998). Scholars investigating aspects of racial identity have largely pursued one of two lines of research: (a) describing factors and processes that contribute to the development of racial identities, or (b) empirically documenting associations between particular racial identities and key adjustment outcomes. However, few studies have integrated these two approaches to simultaneously evaluate developmental and related adjustment aspects of racial identity among minority youth. Consequently, relations between early racial identity developmental processes and correlated adjustment outcomes remain ambiguous. Even less is known regarding the direction and function of these relationships during adolescence. To address this gap, the present study examined key multivariate associations between (a) distinct profiles of racial identity salience and (b) adjustment outcomes within a community sample of African-American youth. Specifically, a person-centered analytic approach (i.e., cluster 
analysis) was employed to conduct a secondary analysis of two archived databases containing longitudinal data measuring levels of racial identity salience and indices of psychosocial adjustment among youth at four different measurement occasions.

Four separate groups of analyses were conducted to investigate (a) the existence of within-group differences in levels of racial identity salience, (b) shifts among distinct racial identity types between contiguous times of measurement, (c) adjustment correlates of racial identity types at each time of measurement, and (d) predictive relations between racial identity clusters and adjustment outcomes, respectively. Results indicated significant heterogeneity in patterns of racial identity salience among these AfricanAmerican youth as well as significant discontinuity in the patterns of shifts among identity profiles between contiguous measurement occasions. In addition, within developmental stages, levels of racial identity salience were associated with several adjustment outcomes, suggesting the protective value of high levels of endorsement or internalization of racial identity among the sampled youth. Collectively, these results illustrated the significance of racial identity salience as a meaningful developmental construct in the lives of African-American adolescents, the implications of which are discussed for racial identity and practice-related research literatures. 
I. INTRODUCTION

II. LITERATURE REVIEW 6

Developmental Science $\quad 7$

Identity $\quad 12$

Racial Identity 10

Racial Identity Development $\quad 11$

Adjustment Correlates of Racial Identities $\quad 15$

Limitations of the Existing Research on

Racial Identity

Research on Early Race-Related Constructs in Youth Populations 19

$\begin{array}{ll}\text { Adolescence as a key developmental stage } & 20\end{array}$

Benefits of Understanding Racial Identity Salience in Adolescence $\quad 21$

Racial identity Salience within a Developmental

Psychological Framework $\quad 22$

The Current Study $\quad 26$

III. METHODOLOGY 30

Description of Database $\quad 30$

Participants $\quad 30$

Measures $\quad 33$

Analytic Procedures $\quad 41$

Research Questions of the Current Study 41

Analytic Plan $\quad 42$

IV. RESULTS 44

Research Question 1. $\quad 44$

Wave 1 Cluster Analysis $\quad 45$

Wave 2 Cluster Analysis $\quad 48$

Wave 3 Cluster Analysis $\quad 50$

Wave 4 Cluster Analysis $\quad 52$

Summary of Cluster Solutions across the Four

Waves of Measurement $\quad 55$

Research Question $2 . \quad 56$

Wave 1 to Wave 2 Crosstabulations $\quad 57$

Wave 2 to Wave 3 Crosstabulations $\quad 59$

Wave 3 to Wave 4 Crosstabulations 61

Summary of Cluster Shifts Between Each Contiguous

Pair of Measurement Occasions 
Research Question 3. $\quad 67$

Adjustment Outcomes by Cluster in Wave 1 68

Adjustment Outcomes by Cluster in Wave 2 68

Adjustment Outcomes by Cluster in Wave $3 \quad 69$

Adjustment Outcomes by Cluster in Wave 4 70

Summary of Adjustment Outcomes across the Four

Measurement Occasions 71

Research Question 4.

Early Racial Identity Salience Clusters as Predictors of Later Adjustment Outcomes 73

Early adjustment indices as predictors of later levels of racial identities $\quad 77$

Summary of analyses of reciprocal cross-time relations 79

V. DISCUSSION 112

Summary of Key Findings $\quad 113$

Synthesis of Current Research and the Findings of this Study 116

Heterogeneity in Patterns of Racial Identity Salience 116

Continuity/Discontinuity in Patterns of Racial Identity Salience 121

Associations between Racial Identity Salience

and Adjustment Outcomes 124

Implications of Findings $\quad 127$

Theoretical Implications $\quad 127$

Practice-Related Implications $\quad 129$

Study Limitations and Directions for Future Research 133

LIST OF REFERENCES 136

$\begin{array}{ll}\text { APPENDIX } & 150\end{array}$

$\begin{array}{ll}\text { VITA } & 176\end{array}$ 


\section{LIST OF TABLES}

TABLE

PAGE

1. Demographic Information for Entire Waves 1 through 4 Samples

2. Demographic Information for African-American Sample in Waves 1 through 4 Samples

3. Means for Unstandardized Racial/Ethnic Identity Variables for African-American Youth Generated by Cluster Analysis in Wave 1

4. Means for Unstandardized Racial/Ethnic Identity Variables for African-American Youth Generated by Cluster Analysis in Wave 2

4. Means for Unstandardized Racial/Ethnic Identity Variables for African-American Youth Generated by Cluster Analysis in Wave 3

6. Eigenvalues from Principal Factoring Method Employed for Racial Identity Salience Variables.

7. Means for Unstandardized Racial/Ethnic Identity Composite Variables for African-American Youth Generated by Cluster Analysis in Wave 4

8. Means for Unstandardized Racial/Ethnic Identity Variables for African-American Youth Generated for Cluster Analysis in using the reduced Wave 3 sample

9. Wave 1 Means, Standard Deviations, and Significance Tests for Adjustment Outcomes by Cluster Membership

10. Wave 2 Means, Standard Deviations, and Significance Tests for Adjustment Outcomes by Cluster Membership

11. Wave 3 Means, Standard Deviations, and Significance Tests for Adjustment Outcomes by Cluster Membership

12. Wave 4 Means, Standard Deviations, and Significance Tests for Adjustment Outcomes by Cluster Membership 
13. Prevalence of Lifetime Psychiatric Disorders Diagnoses by Cluster Membership at Wave 4

14. Prevalence of Past-year Psychiatric Disorders Diagnoses by Cluster Membership at Wave 4

15. Hierarchical Multiple Regression Model Predicting CESD Depression $(\mathrm{N}=272)$

16. Hierarchical Multiple Regression Model Predicting Personal Resources $(\mathrm{N}=272)$

17. Hierarchical Multiple Regression Model Predicting Numbers of alcoholic drinks per month $(\mathrm{N}=244)$

18. Hierarchical Multiple Regression Model Predicting Number of times using marijuana during the past month $(\mathrm{N}=267)$

19. Hierarchical Multiple Regression Model Predicting Number of lifetime sexual partners $(\mathrm{N}=255)$

20. Hierarchical Multiple Regression Model Predicting amounts of substance use before or during sexual intercourse $(\mathrm{N}=244)$

21. Hierarchical Multiple Regression Model Predicting percentage of episodes of protected sexual intercourse $(\mathrm{N}=239)$

22. Hierarchical Multiple Regression Model Predicting Racial Significance by earlier levels of Family Pride $(\mathrm{N}=271)$

23. Hierarchical Multiple Regression Model Predicting Racial Significance by earlier levels of Self-Derogation ( $N=266)$ 


\section{Theoretical Perspective}

Built upon an evolving framework for understanding behavior, developmental psychology has emerged as a field dedicated to describing and explaining systematic changes occurring over time (Lerner, 1998; Miller, 2002; Overton, 1998). Contemporary perspectives within this field of study have proposed increasingly complex characterizations of development that highlight the inclusive, integrative, and dynamic properties of change that occur throughout a lifetime (Lerner, 1998; Cairns, 1998). The value of current development psychological approaches resides in their ability to inform a broad range of existing areas of psychological study by maintaining that particular periods of development (e.g., childhood, adolescence, or adulthood) and particular developmental outcomes (e.g., adaptive or maladaptive) cannot be meaningfully disconnected from one another within the larger life-span context (Lerner, 1998; Cairns, 1998).

Often depicted as a transitional time involving psychological distress and instability, entry into adolescence is characterized by an emerging sense of self, the search for autonomy, and an increasing importance placed on individualism (Erikson, 1968). These hallmarks of this developmental stage mutually contribute to the critical task of identity formation - an intrapersonal processes requiring that individuals negotiate who they are in relation to their social environment (Grotevant, 1992; Erikson, 1959, 1968). Therefore, identity serves as the basis for guiding how we come to know ourselves and, in turn, contributes to the manner in which we function within society. Insofar as the development of individuals' identities is associated with a broad range of 
developmental outcomes (Erikson, 1985; Grotevant, 1992; Spencer, 2001), there is an expanding interest in investigating complex and multifaceted aspects of identity within specific domains (Grotevant, 1986; Hewitt, 1989).

Given the historic and present attention placed upon race and ethnicity within our society, racial identity long has been nominated as a significant and influential factor for human development (Cross, 1971; Kando, 1977). Numerous scholars representing a wide range of disciplines have described, measured, and posited explanations of various aspects of racial identity (e.g., Cross, 1971; Helms, 1990; Phinney et. al, 1997; Smith, Walker, Fields, Brookins, \& Seay, 1999; Steele, 1997), particularly among racial and ethnic minorities. The principal aims pursued by racial identity research primarily fall into one of two camps of research: (a) empirical investigations of mechanisms and processes that contribute to the development of racial identities (e.g., Cross, 1971; Helms, 1990), or (b) descriptions of associations between particular racial identities and a range of adaptive or maladaptive outcomes (e.g., Sellers \& Shelton, 2003; Steele, 1997). However, few studies have attempted to synthesize these two lines of research to evaluate simultaneously both the ontogenetic and the adjustment aspects of racial identity among minority youth. Consequently, little is understood regarding relations between early developmental processes contributing to the construction of racial identities and the diversity that exists in patterns of behavioral adjustment associated with different racial identities.

Even less well understood are the direction and function of these relationships during adolescence. While extensive racial identity research involves college-aged or adult populations, only a modest amount of empirical research has been dedicated to this 
construct in younger groups of individuals (Resnicow et al., 1999; Stevenson, 1995). Rather, numerous studies involving adolescents and children focus on precursors for specific racial and ethnic identities (or early race-related constructs), such as levels of race-awareness, racial orientation, and racial identity salience (e.g., Biafora, Taylor, Warheit, Zimmerman, \& Vega, 1993; McGraw, Durm, \& Durnam, 1989; Spencer, 1984). Specifically, among African-American youth there is a considerable amount of evidence that these race-related constructs become relevant at an early age (Aboud, 1988; Aboud $\&$ Ruble, 1987; Spencer, 1970). In addition, the relative importance of these early racerelated constructs lies in their purported associations with key adjustment outcomes including, academic achievement, levels of self-esteem and depression, delinquency, and substance use (Parham \& Helms, 1985; Smith, Walker, Fields, Brookins, \& Seay, 1999; Taylor \& Turner, 2002).

With regard to African-American youth, growing literatures have contended that determination of individuals' racial identity clearly involves complex and dynamic psychological and socialization processes that are significantly associated with adjustment outcomes. However, the strength and stability of race-related constructs, such as racial awareness and the racial identity salience, within this critical stage of human development remains unclear (Shelton \& Sellers, 2000; Stevenson, 1995). Specifically, little is currently understood regarding the degree of continuity/discontinuity in associations between race-related constructs and co-occurring indices of adjustment across stages of adolescence. Therefore, by integrating developmental and racial identity literatures, the present study proposed to examine the continuity/discontinuity and the 
significance of race-related constructs (primarily that of racial identity salience) during adolescent development using a community sample of African-American youth.

Purpose of Study

As the quality of early adjustment has been linked to key developmental outcomes (Cicchetti \& Rogosch 2002; Lerner \& Galambos, 1998), documenting relations between early adolescent indicators of racial identity salience and late adolescent/young adult (a) indicators of racial identity salience and (b) key indices of psychosocial adjustment is significant and expands the existing racial identity research literature (McLoyd \& Steinberg, 1998; Parham, 1989). Thus, using a secondary analysis of longitudinal community data, the present study sought to document cross-sectional and cross-temporal relationships between adolescent indices of racial identity salience and patterns of adjustment in adolescence and young adulthood. This study had four aims. The first aim of the study was to identify homogenous subgroups of African-American youth on the basis of their reported levels of racial identity salience during adolescence and young adulthood. The second aim of the study was to document patterns of continuity/discontinuity in associations between racial identity salience and adolescent adjustment outcomes among homogenous clusters of African-American youth. The third aim of the study was to document cross-sectional relations between identity subgroup membership and patterns of adolescent behaviors at four times of measurement ranging from early adolescence to young adulthood. The fourth aim of the study was to determine whether (a) levels of racial identity salience are associated with changes in adjustment and/or (b) levels of psychosocial adjustment are associated with changes in levels of racial identity salience. 
The proposed study was significant for three reasons. First, integrating assessments of factors influencing race-related constructs with related mental health and adjustment outcomes occurring over time may promote better understanding of adolescent development than currently exists. Second, by using an adolescent sample, this study contributed to existing knowledge of how levels of racial identity salience are associated with key developmental processes and adjustment outcomes prior to adulthood. Third, documenting the continuity/discontinuity of levels of racial identity salience across developmental transitions in adolescence has direct implications for identifying risk and protective factors associated with key indices of adjustment. Fourth, greater understanding of the impact of racial identity salience in the transitions from adolescence through young adulthood may provide information that can aid in the development of more effective interventions with African-American youth. In view of these purposes, understanding core processes contributing to the quality of adolescent adjustment may lead to intervention and prevention strategies that increase the utilization and effectiveness of mental health services for vulnerable African-American youth populations. 


\section{Chapter II: Literature Review}

This review of literature will focus on the implications of constructs related to racial and ethnic identity development and related adjustment outcomes. Based upon several important advancements that have occurred in the field of developmental psychology, this chapter will highlight an emerging potential for this discipline to revisit and broaden current understanding of key developmental phenomena related to these two constructs. Given the documented significance of identity for human development, developmental risk and protective aspects of this construct will be explored in depth. Specifically, a developmental psychological framework may inform existing knowledge of both the underlying developmental processes and adjustment outcomes related specifically to racial identity salience and other related constructs. Building upon an extensive literature regarding racial and ethnic identity, this framework has the potential to unify unique and traditionally distinct aspects of the existing race, ethnicity, and identity developmental literatures to generate a more compelling picture of the comparable significance of these factors for individuals. In particular, within the important developmental stage of adolescence, this knowledge would be extremely useful for identifying risk and protective factors associated with race- and ethnicity-related constructs. In addition, this framework may also inform the development of more efficacious and effective intervention and prevention strategies aimed specifically at reducing maladaptive outcomes among members of vulnerable racial and ethnic groups. Each of these components will be discussed and integrated in this chapter. 
As a discipline, developmental psychology has focused on describing and explaining patterns of change occurring over key periods in the life span (Cairns, 1998; Lerner, 1998). However, the manner in which development has been viewed by investigators in different contexts (Kuhn, 1962) has dictated the approaches utilized to investigate it scientifically (Miller, 2002). Traditional theories of development often explained change using singular components such as biological, cognitive, or emotional variables. Yet over time, theoretical and methodological advances deemed these conceptualizations inadequate insofar that they were overly simplistic, exclusive, and often reduced scientific understanding to competing explanations of development (e.g., nature versus nurture) (Gottlieb, Wahlsten, \& Lickliter, 1998; Lerner, 1998; Overton 1998).

To remedy limitations in these traditional approaches, more complex characterizations of development were warranted, requiring that explanations be capable of accounting for inclusive, integrative, and dynamic properties of change. Such requirements prompted developmental investigators to identify and delineate underlying processes and mechanisms facilitating change (Lerner, Taylor, \& von Eye 2002). As a result, developmental approaches and theories incorporating integrated (i.e., interdisciplinary) models of development have emerged and contributed significantly to contemporary perspectives. For example, bio-ecological models (Bronfenbrenner \& Crouter, 1983; Bronfenbrenner \& Morris, 1998), person-context interaction theories (Magnusson \& Stattin, 1998), and psychobiological perspectives (Gottlieb, Wahlsten, \& Lickliter, 1998) illuminate the results of multidisciplinary collaboration and integration 
aimed at understanding developmental phenomena. In addition, other recent developmental psychological frameworks such as life-span theory (Baltes \& Goulet, 1970; Baltes, Lindenberger, \& Staudinger, 1998), life-course theory (Elder, 1998), and personhood perspectives (Csikszentmihalyi, 1996; Csikszentmihalyi \& Rathunde, 1998) negate the notion that development is age-specific and unidirectional, and instead suggest an organized, dynamic and relational view of development occurring over a lifetime. These person-centered approaches describe a range of correlates and outcomes associated with developmental processes that may be differentially experienced among specific population subgroups, and improve understanding of heterogeneity in individuals' behavior (Bergman, 2000; Magnusson \& Bergman, 1990; Magnusson \& Stattin, 1998).

Quite different from earlier perspectives, contemporary developmental frameworks adopt the perspective that particular periods of development (e.g., childhood, adolescence, or adulthood) and particular developmental outcomes (e.g., adaptive or maladaptive) cannot be meaningfully studied in isolation from one another. Moreover, an understanding of development requires appreciating key relations between individuals and their environments within a life-span context (Lerner, 1998; Cairns, 1998). Therefore, current developmental psychological frameworks inherently avoid reductionistic explanations of how and why individuals develop by embracing multiple levels of analysis. Doing so reveals relational and multidirectional influences linking developmental factors, individuals, and outcomes (Overton, 1998). Characterizing development in this way enables investigators to integrate domains previously considered unrelated, thereby potentially informing a broad range of existing areas of psychological study. Therefore, contemporary developmental psychological frameworks often provide 
direction regarding the integration and synthesis of models of development, that lead to more appropriate methodological strategies and the establishment of salient explanatory constructs.

\section{Identity}

Understanding the processes by which individuals come to understand themselves in the midst of vast amounts of biological and environmental information has been a critical and long-term endeavor for developmental scientists (Cairns, 1998). One construct that has emerged from this endeavor and elicited a great deal of attention within developmental literatures is that of identity. Characterizing the psychosocial significance of identity for human behavior, the conceptual framework of symbolic interactionism highlights processes by which individuals construct the social realities in which they operate (Blumer, 1969; Kando, 1977; Mead, 1934). Deconstruction of this perspective reveals a tripartite division of basic behavioral functions of individuals: a) individuals obtain knowledge and understanding through ascribing meaning to objects, $b$ ) meaning is obtained through social interaction and, c) through social interaction, individuals construct their realities. (Griffin, 1997; Kando, 1977).

Elaborating upon these key elements of symbolic interactionism, Herbert Blumer writes, "Thus, human interaction is mediated by the use of symbols, by interpretation, or by ascertaining the meaning of one another's actions. This mediation is equivalent to inserting a process of interpretation between stimulus and response in the case of human behavior" (Blumer, 1969, p. 180). As defined by Erikson (1968), identity fits well into this context as "that sense of inner solidarity with the ideals and values of a significant social group" (Kroger, 2000, p. 5). This position is embedded in both Erikson's (1968) 
theory of ego identity development and Marcia's (1980) stage model of identity formation, contending that the construction of individuals' identity involves the psychosocial positioning of one's self based upon physical, demographic, and environmental limitations (Ianni, 1983; Smith, 1976). Therefore, as a platform for understanding development, symbolic interactionism proposes the central premise: the manner in which individuals identify themselves is guided by biological, psychological, social, and cultural influences (Miller, 2002). Through the availability of specific sets of symbols and adhering to them in unique fashions, individuals identify themselves.

\section{Racial Identity}

Stepping beyond a general understanding of identity, many researchers have used general identity theory and models to understand more specific elements that appear to compose or influence identity, such as gender, culture, race, and ethnicity (Grotevant, 1986; Hewitt, 1989). For example, given the historic and present attention placed upon race within American society, racial identity has been nominated as a significant and influential factor for human development (Cross, 1971; Gandy, 2001; Hargrow, 2001; Helms, 1990; Kando, 1977; Neville \& Lilly, 2000; Parham \& Helms, 1985). Racial identity has traditionally referred to the classification of one's self within a particular racial group. Specifically, racial identity signifies "a sense of group or collective identity based on one's perception that he or she shares a common racial heritage with a particular racial group" (Helms, 1990, p. 3). Primarily associated with historically marginalized racial groups, this process of self-identification is also influenced by several factors including individuals' emotional status (Cross, 1971), social-political norms (Helms, 
1995), and the degree to which individuals internalize social prejudices and racism (Jones, 1997; Kohatsu \& Richardson, 1996).

Furthermore, the construction of individuals' racial identities involves psychological subscriptions to social ideologies that are congruent with the symbolic interactionist perspective. Stated differently, individuals' racial identities cannot be meaningfully understood without an appreciation of social values such as the salience of race, prejudice, and discrimination (Jones, 1997). Therefore, characterizing the interaction of individuals and their environments enables investigators to more sufficiently describe underlying patterns of development leading to different racial identities.

\section{Racial Identity Development}

Delineating factors that contribute to individuals' racial identities has been a central aim of racial identity theorists for over three decades (Shelton \& Sellers, 2000). Within this established research literature, developmental factors and processes leading to the construction of minority (non-White) racial identities have received the greatest attention from researchers. As a result, several models of racial identity development have been established predominately for Black, and in particular African-American individuals, and more recently for Asian, White, and mixed-race individuals. Typically, these models have characterized normative developmental processes regarding how individuals perceive their race within contemporary American society. Clear examples of these processes are depicted in the predominant models of Black racial identity development (e.g., Cross, 1971; Helms, 1986; 1991; Thomas, 1971). 
Early investigations of Black or African-American identity conceptualized the development of a racial identity as critical for survival within an oppressive and White society (French, Seidman, Allen, \& Aber, 2000; Thomas, 1971). Specifically, Thomas' (1971) work on negromachy (or having a confused Black identity due to a dependency upon White society) sketched a directional progression that Black individuals may undergo to establish a healthy and productive Black identity. This progression ranged from an initial phase of verbally denigrating White people towards a more transformative phase of respecting and serving Black communities and institutions. Building upon this initial work, the most often cited model of Black identity is Cross' (1971) nigrescence (or becoming Black) theory of racial identity development. In its original form, this theory describes the process of affirming one's Black identity by progressing through increasingly more complex stages (Shelton \& Sellers, 2000; Parham \& Helms, 1985).

In this model, Black identity is achieved by progressing through five developmental stages ranging from anti-Black to pro-Black attitudes and beliefs (Cross, 1971). The first stage, Pre-Encounter, depicts the idealization of White society and values coupled with a simultaneous depreciation of Black society and values. Individuals at this stage of racial identity development reflect self-hatred and in doing so seek to assimilate into White society. For Cross, then, Stage One Pre-Encounter manifests a maladaptive attitude and behavioral style for Black Americans. The Stage Two, Encounter, involves a catalyst event, which explicitly exposes the reality of race, and in turn, racism within American society. This increased awareness may encourage individuals to examine racial aspects of their identity more closely. During Stage Three, Immersion-Emersion, Cross stipulated that Blacks manifest behaviorally their awareness 
gained in the Encounter stage. This is to say, initially, immersion solely into a Black identity necessitates an absolute admiration for all things "Black" and simultaneous devaluation for all things White. Thereafter, emersion marks the lessening of intense anti-White feelings and attitudes, and prepares Black individuals to move toward the Internalization stage. The Internalization stage (Stage Four) describes individuals who have adaptively embraced or internalized their Black identity in a manner comfortable for them. Last, Stage Five of nigrescence, Internalization-Commitment, constitutes engagement in political and social activism for all civil rights issues. Revisiting his nigrescence model, Cross $(1991,1995)$ amended several key aspects of the proposed developmental stages. One discernable change includes highlighting the importance of social interactions and experiences for determining the extent to which race becomes salient for Black individuals (Pope-Davis, Liu, Ledesma-Jones, \& Nevitt, 2000; Vandiver, 2001).

Expanding upon this modification and moving away from stage-like explanations of identity development, Helms $(1984,1986,1990)$ suggested that a more compelling delineation of racial identity development could be illustrated using the notion of statuses - a notion similar to the work of Marcia (1966) and others. Specifically, Helms theorized that each stage of Black racial identity development originally afforded by Cross's nigrescence model, inherently consisted of multiple levels (i.e., statuses) of racial attitudes and beliefs. According to Helms (1984), Pre-Encounter involved an idealization of Whiteness and a denigration of Blackness, Encounter involved levels of race consciousness, Immersion/Emersion involved an idealization of Blackness and a denigration of Whiteness, and Internalization involved levels of racial transcendence. 
Moreover, Helms proposed that developmental progressions of race-related identities occurred among bimodal resolutions of how individuals view themselves within each stage. Recently, this step away from linear and unidirectional stage progression has been developed further to suggest that an individual's precise position along these continua of Black identity is informed by diverse racial stimuli obtained through social experiences (Helms, 1990; Neville \& Lilly, 2000). In support, Parham (1989) suggested that individual differences (e.g., race salience and racial attitudes) produce unique patterns of stage progression, and perhaps more compelling, that individuals may revisit stages throughout their lifetime. Furthermore, these ideas have since been expanded towards other race-related constructs including racial orientation and racial pride (e.g., Phinney, 1990; Spencer \& Markstrom-Adams, 1990).

In addition, empirical assessments have suggested that movement along dimensions of Black racial identity occurs as a function of broader racial and ethnic socialization processes (Stevenson, 1995, 1997). Studies have documented that school (e.g., Kerwin \& Ponterotto, 1995; Pope, 2000; Shelton \& Sellers, 2000), peer (e.g., Plummer, 1995; Thompson, 1994), and family environments (e.g., McRoy \& Zurcher, 1983; Peters, 1985; Thomas \& Speight, 1999) all contribute directly and indirectly to the manner by which individuals come to identify themselves racially and ethnically. For example, an emerging research literature has suggested that through parental interaction, Black parents communicate to their children racially relevant thoughts, values, and attitudes (e.g., how to deal with racial bias and discrimination) that help youth navigate their social environments (Demo \& Hughes, 1990; Hughes, 2003). These recent contributions to the racial identity literature are significant because they have highlighted 
the importance of viewing Black racial identity development as being less static (i.e., independent of other factors) and more multidimensional and dynamic (Banks, 1989). Therefore, current understanding of racial identity development lends itself to the simultaneous investigation of multiple domains, including biological and environmental stimuli, psychological understanding and social behavior, and developmental stage. An appreciation for each of these factors lends itself to the broader potential of a contemporary developmental psychological perspective for investigating racial identity. Adjustment Correlates of Racial Identities

Beyond developmental processes, explorations of associations between racial identity and psychosocial adjustment outcomes are equally critical to understanding the overall significance of this construct for individuals. Numerous studies have investigated relations between racial identity and key individual- and social-level adjustment outcomes (Carter \& Helms, 1990; Helms, 1990; Parham \& Helms, 1985; Sellers, Chavous, Cooke, 1998; Taub \& McEwen, 1992). Two central foci maintained within this research literature have been to (a) determine if racial identity is predicative of specific adjustment outcomes, and (b) describe differential patterns in these outcomes that may exist between different racial identities (Taub \& McEwen, 1992; Stevenson, 1997). Together, these foci have addressed the identification and explanation of patterns of adjustment outcomes in academic, familial, psychosocial, and psychiatric domains.

Reflecting the recognized significance of racial identity as a basis for understanding individuals' experiences, several researchers have developed and employed racial identity inventories designed to explore key race-related attitudes and beliefs that individuals possess. Responses from these inventories have been utilized to 
establish indices of the self-reported salience and importance that individuals place on their racial identities (Helms, 1990). Examples of such inventories include the Developmental Inventory of Black Consciousness (Milliones, 1980), the Black Racial Identity Attitudes Scale (Parham \& Helms, 1981), the Suinn-Lew Asian Self-Identity Acculturation Scale (Suinn, Rickard-Figueroa, Lew, \& Vigil, 1987), the White Racial Identity Attitudes Scale (Helms \& Carter, 1990), as well as ethnic identity inventories such as the Multi-group Ethnic Identity Measure (Phinney, 1992). For the most part, these inventories have been developed in accordance with pre-existing models of racial identity development, so that individuals' responses could be readily associated with specific stages or statuses of racial identity (Brookins, Anywabwile, \& Nacoste, 1996; Helms, 1990). By classifying racial identity typologies, researchers have then been able to link precise levels of racial identity with patterns in adjustment outcomes (Neville \& Lilly, 2000).

A critical area of adjustment that has been associated with racial identity, particularly among African-American individuals, is that of psychological adjustment (Carter, 1991; Helms \& Carter, 1990; Pope, 1998; Taub \& McEwen, 1992). Specifically, through a range of methodological strategies, researchers have maintained that more internalized, salient, and positive African-American identities are associated with factors such as enhanced self-esteem and self-image (McRoy \& Zurcher, 1982; Parham and Helms, 1985), higher perceptions of racial and ethnic orientation (Chavous, 2000), increased moral reasoning and development (Moreland \& Leach, 2001), and increased autonomy (Taub \& McEwen, 1992). Similar findings have been documented in studies investigating racial and ethnic identity-related constructs in Asian and other ethnic 
minority populations (e.g., Lysne \& Levy, 1997, Spencer \& Markstrom-Adams, 1990;

Phinney, Cantu, Kurtz, 1997).

Another domain deemed relevant to racial identity is that of social adjustment. The central issue of this area of research has been to determine whether particular levels of racial identity are systematically associated with incrementally more positive or negative social behaviors. Among African-American individuals in particular, some studies have demonstrated positive relationships between indices of racial identity and levels of pro-social (i.e., non-delinquent) behaviors (Bowman \& Howard, 1985; Stevenson, 1997; Winston \& Miller, 1987), positive familial relationships (Johnson, Shireman, \& Watson, 1987), adaptive organizational involvement (i.e., school activities, community organizations; Chavous, 2000), and mature interpersonal relationships (Pope, 1998; Taub \& McEwen, 1992). However, some contrasting evidence has been found primarily through studies investigating adjustment outcomes among African-American individuals in academic environments. For example, some researchers contend that individuals manifesting a strong Black racial identity may decrease their identification with educational achievement, and therefore decrease their academic functioning (Fordham \& Ogbu, 1986; Steele \& Aronson, 1995). Yet, because consistent evidence confirming the extent to which racial identities are associated with adjustment outcomes over time and across diverse social contexts has not yet emerged, continuing research employing person-centered analytic approaches (Bergman, 2000) to delineate the significance racial identity within individuals' lives will better clarify this important issue (Miller, 1999). 


\section{Limitations of the Existing Research on Racial Identity}

To date, the existing body of literature focusing on racial identity-related constructs has yielded significant insight into an important domain of adolescent development. However, when evaluating this body of literature through a developmental psychological perspective, much of the existing knowledge appears discontinuous and poorly integrated (Stevenson, 1995). Specifically, the principal aims pursued by racial identity researchers primarily fall into one of two distinct camps focusing on: (a) factors contributing to the development of particular racial identities or (b) adjustment outcomes associated with particular racial identities. Separately, empirical investigations within these two camps of research have either (a) identified mechanisms that facilitate the development of racial identities or (b) described associations between particular racial identities and various adjustment outcomes. Although these two research lines do not inherently represent competing research programs regarding racial identity, few studies have aimed to integrate the research to evaluate simultaneously both the ontogenetic and the adjustment aspects of racial identity within a specific developmental period.

However, to fully understand the implications of racial identity-related constructs, integration of the different foci captured in each line of research is necessary. Many of the initial theories and models of racial identity were derived prior to the advancement of more complex developmental psychological frameworks. Thus, current depictions of racial identity suggest static and narrower developmental concepts than those that potentially could be pronounced through contemporary perspectives. Specifically, through the multidisciplinary collaboration and exploitation of interdependent developmental concepts gained from employing an integrated developmental 
psychological framework, a renewed look at racial identity-related constructs may broaden current ideas of their development. Synthesizing the contributions of both research lines within an integrated developmental psychological framework may better inform scientific understanding and allow for a more compelling description of the significance of racial identity-related constructs for individuals.

\section{Research on Early Race-Related Constructs in Youth Populations}

Another shortcoming of existing racial identity research literatures concerns limited efforts to merge these two camps of research within an expanded life-span perspective. Currently, little is understood regarding relations between (a) early adolescent developmental processes contributing to the construction and maintenance of salience of racial identities and (b) the diversity that exists in patterns in behavioral and mental health adjustment outcomes among adults manifesting different levels of identity salience. As a result, the direction of influences in and function of these relationships during adolescence and early adulthood have gone largely unexamined (Resnicow, Soler, Braithwaite, Selassie, \& Smith, 1999). While extensive racial identity research utilizes data derived from college-aged and adult samples, only a modest amount of empirical research has been dedicated to the development of this construct in younger populations (Resnicow et al., 1999; Stevenson, 1995). Furthermore, when studies have incorporated adolescent and child samples, they typically have focused only on precursors for racial identities (or early race-related constructs), such as levels of race-salience or awareness (e.g., Biafora, Taylor, Warheit, Zimmerman, \& Vega, 1993; McGraw, Durm, \& Durnam, 1989; Spencer, 1984). In addition, constructs such as racial mistrust (Biafora et al., 1993; Jefferson \& Caldwell, 2002;), racial socialization experiences (e.g., Hughes, 2003; Peters, 
1985; Stevenson, 1995), and the negotiation of multiple identities among mixed-race individuals (e.g., Carter, DeSole, Sicalides, Glass, \& Tyler, 1997; Spencer, 1983; Tizard \& Phoenix, 1993) have also been empirically investigated within youth samples.

Beyond mere descriptive concepts, the significance of these early race-related constructs lies in their potential associations with several key adjustment processes and outcomes during adolescence. Specifically, typical adjustment outcomes investigated in conjunction with race-related measures among youth populations include academic achievement, levels of self-esteem and depression, delinquency, and substance use (Parham \& Helms, 1985; Smith, Walker, Fields, Brookins, \& Seay, 1999; Taylor \& Turner, 2002). For the most part, studies have demonstrated positive associations between racial identity-related constructs and adjustment, in particular for psychological, substance use, and social outcomes (Helms, 1990; Herd \& Grube, 1996; Oyserman et al., 1995; Scribner, Hohn, \& Dwyer, 1995). Collectively, these empirical conclusions point towards a protective influence of positive racial identity-related constructs during adolescence. Therefore, these constructs have been recognized as key components for planning health and mental health risk reduction programs targeting vulnerable youth populations (Gil, Wagner, \& Vega, 2000; Greene, Smith, \& Peters, 1995). Adolescence as a key developmental stage

The limited amount of current understanding regarding racial identity-related constructs during adolescence is problematic because this developmental stage is considered to involve complex psychological and social transitions. These developmental changes potentially have significant implications for later adjustment outcomes (Crockett \& Silbereisen, 2000; Lerner \& Galambos, 1998), such as substance 
use, social relationships and mental health adjustment. Some researchers have underscored the importance of adolescence by contending that significant adjustment problems are more likely to be observed during this period compared to other stages of the life-cycle (Howe, 1997; Rosenthal, 1993; Tizard, 1991). Coupled with an emerging sense of self and autonomy, the task of identity formation during adolescence (see Erikson, 1959, 1968) can be influenced by many other individual experiences. For instance, puberty is a benchmark for entry into adolescence (Graber \& Brooks-Gunn, 1996), and this biological event can make development incrementally more stressful (Graber, Lewinsohn, Seeley, Brooks-Gunn, 1997; Wiesner \& Ittel, 2002). In contrast, social and cognitive transitions that promote awareness of personal choice and commitment typically emerge in late adolescence (Keniston, 1971; Konopka, 1973), which can be an empowering characteristic for individuals. In this way, transitional models of development have been utilized to describe and explain change in terms of unique experiences and events that adolescents face. However, some researchers contend that problems within specific areas of adjustment can exacerbate the challenges individuals encounter as they matriculate through adolescence (Caspi \& Moffitt, 1991). Therefore, factors that youth use to negotiate how they view themselves, including levels of racial identity salience, are critically important for adolescent development. Furthermore, the relations between these factors and key adjustment outcomes may be expressed differentially within specific contexts and across different stages of adolescence. 
In an initial attempt to formulate a model of African-American adolescent racial identity development, Resnicow, Soler, Braithwaite, Selassie, and Smith (1999) concluded that, like adult racial identity, adolescent racial identity is a multidimensional construct. However, in-depth delineation of developmental processes was not possible because this pioneering investigation employed a cross-sectional design. To uncover such processes, longitudinal study designs are necessary to increase our understanding of the range of factors that influence racial identity salience for specific racial groups. Indeed, there are race-specific factors involved in complex interactions among individual, familial, and social influences that result in a wide range of outcomes during this developmental period, depending in part on the adolescent's developmental history, experience of adversity, and access to social resources (Cicchetti \& Rogosch 2002; Masten \& Coatsworth, 1998). Thus, the identification of risk and protective factors associated with the onset and maintenance of adaptive and maladaptive patterns of behavior is a key goal for developmentalists who study health- and mental health-related outcomes for adolescent populations. In particular, determining the role that racial identity salience plays across key adjustment domains may inform the design of effective intervention and prevention strategies for adolescents who are incrementally more vulnerable to maladaptive adjustment outcomes (Gil, Wagner, \& Vega, 2000).

Insofar as early adjustment has been linked to later developmental outcomes (Cicchetti \& Rogosch 2002; Lerner \& Galambos, 1998), delineating the underlying processes contributing to adolescent adjustment may promote more comprehensive understandings of developmental phenomena later in life. Specifically, characterizing the 
relations between early indicators of racial identity salience and both (a) later indicators of identity salience and (b) longitudinal patterns of adolescent functioning across various indices of psychosocial adjustment may reveal more complex developmental patterns than those characterized by the existing research literature (DuBois et al., 2002; McLoyd \& Steinberg, 1998; Robinson, 2000). For example, early research has suggested that in some contexts racial identity is capable of buffering negative environmental influences and promoting positive adjustment (e.g., Bowman \& Howard, 1985; Cross, Parkham, \& Helms, 1991; Peters, 1985). In addition, charting the progression of race-related attitudes from early through late adolescence may inform our understanding of factors that contribute to the development of racial identities in older populations (Plummer, 1996). Furthermore, mapping of identifiable similarities and differences among these developmental patterns between diverse groups (or clusters) of individuals and over time may highlight significant continuity/discontinuity in these race-related constructs as meaningful factors in adolescent adjustment for homogenous subgroups. As a result, an investigation of the function of race-related constructs over time will likely unify the existing bifurcated racial identity research literature by linking developmental factors with adjustment correlates, through the medium of racial identity salience. Racial Identity Salience within a Developmental Psychological Framework Integrating the two predominant camps within the racial identity literature through an integrated developmental psychological approach may promote consideration of a broader range of research questions or stimulate the use of increasingly significant analytical strategies than those offered by one line of research in the absence of the other. However, given the current split in research foci, researchers have not been able to 
comprehensively address the overall significance of racial identity-related constructs for individuals across their lifespan (Sellers et al., 1998). Separately, investigations have either (a) characterized developmental models in the absence of the consequences associated with specific identity-related typologies, or (b) illuminated relations between racial identities and adjustment outcomes while discounting underlying developmental processes that contribute to their construction. These singular approaches have fallen short of enlightening a complete picture of the psychosocial importance of these constructs. However, integrating these two foci within a developmental psychological framework potentially enables researchers to identify the person-centered significance of racial identity-related constructs at key stages of the life-span.

Applying this framework to adolescent development may broaden current understanding of racial identity salience prior to adulthood, and in doing so, inform health and mental health intervention and prevention strategies (e.g., aimed at reducing problem behaviors or maladaptive substance use behaviors) for vulnerable youth (Green, Smith, \& Peters, 1985; Randolph \& Banks, 1993; Ward, 1995). It has been asserted in recent mental health counseling literature that the extent to which counselors are effective in promoting adaptive outcomes for clients is qualified by their ability to recognize underlying factors contributing to maladjustment (Vinson \& Neimeyer, 2000). For health practitioners or mental health counselors working with racially and ethnically diverse populations, understanding not only how clients come to identify themselves but also how various psychosocial influences maintain that sense of identity is critical for effective counseling (Brown, Parham, \& Yonker, 1996; Vinson \& Neimeyer, 2000). This may require that counselors gain knowledge and understanding of particular modes and 
models of racial identity development, behavioral correlates of those identities, as well as a general comprehension of how such factors interact to produce challenges to adaptive development for individuals. Within this context, race-related constructs can be viewed as meaningful and plausible intervention variables (Kwan, 2001).

Elaborating on this point, it is important to note that it may be counterproductive for health professionals to focus on changing clients' past developmental experiences or racial identities. However, and in particular when working with young adolescents, an integrated framework of racial identity may enable mental health counselors to assist clients in renegotiating the significance of past experiences in order to promote more positive future adjustment. Moreover, adopting a developmental psychological framework for understanding the range of possible influences that potentially contribute to clients' race-related identity development and associated outcomes extends the utility of the counseling process for both counselors and clients (Hargrow, 2001; Thorn \& Sarata, 1998). Therefore, effective counseling strategies necessitate an appreciation for multiple pathways and diverse outcomes (e.g, equifinality and multifinality; Sroufe, 1997) within their characterization of clients' growth and development. As a result, counselors may address key health issues on more client-centered levels, wherein the significance of racial identity as it relates to specific health behaviors can be characterized as it pertains to each client.

Critical to the continued benefits of racial identity research, framing racial identity research within a developmental psychological perspective allows researchers to advance methodologies capable of addressing more complex scientific questions and health professionals to generate more efficacious and effective intervention strategies than have 
been traditionally available. The need for such an undertaking is clear and has been expressed in relevant research literature. Discussing a broader vision of racial identity within a life-span context, Stevenson (1995) wrote, "The appreciation of interrelated developmental, contextual, and cultural influences will only broaden our understanding and measurement of racial identity and socialization... and developmental psychology will find the area of racial socialization and identity fertile ground for future extension." (Stevenson, p. 67)

\section{The Current Study}

The purpose of the current study was to examine key adjustment processes and outcomes associated with specific subgroups of African-American youth reporting distinct patterns of racial identity salience. A person-centered analytic approach was employed in this study to facilitate the description of multivariate associations between levels of racial identity salience and adjustment outcomes over four measurement occasions during adolescence. To date, few empirical studies have applied such an approach to examine patterns of continuity/discontinuity in race related constructs within a community-based minority youth sample, and in particular, during adolescence. Given this gap in the current literature, this study sought to address the following research questions:

Research Question 1. The first question addressed by this study asked: Were there distinct groupings or clusters of minority youth that manifested significantly different patterns of racial identity salience across four times of measurement; and by demographic characteristics such as gender? Research on racial identity and racial awareness (e.g., Cross, 1971; DuBois et al., 2002; Helms 1990) has suggested that these constructs are 
developed within localized racial and cultural socialization niches (Hughes, 2003;

Stevenson, 1995). These socio-cultural niches potentially yield fundamental differences among individuals and between genders. Therefore, it was hypothesized that distinct and meaningful subgroups or clusters of youth manifesting unique patterns of racial identity salience would be identified within the current community sample.

Research Question 2. The second question addressed by the current study asked: To what degree was racial identity salience continuous or discontinuous across the adolescent transition? According to Erikson (1968), identity is conceptualized as being a continuous characteristic of one's sense of self throughout their lifetime. However, research exploring key developmental transitions occurring during adolescence (e.g., Caspi \& Moffitt, 1991; Graber, Lewinsohn, Seeley, Brooks-Gunn, 1997) suggests that this period of the lifespan necessarily involves meeting critical developmental challenges and actively negotiating who one is, including how one identifies themselves racially and ethnically (French, Seidman, Allen, \& Aber, 2000). Furthermore, Spencer (1984) suggests that in particular for African-American youth, due to increased social relationships and experiences, a Black identity develops more completely as AfricanAmericans grow older. Therefore, it was hypothesized that levels of racial identity salience would be discontinuous, (i.e., stronger or weaker) at key periods of adolescent development.

Research Question 3. The third question addressed by this study asked: Were there associations between cluster membership (based on racial identity salience variables) and indices of psychosocial adjustment across stages of adolescent development? Numerous studies have suggested that internalized or positive racial 
identities serve as protective factors for adaptive functioning in older samples (Resnicow et al., 1999), and in particular within academic functioning, familial and peer relationships, and social behavioral domains (e.g., Phinney \& Chavira, 1992; Roeser, Eccles, \& Sameroff, 1998; Scribner, Hohn, \& Dwyer, 1995). Therefore, it was hypothesized that distinct cluster memberships would be associated with specific levels of adjustment, such that increasingly more endorsement of racial identities would be associated with more adaptive psychosocial outcomes within each adolescent developmental stage measured using the current youth sample.

Research Question 4. The fourth and last question addressed by this study asked: Were there significant cross-time influences between levels of racial identity salience and patterns of psychosocial adjustment across key adolescent stages? Roeser, Eccles, \& Sameroff's (1998) longitudinal study documenting relations between adolescent attitudes/beliefs and academic functioning/adjustment outcomes revealed reciprocal and consistent patterns of influence, such that each were predicative of each other over time. However, the extent to which such reciprocal associations between race -related constructs and individual- and social-level adjustment domains may exist in domains other than academic performance is currently unknown. Therefore, analyses conducted to address this research question were deemed exploratory.

By employing a person-centered approach to identify descriptive racial identity salience typologies that may be associated with divergent patterns of adjustment at distinct developmental stages during adolescence, this study was designed to investigate the significance and developmental properties of these constructs within the lives of minority youth. It was anticipated that findings from this study would underscore the 
importance of investigating racial identity-constructs longitudinally to delineate their significance for both the ontogenetic and adjustment-related aspects of development. Findings from such a descriptive investigation could be used to design specialized prevention and intervention strategies for unique racial identity salience profiles among African-American youth facing increased developmental challenges. 


\section{Chapter III: Methodology}

\section{Description of Database}

The current study analyzed data from two archived databases measuring aspects of racial/ethnic identities and key indices of adolescent adjustment including substance use and mental health outcomes. Merged within a longitudinal design, the first three waves of data employed in the current study were obtained from the South Florida Youth Study - a multiethnic school-based study that used self-report questionnaires to assess risk factors for substance abuse in early adolescence. The fourth wave of data employed in the current study was obtained from the Transitions Study, a community-based follow up of the South Florida Youth Study $(N=1803)$ - that used Computer Aided Personal Interviewing (CAPI) methods in face-to-face structured interviews and contains data fundamentally corresponding to that of the initial three waves. Both studies consist of racially/ethnically diverse samples of participants originally recruited from public schools located in Miami-Dade County.

\section{Participants}

Waves 1 through 3 - The South Florida Youth Study. Data in Waves 1 through 3 were collected via self-report paper and pencil measures administered to middle-school students in Miami-Dade County during the 1990, 1991, and 1993 school years, respectively. Of the 48 middle schools operating in the greater Miami-Dade area during these three years, all consented to take part in the study (Biafora et al., 1993), yielding a youth sample representative of the racial/ethnic and economic diversity of this region of the United States (Gil, Vega, \& Biafora, 1998). Of 9,763 male students and 669 female students contacted prior to entering the sixth or seventh grades, $7,386(70.8 \%)$ 
participated at Wave 1. Among those interviewed at Wave 1, 6,646 (90.0\%) were successfully retained for participation at Wave 2. At Wave 3, 5,924 (80.2\%) of the initial Wave 1 participants were successfully reinterviewed (see Table 1 for overall demographic information). Results from attrition analyses revealed no significant differences between the participants who dropped out of the study versus those who remained in the study for all three waves on key variables including: age, race/ethnicity, number of parents in the household, and participants' reported levels of substance use (see Vega \& Gil, 1998).

The current study focuses on participants who identified themselves as being African-American. Given the diverse historical and contemporary experiences of different racial/ethnic and cultural groups living in Miami-Dade County, the initial researchers distinguished between Black participants who self-identified as being African-American, Haitian, and Caribbean Black (Biafora et al., 1993; Vega \& Gil, 1998). Specifically, in Wave 1, there were 1,328 Black participants identified, 946 (71.2\%) of whom were African-American. However, due to the fact that the smaller groups of Black youth were not part of the follow-up study, the sample for this study included only the African-American participants with complete questionnaire data for Waves 1 through 3 (i.e., $n=742$ ). Table 2 illustrates demographic information for actual sample sizes for the African-American youth in this study.

Wave 4 - The Transitions Study. The Wave 4 sample of young adults was derived from a random sample of 1,273 male participants and all $(n=410)$ female participants who remained in the study at Wave 3. An additional 888 females were recruited to be potential participants at Wave 4 from the original 1990 sixth- and seventh-grade 
classroom rosters so as to facilitate comparisons of young adults by gender at Wave 4 . Follow-up interviews were conducted from 1998 to 2000, resulting in an overall participation rate of 1,803 (of 2,$571 ; 70.1 \%$ ) that varied for Wave 3 male ( 956 of 1,273 , $75.1 \%)$, Wave 3 female ( 330 of $410,80.5 \%$ ), and new female ( 517 of $880,58.2 \%$ ) young adults. The Wave 4 sample was drawn to include $25 \%$ White non-Hispanic, $25 \%$ African-American, 25\% Cuban, and 25\% other Caribbean Basin Hispanic participants, and included 952 males and 851 females (Turner \& Gil, 2002). However, analyses in the current study regarding data from Wave 4 are limited to (a) African-American young adults $(N=436)$, including 242 males $(55.5 \%)$ and 194 females $(45.5 \%)$, with ages ranging from 18 to 23 years $(M=20.03$ years; $S D=1.05$ years) (see Table 2 for specific demographic information for Wave 4).

Comparisons between young adults who completed Wave 4 interviews $(n=1286)$ and participants in the first three waves of the study who either (a) refused participation in Wave 4 or (b) could not be located (combined $n=768$ ) yielded few statistically significant differences $(p>.05)$. Specifically, Wave 4 participants were more likely to report being in a two-parent household at Wave $1(64.3 \%$ vs. $55.1 \%)$ and Wave $3(59.3 \%$ vs. $46.9 \%$ ) compared to Wave 4 non-participants. Wave 4 participants were also more likely to report lifetime use of drugs other than alcohol or marijuana at Wave 1 (4.4\% vs. 2.5\%) compared to Wave 4 non-participants. Comparisons of parent-reported variables revealed that households of participants had significantly higher mean yearly incomes at Wave 1 , as well as a higher proportion of fathers at Wave 1 who had ever used alcohol ( $58.5 \%$ vs. $49.3 \%$ ) compared to non-participants. There were, however, no statistically significant differences between Wave 4 participants and non-participants for several 
Wave 1 variables including: child-reported maternal or paternal education, parentreported marital status, parent smoking variables, mother's lifetime alcohol use, or the number of days fathers drank alcohol during the past month. Similarly, there were no statistically significant differences between Wave 4 participants and non-participants for several adolescent-reported Wave 1 and Wave 3 variables including: Lifetime alcohol and marijuana use, lifetime other drug use (Wave 3 only), alcohol or drug use problems, family alcohol or drug use problems, peer drug use, or depression symptoms. In addition, the proportion of the young adult interviewees who had dropped out of high school $(20.5 \%)$ was comparable to school board figures for the proportions of males $(21.1 \%)$ and females (15.2\%) who dropped out of the Miami-Dade County school system in the same cohort.

\section{Measures}

While the longitudinal design of the current study combines the more recent Wave 4 data with the earlier three waves of data, all four waves measured constructs that were related to racial/ethnic identity, as well as multiple measures of psychological adjustment. Adjustment measures included psychiatric disorders, substance use behaviors, familial influences, deviant behaviors, sexual risk behaviors, racial mistrust, and self-esteem. However, it should be noted that significant differences exist between some of the measures employed in Waves 1 through 3 and those employed in Wave 4, insofar that improvements were made to questionnaire designs of the latter (e.g., rewording of the questions asked) to obtain more comprehensive assessments from participants and the number of constructs measured greatly increased as well. The 
following section outlines the specific measures used in the current study in Waves 1 through 3 and in Wave 4.

Racial identity salience. Numerous studies have suggested that the attitudes young adults possess regarding (a) belonging to their own racial/ethnic group or (b) individuals outside of their racial/ethnic group have significant implications for behavioral adjustment (Biafora, Taylor, Warheit, Zimmerman, \& Vega, 1993; Jaggers \& Mock, 1993). To explore these implications among African-American adolescents, the current study investigated race-related constructs drawn from previous studies conducted by Wilson (1980) and McAdoo (1983), which described mental health and family support characteristics among African-Americans. Specifically, the race-related constructs used tapped levels of participants' racial/ethnic awareness, pride, and perceived significance. In contrast to traditional measures of racial identity, the measures employed in the current study were, collectively, indicators of racial identity salience, and are referred to as such.

To tap racial identity salience in the first three waves, African-American participants responded to five questions which comprised a previously used racial awareness scale $(\alpha=.62)$ developed by Biafora et al. (1993). The five scale items were, "Members of my family have told me about problems they have had because they are Black", "I want to know more about how Black people have overcome problems in America", "Members of my family have talked with me about dealing with racism and prejudice", "I always defend the rights of Blacks", and "I feel like all Blacks are my brothers and sisters". Response formats were: very true (1), pretty true (2), not very true (3) and, (4), not at all true. 
Correspondingly, in Wave 4, levels of racial identity salience among AfricanAmerican youth were assessed using an 11-item scale $(\alpha=.82)$ covering a range of attitudes regarding how one identifies with members of their racial group. For example, participants were asked to respond to statements such as "You have a strong sense of yourself as a member of your racial/ethnic group", "You identify with other people from your racial/ethnic group", "Your racial heritage is important in your life", and "Your racial/ethnic group had a lot to do with who you are today". Potential responses ranged from strongly agree (1) to strongly disagree (7).

Past-year and month alcohol and marijuana usage. To document prevalence and amounts of alcohol and marijuana use, the average number of drinks and the average number of times participants used marijuana for the (a) past month, and (b) past year were recorded for each measurement occasion.

Familial Influences. To measure associations between racial identity salience and patterns of family influences (e.g., Kandel, 1980), the current study assessed levels of participants' perceived family cohesion and support. Specifically, for African-American youth interviewed during Waves 1 through 3 of the original school- based longitudinal study, questions taken from Olson et al.'s (1983) Family Adaptability and Cohesion Scales (FACES-II) to measure (a) family pride (Chronbach's $\alpha=.91$ ) and (b) family loyalty (Chronbach's $\alpha=.84$ ). Both of these scales have been employed in previous studies investigating familial influences on key youth outcomes (e.g., Gil, Vega, \& Biafora, 1998; Vega et al., 1993). Sample items measuring family pride included, "we are proud of our family, "family members respect one another", and "things work out well for us as a family", and response choices ranged from "agree a lot" (1), to "disagree a 
lot" (4). Correspondingly, items measuring family loyalty probed how true participants felt the following statements were: "family members like to spend free time with each other", "family members feel very close to each other", and "family togetherness is very important" and response choices ranged from "never" (1), to "always" (4).

Building upon these items, at Wave 4 family relationships were measured using a 14-item scale $(\alpha=.87)$ tapping participants' relationships with their families. Participants were asked to report how strongly they agreed or disagreed with statements about their current family relationships. Items included, "You feel very close to your family", "You know that your family has confidence in you", "You feel that your family really cares about you", and "You often feel really appreciated by your family". Response formats were: strongly agree (1), agree (2), neither agree nor disagree (3), disagree (4), strongly disagree (5).

Racial Mistrust. Recent studies have examined relations between individuals' attitudes and perceptions regarding racial and cultural outgroups and non-normative adolescent behavior (e.g., Biafora et al., 1993). In Waves 1 through 3, racial mistrust among African-American youth was measured using a 4-item subscale $(\alpha=.76)$ of the Cultural Mistrust Inventory (Terrell \& Terrell, 1981), that had been employed in previous studies, (e.g., Biafora et al., 1993; Taylor, Biafora \& Warheit, 1994), and documented levels of trust that participants have for members of other racial/cultural groups. These items primarily targeted racial mistrust within academic settings by asking, "Black parents should teach their children not to trust White teachers", "When a White teacher talks to a Black student it is usually to get information that can be used against him or her", "White teachers as hard questions to Black students on purpose so they will fail", 
and "Blacks should be suspicious of a White person who tries to be friendly". Response formats ranged from "agree a lot" (1), to "disagree a lot" (4).

For Wave 4, measures of racial mistrust were expanded to nine independent items that tapped levels of trust/mistrust of others in three different non-academic social situations. Each of these measures explored both within- and out-group levels of trust/mistrust among the African-American youth in this study. Specifically, participants were asked to report the extent to which they would: (a) be suspicious of a stranger if that person were Black, Hispanic or White, respectively, (b) trust a co-worker if that person were Black, Hispanic or White, respectively, and (c) feel they could count on a person if that person were Black, Hispanic or White, respectively. These items had the responses, strongly agree (1), agree (2), neither agree nor disagree (3), disagree (4), strongly disagree (5).

DSM-IV Psychiatric Diagnoses. Lifetime and past year DSM-IV psychiatric diagnoses were measured using the Composite International Diagnostic Interview (CIDI). The CIDI, developed by the World Health Organization (WHO), is a structured diagnostic interview that can assess disorders as defined by the American Psychiatric Association's Diagnostic and Statistical Manual (DSM-IV). The brief Michigan version of the CIDI that was developed by Kessler et al. (1998) was used in the current study. Analyses of these measures revealed high inter-rater reliability (Wittchen et al., 1991), test-retest reliability (Wacker, Battegay, \& Schlosser, 1990), and validity (Janca, Robins, Cottler, \& Early, 1992; Spengler \& Wittchen, 1989; Spitzer, Williams, Gibbon, \& First, 1990). Due to the initial inclusion of these measures in participants' questionnaires at Wave 4, CIDI-generated diagnoses were employed in analyses to describe associations of 
documented psychopathology with levels of racial identity salience only in the final occasion of measurement in the current study. Diagnostic categories assessed in the current study were: affective disorders, anxiety disorders, conduct disorder, posttraumatic stress disorder (PTSD), antisocial personality disorder, and alcohol and drug use disorders. With regard to each disorder investigated, multiple questions were asked of participants to ensure accurate assessments (for additional details, see Turner \& Gil, 2002).

CESD-Depression. As the CIDI-generated psychiatric diagnoses outlined above were only measured in at Wave 4, a past-month depressive symptomatology measure that was employed in all four waves using a modified version of the Center for Epidemiology Studies Depression Scale (CESD; Radloff, 1977) was used. This measure has been used in previous studies (e.g., Taylor \& Turner, 2002; Vega, Zimmerman, Warheit, Apospori, \& Gil, 1993) and had scores ranging from 1 to 4 , with higher scores indicating higher levels of depression. Sample items from this measure included, "I felt sad", "I could not get 'going", and "I felt depressed". Response formats were: rarely (1), some of the time (2), occasionally (3), and most of the time (4).

Sexual Risk Behaviors. Taken from a broader assessment of participants' sexual history and past year sexual risk behaviors, seven items were used as indices of sexual risk for exposure to HIV and other STDs only at Wave 4. These specific items were chosen because they are widely used to assess key elements of sexual risk for exposure for HIV/STDs (e.g., Pinkerton et al., 1998). At the fourth wave, participants were asked to report their total number of lifetime sex partners, i.e., "how many different people, including men and women, have you had sex (vaginal, anal, or oral) even if only one 
time." In addition, participants reported their total number of past year sex partners. Participants were asked to report the number of times during the last 12 months they had (a) vaginal sex, (b) anal sex, or (c) oral sex, as well as the number of these sexual acts that included the use of condoms by the study participant or a partner.

Proportions of protected acts of intercourse were calculated by dividing protected acts of (a) penile-vaginal intercourse and (b) penile-anal intercourse by the total numbers of acts for each of these two types of intercourse. Since study participants rarely used condoms or other barrier methods for oral sex, this sexual activity was not included in an overall proportion of protected intercourse, formed when the proportions for protected penile-vaginal and penile-anal intercourse were averaged, thereby reducing these items to a single score. Finally, participants were asked to report, in the past 12 months, how often they or a partner (a) drank alcohol before or during sex or (b) used any drugs to get high or intoxicated before or during sex. These last two items had the responses: always (5), usually (4), sometimes (3), rarely (2), or never (1). These items were included because they tap recognized risk factors for HIV/STD exposure (e.g., Kalichman, 1998).

Delinquent Behaviors. In Waves 1 through 3, delinquent (or deviant) behaviors were measured by 13-items taken from the Kaplan Deviance Scale (Kaplan, Johnson, \& Bailey, 1986). Asked of all participants, this scale probed whether they had or had not engaged in several problem behaviors such as taking more $\$ 50$ dollars without permission, damaging or destroying someone else's property, taking part in gang fights, and carrying a weapon. These behaviors may be seen as a precursor to a diagnosis of conduct disorder. In the fourth wave, delinquent behavior was measured using a reduced 
7-item version of the scale used in the previous three waves. These scales required a yes (1) or no (2) response from participants.

Self-derogation and Personal Resources. Findings from several studies have suggested that race/ethnicity constructs related to identity have been shown to be associated with cognitions about the self such as self-esteem (Cross, 1991; Phinney \& Chavira, 1992). In the initial three waves, thirteen items taken from the Kaplan SelfDerogation Scale (Kaplan, Johnson, \& Bailey, 1986) measured the average number of negative statements about ones' self with which participants agreed. Example items were: "I am not liked by other kids", "I don't like myself as much as I used to", "At times I think I am no good at all", and "My parents do not like me very much". Response formats were on a 4-point Likert scale, ranging from "very true (1) to not true at all (4). However, the self-derogation items used in the first three waves were not included in the structured interview used at Wave 4. Therefore, personal resources were explored as comparable indicators of youth self-esteem and self-efficacy. Studies have linked youth's perceptions of their own personal resources as a critical tool for successfully coping with stressors and achieving positive outcomes for themselves (e.g., Gallagher, 1990; Lazarus \& Folkman, 1984). Therefore, a subset of questionnaire items tapping participants' perceived personal resources were used to generate a scale of 15 items including, "you are responsible for your own success", "overall, you expect more good things to happen to you than bad things", "what happens to you in the future depends mostly on you", and "you are usually able to protect your personal interests". Response formats were on a 5-point Likert scale ranging from strongly agree (1) to strongly disagree (5). 
Secondary data analyses for this study were conducted using the SPSS-for Windows version 11.0 statistical software (SPSS, Inc., 2001). All tests conducted throughout the study will be considered significant at $p<.05$, but may also be tested at a $<.01$ level when making multiple comparisons. The statistical procedures to be used to address the research questions posed by this study are as follows:

\section{Research Questions of the Current Study}

Research Question 1. The first research question of the current study asked, were there distinct groupings or clusters of minority youth who manifested significantly different patterns of racial identity salience across four separate occasions of measurement? Did these groups vary by key demographic characteristics, such as gender?

Cluster analyses were performed at each occasion of measurement to identify distinct and meaningful groups of participants by levels of reported racial identity salience component variables. Identified clusters were compared to describe any demographic differences, using ANOVA or Chi-square tests.

Research Question 2. The second research question of the current study asked, to what degree were levels of racial identity salience continuous or discontinuous across adolescence?

Chi-square analyses were used to document significant shifts in category membership between contiguous occasions of measurement. 
Research Question 3. The third research question of the current study asked, were there associations between cluster membership and indices of adjustment at each stage of adolescent development?

MANOVAs, ANOVAs, and Chi-square tests were conducted to document associations between cluster membership and adjustment outcomes, at all four times of measurement.

Research Question 4. The fourth and final research question of the current study asked, were there significant cross-time influences between levels of racial identity salience and patterns of psychosocial adjustment during adolescence?

To identify significant predictors of changes in (a) salience levels of racial identities and (b) indices of adjustment, hierarchical multiple regression (HMR) analyses were conducted first between Wave 3 racial identity salience clusters and Wave 4 adjustment indices, and then between Wave 3 adjustment indices and Wave 4 racial identity salience clusters.

Analytic Plan

Descriptive racial identity salience profiles of participant subgroups were generated at each time of analysis using cluster analysis. Profiles were constructed based upon mean scores for levels of racial identity salience for African-American youth. While comprehensive and traditional inventories of racial identity measures were not employed, the current variables used to tap levels of racial identify salience did in fact exemplify typical measures identified in the existing literature as significant precursors for racial identities (Stevenson, 1995; Smith, Walker, Fields, Brookins, \& Seay, 1999). Using the Quick Cluster algorithm available in the SPSS 11.0 software package, K-means 
cluster analysis was conducted to generate distinct, non-overlapping clusters of participants based upon the aforementioned component variables. Optimal cluster solutions were selected based upon desirable sample attributes, including conceptual relevance of typologies to existing racial identity literature, cluster sizes for statistical comparisons, and the resulting F-tests (Aldenderfer \& Blashfield, 1984; Bergman, 2001). 
Chapter IV: Results

Research Question 1: Are there distinct groupings or clusters of youth with significantly different patterns of racial/ethnic identities across four different occasions of measurement?

To address the first research question of the current study, it was hypothesized that distinct and meaningful subgroups or clusters of African-American youth manifesting unique patterns of responses to racial identity variables would be identified across four different occasions of measurement. Accordingly, for the first three waves of data, descriptive profiles were generated for groups of participants based the following five component racial identity-salience variables: (a) the extent to which family members talked to participants about problems they encountered because they were Black; (b) participants' interest in knowing more about how Blacks have overcome problems in America; (c) the extent to which family members have discussed strategies for dealing with racism and prejudice; (d) participants' efforts to always defend the rights of Blacks, and, (e) participants' attitudes that all Blacks are brothers and sisters.

Separate repeated-measures multivariate analysis of variance (MANOVA) were conducted to document patterns of responses to these five items for the youth in this study across the first three Waves. The results of the repeated measures MANOVAs failed to detect significant mean differences for items across Waves 1-3: $(V=.001, F=$ $.31,2 / 583 d f$, NS, for item "a" $) ;(V=.000, F=.02,2 / 572 d f, p=\mathrm{NS}$, for item "b"); ( $V=$ $.006, F=1.7,2 / 563 d f, p=\mathrm{NS}$, for item "c"); $(V=.005, F=1.5,2 / 569 d f, p=\mathrm{NS}$, for item "d"); and ( $V=.001, F=.39,2 / 872 d f, p=\mathrm{NS}$, for item "e"). Therefore, the mean 
levels of self-reports for each of these items did not change systematically as youth progressed in age during the first three Waves.

The cluster solutions generated for Waves 1 through 3 were based upon 642 (87.2\%) African-American participants who answered every item included in the component variables in these initial waves. Correspondingly, 95 (12.8\%) AfricanAmerican participants were missing data for one or more of the five component variables used in the cluster analysis. The current cluster analyses were conducted using standardized scores for racial/ethnic salience component variables. However, to simplify the interpretation of between-cluster differences, Tables 3,4 , and 5 provide summaries of the means, standard deviations, and significance tests for adolescents' reports of the five racial/ethnic identity salience component variables using unstandardized scores.

Wave 1 Cluster Analysis

Based upon the considerations for selecting cluster solutions outlined in the previous chapter, it was determined that a 4-part cluster solution was optimal for Wave 1. For Wave 1, the Pillai-Bartlett test for the MANOVA revealed significant between-group differences across the five racial salience component variables by cluster membership, $(\mathrm{V}$ $=1.53, F=132.79,15 / 1923 d f, p<.001)$. In addition, there were significant univariate effects of cluster membership for each component variable: the extent to which family members talked to participants about problems they encountered because they were Black, $(F=93.41,3 / 643 d f, p<.001)$; participant interest in knowing more about how Blacks have overcome problems in America, $(F=175.95,3 / 643 d f, p<.001)$; the extent to which family members have discussed strategies for dealing with racism and prejudice, $(F=165.10,3 / 643 d f, p<.001)$; participants' efforts to always defend the rights of 
Blacks, $(F=334.35,3 / 643 d f, p<.001)$; and participants' attitudes that all Blacks are brothers and sisters, $(F=73.74,3 / 643 d f, p<.001)$.

With respect to items tapping levels of racial identity salience, lower means represented more agreement or endorsement with each item. Based upon the Scheffé test statistic, there were significant between-cluster differences $(p<.05)$ in the extent to which family members talked to participants about problems they encountered because they were Black with Cluster $4(n=316)$ reporting significantly more communication of this type than members of Cluster $3(n=123)$, both of which reported significantly higher levels of this variable than Cluster $2(n=83)$ and Cluster $1(n=125)$. Between-cluster comparisons of participant interest in knowing more about how Blacks have overcome problems in America revealed that Clusters 1 and 2 reported significantly lower levels of interest than Clusters 3 and 4. In addition, significant group differences were detected among the four clusters with regard to the extent to which family members have discussed strategies for dealing with racism and prejudice, with Cluster 4 reporting the highest level of communication of this sort, Clusters 1 and 2 reporting the second highest levels, followed by Cluster 3. Correspondingly, with regard to participants' efforts to always defend the rights of Blacks, Clusters 1 and 4 endorsed this effort significantly more than Cluster 3, while Cluster 2 was the least likely to do so. Finally, significant group differences were detected among the four clusters with regard to participants' attitudes that all Blacks are brothers and sisters, with Clusters 1, 3, and 4 endorsing significantly more strongly with this attitude than did Cluster 2.

To make interpretations of clusters clearer, descriptive labels were applied that illustrate the overall pattern of responses manifested by each cluster. These labels are not 
depictions of specific behaviors or attitudes, but rather meaningful descriptions of underlying group tendencies with regard to response patterns to the five identity items. While these tendencies may not accurately depict every member of the cluster for specific items, they still offer insight into the broader racial/ethnic identity typologies captured in this study (see Bergman, 2000). The specific labels generated to describe racial identity types at Wave 1 were: "Affirming" (Cluster 4), "Low Preparation for Bias" (Cluster 3), "Uninformed Connectedness" (Cluster 1), and "Disengaged" (Cluster 2). As shown in Table 3, the largest group of youth was the "Affirming" cluster. These youth responded to racial identity variables in a manner distinguished by the highest levels of agreement with each of the five component variables. The "Uninformed Connectedness" and "Low Preparation for Bias" clusters consisted of similar numbers of participants and both reported moderate levels of overall racial identity salience.

However, key differences between these two clusters include the "Uninformed Connectedness" cluster reporting the least interest in knowing more about how Blacks have overcome problems in America, while the "Low Preparation for Bias" cluster reported the least amount of familial communication regarding the extent to which they have dealt with racism and prejudice and a relatively low degree of advocacy on behalf of other Black individuals. Finally, the "Disengaged" cluster reported the lowest overall pattern of racial identity salience compared to all other clusters in Wave 1.

In Wave 1, significant differences between clusters were found by proportional membership by gender: "Uninformed Connectedness" (90.4\% male, $9.6 \%$ female), “Disengaged" (81.9\% male, 18.1\% female), "Low Preparation for Bias" (87.0\% male, $13.0 \%$ female), and "Affirming" (77.8\% male, $22.2 \%$ female), $\chi^{2}(3, N=647=11.90, p<$ 
.01 . Despite being greatly underrepresented in the overall sample, females were overrepresented in the "Disengaged" and "Affirming" cluster in Wave 1.

\section{Wave 2 Cluster Analysis}

In Wave 2, a 5-part cluster solution was determined to be optimal. For Wave 2, the Pillai-Bartlett test for the MANOVA revealed significant between-group differences across the five racial salience component variables by cluster membership, $(V=1.89, F=$ $117.42,20 / 2620 d f, p<.001)$. In addition, there were significant univariate effects of cluster membership for each component variable: the extent to which family members talked to participants about problems they encountered because they were Black $(F=$ $98.65,4 / 656 d f, p<.001$ ); participant interest in knowing more about how Blacks have overcome problems in America, $(F=120.57,4 / 656 d f, p<.001)$; the extent to which family members have discussed strategies for dealing with racism and prejudice, $(F=$ $88.39,4 / 656 d f, p<.001)$; participants' efforts to always defend the rights of Blacks, $(F=$ $292.13,4 / 656 d f, p<.001)$; and participants' attitude that all Blacks are brothers and sisters, $(F=218.04,4 / 656 d f, p<.001)$.

Based upon the Scheffé test statistic, significant differences $(p<.05)$ were found among clusters regarding the extent to which family members talked to participants about problems they encountered because they were Black with Clusters $3(n=301)$ and $5(n=$ 93) reporting significantly more communication of this type than members of Clusters 1 $(n=123)$ and $2(n=75)$, both of which reported significantly more than Cluster $4(n=$

132). Between-cluster comparisons of participants' interest in knowing more about how Blacks have overcome problems in America revealed that Clusters 2, 3, and 5 reported significantly greater interest than Cluster 4, with Cluster 1 reporting the lowest level of 
interest. In addition, significant group differences were detected with regard to the extent to which family members have discussed strategies for dealing with racism and prejudice, with Clusters 3 and 5 reporting the highest levels of familial communication, followed by Clusters 1 and 2, with Cluster 4 reporting the lowest levels of familial communication. Correspondingly, with regard to participants' efforts to always defend the rights of Blacks, Clusters 3, 4, and 5 endorsed this effort significantly more than Clusters 1 and 2. Finally, significant group differences were detected between each of the five clusters with regard to participants' attitudes that all Blacks are brothers and sisters, with Cluster 1 endorsing this attitude the most and Cluster 5 endorsing this attitude the least.

As provided at Wave 1, descriptive labels were applied to clusters at Wave 2 that illustrate the overall pattern of responses manifested by each cluster. The specific labels generated to describe the five racial identity types at Wave 2 were: "Affirming" (Cluster 3), "Low Preparation for Bias" (Cluster 4), "Non-Advocating" (Cluster 2), "Disengaged" (Cluster 1), and "Individualistic Affirming" (Cluster 5). Consistent with Wave 1, Table 4 illustrates that the "Affirming" cluster in Wave 2 remains the largest cluster. Also similar to Wave 1 analyses, two clusters ("Non-Advocating" and "Low Preparation for Bias") emerge as demonstrating moderate levels of racial identity salience, as well as the smallest cluster ("Disengaged") manifesting the least salient pattern of responses to racial identity items across the five component variables. Essentially replacing the "Uninformed Connectedness" cluster found in Wave 1, the "Non-Advocating" cluster found in Wave 2 was marked by the lowest levels of endorsement of the statement, "I always defend the rights of Blacks". In addition, an emergent (or fifth) cluster identified in the Wave 2 analyses, "Individualistic Affirming", was distinguished by strong 
endorsement of four of the five component variables, but the least endorsement of the attitude that all Blacks are brothers and sisters, compared to all other clusters. Also in contrast to Wave 1, Chi-square tests conducted to investigate proportional gender differences across the five clusters in Wave 2 failed to reach statistical significance, $\chi^{2}(4$, $N=661)=7.35$, N.S. Therefore, there were no significant differences in the representation of males and females across clusters at Wave 2.

\section{Wave 3 Cluster Analyses}

Similar to Wave 2, a 5-part cluster solution was determined to be an optimal solution for Wave 3. In Wave 3, the Pillai-Bartlett test for the MANOVA revealed significant between-group differences across the five racial salience component variables by cluster membership, $(V=1.85, F=116.99,20 / 2716 d f, p<.001)$. In addition, there were significant univariate effects of cluster membership for each component variable: the extent to which family members talked to participants about problems they encountered because they were Black, $(F=148.95,4 / 680 d f, p<.001)$; participant interest in knowing more about how Blacks have overcome problems in America, $(F=$ $126.78,4 / 680 d f, p<.001)$; the extent to which family members have discussed strategies for dealing with racism and prejudice, $(F=129.39,4 / 680 d f, p<.001)$; participants' efforts to always defend the rights of Blacks, $(F=282.82,4 / 680 d f, p<.001)$; and participants' attitudes that all Blacks are brothers and sisters, $(F=296.20,4 / 680 d f, p<$ $.001)$.

Based upon the Scheffé test statistic, significant differences $(p<.05)$ were found between clusters regarding the extent to which family members talked to participants about problems they encountered because they were Black with Cluster $5(n=256)$ 
reporting significantly more communication of this type than members of Clusters 1 ( $n=$ $116)$ and $3(n=132)$, both of which reported significantly more than Clusters $2(n=67)$ and $4(n=114)$. Between-cluster comparisons of participants' interest in knowing more about how Blacks have overcome problems in America revealed that Clusters 1, 3, and 5 reported significantly greater levels of interest than Cluster 4, with Cluster 2 reporting the lowest level of interest. In addition, significant group differences were detected with regard to the extent to which family members have discussed strategies for dealing with racism and prejudice, with Clusters 1,3 , and 5 reporting the most communication of this sort and Clusters 2 and 4 reporting the least communication. With regard to participants' efforts to always defend the rights of Blacks, Clusters 1, 4, and 5 endorsed this effort significantly more often than Cluster 3 , with Cluster 2 reporting doing so the least. Finally, with regard to participants' attitudes that all Blacks are brothers and sisters, significant group differences were detected, with Cluster 5 reporting this attitude significantly more than Clusters 2 and 3 , while Clusters 1 and 4 resonated with this attitude the least.

Similar to previous Waves, descriptive labels were applied to clusters at Wave 3 that illustrate the overall pattern of responses manifested by each cluster. The specific labels generated to describe the five racial identity types at Wave 3 were: "Affirming" (Cluster 5), "Low Preparation for Bias" (Cluster 4), "Non-Advocating” (Cluster 3), "Disengaged" (Cluster 2), and "Individualistic Affirming" (Cluster 1). With regard to overall patterns of racial identity salience, the trend of (a) the largest Cluster reporting the highest levels and (b) the smallest cluster reporting the lowest levels of ratings on component variables continued in Wave 3. As shown in Table 5, the "Affirming" cluster 
endorsed each of the component variables at incrementally higher levels than any other cluster, while the "Disengaged" cluster reported a coherent pattern of low agreement with these items. Also similar to earlier analyses, clusters reporting moderate levels of overall racial identity salience were distinguished by either (a) lower endorsement of race-related advocacy (i.e., the "Non-Advocating" cluster), or (b) higher levels of racial advocacy and connectedness but limited levels of familial communication of race-related issues (i.e., the "Low Preparation for Bias" cluster). Finally and consistent with findings in Wave 2, Wave 3 analyses documented the "Individualistic Affirming" cluster distinguished by a strong endorsement of four of the five component variables, while simultaneously disagreeing with the attitude that all Blacks are brothers and sisters. In Wave 3, no significant between-cluster differences were noted regarding proportional representation by gender, $\chi^{2}(4, N=685)=7.76, p=.10$.

Wave 4 Cluster Analysis

In Wave 4, items tapping levels of participants' racial identity salience were a modified and expanded set of items parallel to those used in Waves 1 through 3. Specifically, in Wave 4, 11 items were used to measure comprehensively the scope of individuals' racial/ethnic orientation in contrast to the five items used to assess this construct in the initial three waves. Due to this broad range of items used, a factor analysis was conducted to identify underlying structures that might reveal how items could be reduced. However, one item ("Racism is the single most important problem you have had to deal with in your life") was omitted from this analysis because of its low correlation with the other items $(r=.19)$. The results of the factor analysis (using principal component analysis (PCA) and varimax rotation method) with the remaining 10 
items revealed three factors. The first factor was "Racial Identification and Pride" $(\alpha=$ .80 ), which included four items, "You have a strong sense of yourself as a member of your racial/ethnic group", "You identify with other people from your racial/ethnic group", "Your racial/ethnic heritage is important in your life", and "You are proud of your racial/ethnic heritage" and had an eigenvalue of 4.09 . The second factor was "Racial Sociability" $(\alpha=.73)$, which included four items, "Most of your close friends are from your own racial/ethnic group", You are more comfortable in social situations where others are present from your racial/ethnic group", "You prefer to date people from your racial ethnic group", and "Your values, attitudes and behaviors are shared by most members of your racial/ethnic group" and had an eigenvalue of 1.35. The third factor identified was "Racial Significance" $(\alpha=.77)$, which included two items, "Your racial/ethnic group had a lot with who you are today" and "Your race/ethnic background plays a big part in how you interact with others" and had an eigenvalue of 1.00. As illustrated in Table 6 , this three factor solution explained $64.43 \%$ of the total variance.

In order to construct cluster solutions for study participants at Wave 4, the PCA derived scores for the three composite items of "Racial Identification and Pride", "Racial Sociability" and "Racial Significance" were collapsed into distinct subscales and entered into the cluster analysis to generate descriptive profiles. The cluster solution generated for Wave 4 was based upon 428 (98.6\%) African-American participants who answered all 10 of the items used to assess racial identity salience in this wave. Meanwhile, 6 (0.01\%) African-American participants were missing data for one or more of the component variables used in the Wave 4 cluster analysis. The current cluster analyses were conducted using standardized scores for the three racial identity salience component 
subscales. However, to simplify the interpretation of between-cluster differences, Table 7 provides summaries of the means, standard deviations, and significance tests for adolescents' reports of the three racial/ethnic identity salience component variables using unstandardized scores.

In Wave 4, a 4-part cluster solution was determined to be optimal. For Wave 4, the Pillai-Bartlett test for the MANOVA revealed significant between-group differences across the three racial salience component variables by cluster membership, $(V=1.45, F$ $=132.06,9 / 1272 d f, p<.001)$. In addition, there were significant univariate effects of cluster membership for each component variable: Racial Identification and Pride, $(F=$ 98.20, 3/424 df, $p<.001)$; Racial Sociability, $(F=311.03,3 / 424 d f, p<.001)$; and Racial Significance, $(F=556.86,3 / 424 d f, p<.001)$.

Based upon the Scheffé test statistic, there were significant between-cluster differences $(p<.05)$ in levels of "Racial Identification and Pride" with Cluster 3 ( $n=$ 192) reporting significantly more identification and pride than members of Clusters 1 ( $n$ $=118)$ and $2(n=73)$, all of which reported significantly higher levels of this variable than Cluster $4(n=45)$. Between-cluster comparisons of participants' reported levels of "Racial Sociability" revealed significant differences between each of the four clusters, with Cluster 3 reporting the highest levels of sociability, followed in order by Cluster 2, Cluster 1, and by Cluster 4. Similarly, significant group differences were detected between each of the four clusters with regard to participants' reports of mean levels of "Racial Significance", with Cluster 3 reporting their racial heritage as having a greater role in their lives than Cluster 1, followed by Cluster 2, and then by Cluster 4 . 
To make interpretations of these clusters at Wave 4 clearer, descriptive labels were applied that illustrate the overall pattern of responses manifested by members of each cluster. Specifically, the labels generated to describe racial identity types at this fourth occasion of measurement were: "Affirming" (Cluster 3), "Low Racial Sociability" (Cluster 1), "Individualistic Affirming" (Cluster 2), and "Disengaged" (Cluster4). As shown in Table 7, the largest group of youth in Wave 4 was the "Affirming" cluster. These youth responded to the racial identity salience variables in a manner distinguished by the highest levels of agreement with each of the composite items. The "Low Racial Sociability" and "Individualistic Affirming" clusters both reported moderate levels of overall racial identity salience. However, key differences between these two clusters include members of the "Low Racial Sociability" cluster reporting relatively low levels of socialization with individuals outside of their own racial/ethnic group, while the "Individualistic Affirming" cluster reported high levels of "Racial Identification and Pride" despite reporting moderate levels of "Racial Sociability" and "Racial Significance". Finally, the "Disengaged" cluster reported the lowest overall pattern of racial identity salience compared to all other clusters in Wave 4. However, Chi-square tests failed to find significant differences between clusters in terms of proportional membership by gender at Wave $4, \chi^{2}(3, N=428)=5.95, p=.11$.

Summary of cluster solutions across the four waves of measurement

Overall, while mean levels of each of the five component variables did not change across the first three occasions of measurement, descriptive profiles identified in each wave revealed significant heterogeneity in patterns of racial identity salience among the African-American adolescents in this community sample. While the majority of 
participants reported high levels of racial identity salience, smaller distinct subgroups reported differentiated and multidimensional patterns of identity salience across early adolescence. Across all four measurement occasions, a consistent pattern of cluster membership was documented with the "Affirming" cluster representing the largest numbers of youth, the "Disengaged" cluster consistently containing the smallest numbers of youth, and the remaining youth falling into clusters manifesting moderate but nonuniform levels of racial identity salience. In addition, there was a documented increase in the number of clusters identified from Wave 1 to Waves 2 and 3 (i.e., from four clusters to five clusters). This emergent (fifth) cluster at Waves 2 and 3 suggests a developmental transition among youth involving incremental increases in complexity and differentiation with regard to the salience of racial/ethnic identification (Phinney, 1993; Spencer, 1984). Furthermore, despite using different variables to cluster adolescents at Wave 4, the identification of similar typologies across all waves suggests substantial continuity in broad patterns of racial identity salience as individuals move through adolescence and into emerging adulthood.

Research Question 2: To what degree are levels of racial identity salience continuous or discontinuous during adolescence?

To address the second research question of the study, it was hypothesized that racial/ethnic identity-related constructs will be discontinuous as individuals progress through adolescence. Therefore, three separate cross-tabulation analyses were conducted to evaluate shifts in identity clusters between contiguous times of measurement. 
Wave 1 to Wave 2 Crosstabulations

As outlined earlier in this chapter, the following four distinct clusters were identified in Wave 1: "Affirming", "Low-Preparation for Bias", "Uninformed Connectedness", and "Disengaged". Therefore, the first cross-tabulation analysis was conducted to identify youth at Wave 1 who remained in a similar cluster or shifted to a different cluster type at Wave 2. The five identified cluster types at Wave 2 were "Affirming", "Low-Preparation for Bias", "Non-Advocating", "Disengaged", and "Individualistic Affirming". Pearson Chi-Square analyses indicated significant differences between clusters with regard to proportional representations of cluster membership at Wave 1 as compared to Wave $2, \chi^{2}(12, N=581)=45.07, p<.01$, indicating significant shifts in cluster membership.

As shown in Figure 1, the results of the first cross-tabulation indicated that of the 286 African-American youth comprising the "Affirming" cluster at Wave 1, a majority (160 or $55.9 \%$ ) endorsed a similar pattern of responses (i.e., they were also in the "Affirming" cluster at Wave 2). In contrast, the remaining youth in the Wave 1 "Affirming" cluster shifted to different clusters at Wave 2: $46(16.1 \%)$ shifted to the "Low-Preparation for Bias" cluster, 26 (9.1\%) shifted to the "Non-Advocating" cluster, $13(4.5 \%)$ shifted to the "Disengaged" cluster, and $41(14.3 \%)$ shifted to the "Individualistic Affirming" cluster. Thus, no clear pattern of shifting away from the Wave 1 "Affirming" cluster to any of the different clusters emerged. As for the 106 youth comprising the "Low Preparation for Bias" cluster at Wave 1, 22 (21.4\%) maintained this pattern of responses at Wave 2 . However, $40(38.8 \%)$ youth shifted to the "Affirming" cluster, $10(9.7 \%)$ shifted to the "Non-Advocating" cluster, 9 (8.7\%) 
shifted to the "Disengaged" cluster, and $22(21.4 \%)$ shifted to the "Individualistic Affirming" cluster by Wave 2. These data suggest that a significant proportion of youth who endorse "Low Preparation for Bias" items at Wave 1 receive significantly more communication with their family members regarding race-related issues as they progress through early adolescence as indicated by the greatest proportional shift to clusters that endorsed the highest levels of agreement with these items (i.e., the "Affirming" and "Individualistic Affirming" clusters).

Among the 118 youth who reported the "Uninformed Connectedness" pattern of responses to the racial identity items assessed in this study at Wave 1, the largest shift to any single cluster at Wave 2 was to the "Affirming" cluster (i.e., 55 youth or $46.7 \%$ ). The second largest shift was to the "Low Preparation for Bias" cluster (i.e., 25 youth or $21.2 \%)$, followed by: $14(11.9 \%)$ shifted to the "Disengaged" cluster, $13(11.0 \%)$ shifted to the "Non-Advocating" cluster, and 11 (9.3\%) shifted to the "Individualistic Affirming" cluster at Wave 2. The significant shift from the "Uninformed Connectedness" cluster at Wave 1 to the "Affirming" cluster at Wave 2 indicates a pattern of increasing interest in knowing more about how Blacks have overcome problems in America as these youth grow older. Finally, of the 74 youth comprising the "Disengaged" cluster at Wave 1, 16 $(21.6 \%)$ remained in the "Disengaged" cluster at Wave 2. In contrast, the remaining youth shifted to different clusters by Wave 2: 19 (25.7\%) shifted to the "Affirming" cluster, 17 (23.0\%) shifted to the "Low Preparation for Bias" cluster, 12 (16.2\%) shifted to the "Non-Advocating" cluster, and $22(21.4 \%)$ shifted to the "Individualistic Affirming" cluster. For youth reporting the lowest levels of agreement with the racial 
identity salience items at Wave 1, no clear trends emerged with regards to shifts in cluster membership by Wave 2 .

Wave 2 to Wave 3 Crosstabulations

To document youth at Wave 2 who remained in a similar cluster or shifted to a different cluster type at Wave 3, a second cross-tabulation analysis was conducted. The same five cluster types identified at Wave 2 were also identified at Wave 3. These cluster types were: "Affirming", "Low-Preparation for Bias", "Non-Advocating", "Disengaged", and "Individualistic Affirming". Pearson Chi-Square analyses indicated significant differences between clusters with regard to proportional representations of cluster membership at Wave 2 as compared to Wave $3, \chi^{2}(12, N=614)=108.04, p<.01$, indicating significant discontinuity discontinuity in cluster membership across a one year period.

As illustrated in Figure 2, the results of this second cross-tabulation indicated that of the 284 African-American youth comprising the "Affirming" cluster at Wave 2, a majority ( 154 or $54.2 \%$ ) endorsed a similar pattern of responses (i.e., were also in the "Affirming" cluster) at Wave 3. These data suggest sigifincant continuity in identity patterns among the majority of youth endorsing the highest levels of racial identity salience from Waves 2 to 3 . In contrast, the remaining youth in the Wave 2 "Affirming" cluster shifted to different clusters at Wave 3: $30(10.6 \%)$ shifted to the Low-Preparation for Bias cluster, 47 (16.5\%) shifted to the Non-Advocating cluster, $16(5.6 \%)$ shifted to the Disengaged cluster, and $37(13.0 \%)$ shifted to the "Individualistic Affirming" cluster. As for the 119 youth comprising the "Low Preparation for Bias" cluster at Wave 2, 32 $(26.9 \%)$ maintained this pattern of responses at Wave 3. However, $33(27.7 \%)$ youth 
shifted to the "Affirming" cluster, 26 (21.8\%) shifted to the "Non-Advocating" cluster, $18(15.1 \%)$ shifted to the "Disengaged" cluster, and $10(8.4 \%)$ shifted to the "Individualistic Affirming" cluster by Wave 3. These results suggest that the "Low Preparation for Bias" cluster largely represents a transient identity status for the youth in this study.

Among the 72 youth who reported the "Non-Advocating" pattern of responses to the racial identity items assessed in this study at Wave 2, $22(30.6 \%)$ maintained membership in this cluster at Wave 3. Of the remaining youth, $18(25.0 \%)$ shifted to the "Affirming" cluster, 15 (20.8\%) shifted to the "Low Preparation for Bias" cluster, 4 (5.6\%) shifted to the "Disengaged" cluster, and 13 (18.1\%) shifted to the "Individualistic Affirming" cluster at Wave 3. Hence, more youth endorsing "Non-Advocating" levels of racial identity salience retained their membership in this cluster as they transitioned from Wave 2 to Wave 3 than shifted to any single other identity type.

Among the 50 youth comprising the "Disengaged" cluster at Wave 2, $13(26.0 \%)$ remained in the "Disengaged" cluster at Wave 3 . In contrast to these youth, the remaining individuals shifted in relatively even proportions to the other clusters by Wave 3: $9(18.0 \%)$ shifted to the "Affirming" cluster, $9(18.0 \%)$ shifted to the "Low Preparation for Bias" cluster, $9(18.0 \%)$ shifted to the Non-Advocating cluster, and $10(20.0 \%)$ shifted to the Individualistic Affirming cluster. Finally, of the 89 youth comprising the "Individualistic Affirming" cluster at Wave 2, 32 (36.0\%) maintained a similar pattern of responses at Wave 3. However, 25 (28.1\%) youth shifted to the "Affirming" cluster, 12 (13.5\%) shifted to the "Low Preparation for Bias" cluster, $14(15.7 \%)$ shifted to the "Non-Advocating" cluster, and 6 (6.7\%) shifted to the "Disengaged" cluster. Therefore, 
for both the "Disengaged" and "Individualstic Affirming" clusters, the largest number of youth remained in a similar cluster from the second to third measurement occasions, indicating significant continuity in patterns of racial identity salience.

\section{Wave 3 to Wave 4 Crosstabulations}

To account for the significant reduction in the number of participants who were interviewed at Wave 4 compared to the initial three waves, an alternative cluster analysis was conducted in Wave 3 using a reduced but matched sample in order to investigate meaningful Wave 3 to Wave 4 shifts in cluster membership. Specifically, this analysis included the 284 African-American participants who answered every item included in the component variables at the third and fourth measurement occasions. It was determined that a 5-part cluster solution was optimal for the reduced sample at Wave 3. For Wave 3, the Pillai-Bartlett test for the MANOVA revealed significant between-group differences across the five racial salience component variables by cluster membership, $(V=1.85, F=$ $47.71,20 / 1112 d f, p<.001)$. In addition, there were significant univariate effects of cluster membership for each component variable: the extent to which family members talked to participants about problems they encountered because they were Black, $(F=$ $128.66,4 / 279 d f, p<.001$ ); participants' interest in knowing more about how Blacks have overcome problems in America, $(F=31.98,4 / 279 d f, p<.001)$; the extent to which family members have discussed strategies for dealing with racism and prejudice, $(F=$ $113.80,4 / 279 d f, p<.001)$; participants' efforts to always defend the rights of Blacks, $(F$ $=15.12,4 / 279 d f, p<.001)$; and participants' attitudes that all Blacks are brothers and sisters, $(F=171.78,4 / 279 d f, p<.001)$. 
Based upon the Scheffé test statistic, there were significant between-cluster differences $(p<.05)$ in the extent to which family members talked to participants about problems they encountered because they were Black with members of Clusters $1(n=$ $133)$ and $3(n=50)$ reporting significantly more communication of this type than members of Clusters $4(n=36)$ and $5(n=40)$, all of which reported significantly higher levels of this variable than members of Cluster $2(n=25)$. Similarly, between-cluster comparisons of participants' interest in knowing more about how Blacks have overcome problems in America revealed that Cluster 1 reported the highest levels of interest, followed by Clusters 4 and 5, and then by Cluster 2 which reported the lowest levels of interest. In addition, significant between-cluster differences were detected with regard to the extent to which family members have discussed strategies for dealing with racism and prejudice, with members of Clusters 1,3 and 5 reporting the highest level of communication of this sort, followed by members of Cluster 2 , and finally by members of Cluster 4. With regard to participants' efforts to always defend the rights of Blacks, Cluster 1 reported engaging in these efforts significantly more than Clusters 4 and 5 , followed by Cluster 2. Finally, significant group differences were detected among the five clusters with regard to participants' attitudes that all Blacks are brothers and sisters, with Clusters 1, 4, and 5 reporting the highest levels of agreement with this attitude, while clusters 2 and 3 reported the least agreement.

To make interpretations of clusters clearer, descriptive labels were applied that illustrate the overall pattern of responses manifested by each cluster. The specific labels generated to describe the five racial identity types classified with this reduced Wave 3 sample were: "Affirming" (Cluster 1), "Low Preparation for Bias" (Cluster 4), 
"Uninformed Connectedness" (Cluster 5), "Individualistic Affirming" (Cluster 3), and "Disengaged" (Cluster 2). As shown in Table 8, the largest group of youth was the "Affirming" cluster. These youth responded to racial identity variables in a manner distinguished by the highest levels of agreement with each of the five component variables. The "Uninformed Connectedness" and "Low Preparation for Bias" clusters consisted of similar numbers of participants and both reported moderate levels of overall racial identity salience. However, key differences between these two clusters emerged. The "Uninformed Connectedness" cluster reported moderate levels of race-related communication, yet endorsed the view that all blacks are brothers and sisters. In contrast, the "Low Preparation for Bias" cluster reported the least amount of familial communication regarding the extent to which they have dealt with racism and prejudice with a relatively low degree of advocacy on behalf of other Black individuals. The "Individualistic Affirming" cluster, as stipulated in previous waves, was distinguished by strong endorsement of four of the five component variables, but the lowest endorsement of the attitude that all Blacks are brothers and sisters compared to all other clusters. Finally, the "Disengaged" cluster reported the lowest overall pattern of racial identity salience compared to all other clusters in this reduced Wave 3 sample.

This 5-part solution using the reduced sample was similar to the original Wave 3 solution insofar that "Affirming", "Low Preparation for Bias", "Individualistic Affirming" and "Disengaged" clusters were identified. However, in the current solution, there was an "Uninformed Connectedness" cluster identified as opposed to the "NonAdvocating" cluster identified in the original solution. In addition, chi-square tests conducted to investigate proportional gender differences across the five clusters in this 
reduced Wave 3 sample failed to reach statistical significance, $\chi^{2}(4, N=284)=3.97$. Therefore, there were no significant differences in the representation of males and females across clusters in the reduced sample at Wave 3.

Using this reduced 5-part cluster solution, a cross-tabulation analysis was conducted to evaluate shifts in identity among youth at Wave 3 who either (a) maintained a similar or (b) shifted to a different racial identity salience type at Wave 4. Moreover, this analysis sought to investigate continuity/discontinuity in membership between the five identified cluster types using the reduced Wave 3 solution (i.e., "Affirming", "LowPreparation for Bias", "Uninformed Connectedness", "Individualistic Affirming”, and "Disengaged" and the four cluster types at Wave 4 (i.e., "Affirming", "Low Racial Sociability", "Individualistic Affirming", and "Disengaged". However, Pearson ChiSquare analyses failed to reveal significant differences with regard to proportional representations of clusters at Wave 3 as compared to Wave $4, \chi^{2}(4, N=276=15.97$, N.S.

As illustrated in Figure 3, the results of Wave 3 to 4 cross-tabulation indicated that of the 130 African-American youth comprising the "Affirming" cluster at Wave 3, a majority ( 74 or $56.9 \%$ ) also endorsed a an "Affirming" pattern of racial identity salience at Wave 4 . These data suggest significant continuity in identity patterns among the majority of youth endorsing the highest levels of racial identity salience from Waves 3 to 4. In contrast, the remaining youth in the Wave 3 "Affirming" cluster shifted to different clusters at Wave 4: 30 (23.1\%) shifted to the Low Racial Socialization cluster, 15 (11.5\%) shifted to the "Individualistic Affirming" cluster, and $11(8.5 \%)$ shifted to the "Disengaged" cluster. As for the 36 youth comprising the "Low Preparation for Bias" cluster at Wave 3, 7 (19.4\%) reported responses indicative of the "Low Racial 
Socialization" pattern of racial identity salience at Wave 4. Correspondingly, 16 (44.4\%) youth shifted to the "Affirming" cluster, $11(30.6 \%)$ shifted to the "Individualistic Affirming" cluster, and $2(5.6 \%)$ shifted to the "Disengaged" cluster at Wave 4 . These results suggest that the "Low Preparation for Bias" cluster largely represented a transient identity status during the transition from middle adolescence to early adulthood among the youth in this study.

Among the 37 youth who reported the "Uniformed Connectedness" pattern of responses to the racial identity items assessed in this study at Wave 3, $12(32.4 \%)$ endorsed items consistent with the "Low Racial Socialization" pattern of racial identity salience. Of the remaining youth, a majority, 19 (51.4\%) shifted to the "Affirming" cluster, while 5 (13.5\%) shifted to the "Individualistic Affirming" cluster, and $1(2.7 \%)$ shifted to the "Disengaged" cluster at Wave 4. These data suggest that for the broadest transition assessed in this study an early "Uniformed Connectedness" level of racial identity was more likely to be associated with an "Affirming" pattern of racial identity salience later.

Among the 25 youth comprising the "Disengaged" cluster at Wave 3, 4 (16.0\%) remained in the "Disengaged" cluster at Wave 4. In contrast to these youth, the remaining individuals shifted in relatively even proportions to the other clusters by Wave 4. Specifically, $8(32.0 \%)$ participants that represented the Wave 3 "Disengaged" cluster shifted to the "Affirming" cluster, while $7(18.0 \%)$ shifted to the "Low Racial Socialization" cluster, and $6(24.0 \%)$ shifted to the Individualistic Affirming cluster at Wave 4. Finally, of the 48 youth comprising the "Individualistic Affirming" cluster at Wave 3, 10 (20.8\%) maintained a similar pattern of responses at Wave 4. However, 22 
(45.8\%) youth shifted to the "Affirming" cluster, 12 (25.0\%) shifted to the "Low Racial

Socialization" cluster, and $4(8.3 \%)$ shifted to the "Disengaged" cluster by Wave 4 .

Therefore, for both the "Disengaged" and "Individualstic Affirming" clusters identified at

Wave 3, the largest number of youth shifted to the "Affirming" cluster at Wave 4

indicating the emergence of incrementally more salient individual and collective racial

identity as youth transition from early adolescence to late adolescence.

Summary of cluster shifts between each contiguous pair of measurement occasions.

Overall, cross-tabulation analyses revealed general discontinuity in shifts in identity clusters between contiguous times of measurement during early adolescence. Specifically, while it was documented that some youth retained a similar or comparable cluster membership across waves, the largest proportion of youth in every Wave 1 cluster shifted to the "Affirming" cluster at Wave 2. This finding supports existing literature suggesting that as individuals progress through adolescence, racial identity constructs become more salient (e.g., Phinney, 1989; Quintana, 1998). However, with regard to shifts in cluster membership composition from Wave 2 to Wave 3 , the largest proportion of individuals in every cluster maintained membership in a comparable cluster, with the exception of the "Low Preparation for Bias" cluster, which essentially retained only as many youth ( 32 or $26.9 \%$ ) at Wave 3 as the number ( 33 or $27.7 \%$ ) who shifted to the "Affirming" cluster. Perhaps this finding is suggestive of racial/ethnic identity becoming incrementally more stable (continuous) as youth transition through early adolescence.

In addition, when considering shifts between the two most conceptually dissimilar clusters documented during early adolescence (from Wave 1 to 3), the largest number of youth in the Wave 1 "Disengaged" cluster (16 or 21.6\%) moved to the "Affirming" 
cluster by the third occasion of measurement. In contrast, the lowest proportion of youth in any cluster ( 12 or $4.0 \%$ ) in the Wave 1 "Affirming" cluster shifted to the "Disengaged" cluster by the third time of measurement. Although not statistically significant, this pattern was also documented in examination of cluster shifts from the broadest measurement transition (Wave 3 to Wave 4) suggesting that for the youth in this study, an affirming level of racial identity is (a) the most common type of racial identity within each developmental stage, as well as (b) the most common single cluster to which individuals shift as they progress through this critical developmental period.

Research Question 3: Are there associations between cluster membership and indices of adjustment across stages of adolescent development?

To address the third research question of the study, it was hypothesized that cluster membership would be associated with distinct patterns of adjustment at each occasion of measurement. The specific adjustment indices measured during the first three waves were: alcohol and marijuana use, familial pride and loyalty, self-derogation, depression, deviant behaviors, and cultural mistrust. Correspondingly, the comparable adjustment indices measured at the fourth wave were: alcohol and marijuana use, familial pride, CIDI-generated lifetime and past-year psychiatric diagnoses, sexual risk behaviors, personal resources, CESD-generated depression score, and cultural mistrust. This broad range of measures offers a glimpse at both internal and external behavioral patterns that when taken together, provide useful indicators of psychosocial adjustment. Due to inconsistent amounts of missing data per each measure, MANOVAs were not employed in the first three measurement occasions. Despite there being an elevated chance of committing a Type I error, several one-way analyses of variance (ANOVAs) were 
conducted to minimize missing data per adjustment measure. To detect between-cluster differences in Wave 4, MANOVAs, ANOVAs and Chi-square analyses were conducted. Adjustment Outcomes by Cluster in Wave 1

In Wave 1, cluster membership was associated with distinct patterns of adjustment among participants in this study for four of the nine outcomes measured. Table 9 provides a summary of the means, standard deviations, and significance tests for adolescents' reports of the measured outcome variables by cluster membership at Wave 1. Results from the ANOVAs indicated significant main effects for cluster membership within the domains of family pride, $F(3,610)=6.11, p<.01$, family loyalty, $F(3,604)$ $=5.01, p<.01$, self-derogation, $F(3,624)=6.50, p<.01$, and cultural mistrust, $F(3$, $643)=4.56, p<.01$. Specifically, youth in the "Affirming" cluster reported significantly higher levels of family pride than youth in the "Low Preparation for Bias" cluster. In addition, the "Affirming" cluster was marked by significantly higher levels of family loyalty than the "Uninformed Connectedness" cluster, as well as lower levels of selfderogation than the "Low Preparation for Bias" cluster. Also, youth comprising the "Disengaged" cluster reported significantly higher levels of cultural mistrust than youth in both the "Low Preparation for Bias" and "Uninformed Connectedness" clusters. However, the current study found no significant between-cluster differences for indices of substance use, depression, or delinquency at this first measurement occasion. Adjustment Outcomes by Cluster in Wave 2.

In Wave 2, cluster membership was associated with few significant group differences in adjustment. Table 10 provides a summary of the means, standard deviations, and significance tests for adolescents' reports of the measured outcome 
variables by cluster membership in Wave 2. Results from the ANOVAs indicated significant main effects for cluster membership within the domains of family pride, $F$ (4, $629)=3.30, p<.05$, and self-derogation, $F(4,635)=3.26, p<.05$. Specifically, youth in the "Affirming" cluster reported significantly higher levels of family pride than youth in the "Disengaged" cluster. In addition, the "Disengaged" cluster was marked by significantly higher levels of self-derogation than the "Individualistic Affirming" cluster. However, the current study found no significant between-cluster differences for any other adjustment outcome at Wave 2 .

Adjustment Outcomes by Cluster in Wave 3.

In Wave 3, cluster membership was found to be associated with significant differences in several adjustment outcome measures assessed in this wave. Table 11 provides a summary of the means, standard deviations, and significance tests for adolescents' reports of key adjustment outcome variables by cluster membership in Wave 3. Results from the ANOVAs indicated significant main effects for cluster membership within the domains of family pride, $F(4,662)=2.82, p<.05$, self-derogation, $F(4,656)$ $=3.80, p<.01$, and cultural mistrust, $F(3,677)=3.66, p<.01$. Specifically, youth in the "Affirming" cluster reported the highest levels of family pride while youth in the "Disengaged" cluster reported the lowest levels of this measure. With regard to indices of self-derogation, the "Affirming" cluster reported significantly lower levels than the "Disengaged" cluster. In addition, youth comprising the "Disengaged" cluster reported significantly higher levels of cultural mistrust than youth in the "Affirming" cluster. However, the current study found no significant between-cluster differences for indices of substance use, family loyalty, depression, or delinquency in Wave 3. The group 
differences detected are consistent with existing notions that more positive familial relationships and self-concepts are positively associated with levels of racial identity during adolescence (Johnson, Shireman, \& Watson, 1987).

Adjustment Outcomes by Cluster in Wave 4.

In Wave 4, cluster membership was found to be associated with distinct patterns of adjustment for several outcome measures assessed. Table 12 provides a summary of the means, standard deviations, and significance tests for adolescents' reports of the measured psychosocial adjustment outcome variables (with the exception of CIDI generated psychiatric diagnoses) by cluster membership at Wave 4. ANOVA results indicated a significant main effect by cluster membership for CESD depression scores, $F$ $(3,424)=5.50, p<.01$. Specifically, youth in the "Affirming" cluster reported significantly lower levels of depression than youth in the "Disengaged" and "Individualistic Affirming" clusters. In addition, separate one-way ANOVAs of cultural mistrust revealed significant main effects by cluster membership for levels of trust of a co-worker who was Black, $F(3,424)=5.50, p<.01$, Hispanic/Latino, $F(3,424)=5.50$, $p<.01$, and White, $F(3,424)=5.50, p<.01$. Specifically, youth in the "Affirming" cluster reported significantly higher levels of trust for Black co-workers than youth in the "Low Racial Sociability" and "Disengaged" clusters, while youth in the "Individualistic Affirming" cluster reported higher levels of trust for both Hispanic/Latino and White coworkers than youth in the "Low Racial Sociability" and "Disengaged" clusters.

In addition, Tables 13 and 14 summarize the prevalence of selected categories of DSM-IV psychiatric disorders generated by the CIDI across the four clusters of participants grouped by their levels of racial identity salience during lifetime and past- 
year, respectively. Chi-square analyses indicated significant between-cluster differences were found with regard to prevalence of being diagnosed with any affective disorder over participants' lifetime: "Affirming" (9.4\%), "Low Racial Socialization" (9.3\%), "Individualistic Affirming" (24.7\%), and "Disengaged" $(24.4 \%), \chi^{2}(3, N=428)=16.90$, $p<.001$ and past-year: "Affirming" (6.3\%), "Low Racial Socialization" (5.1\%), "Individualistic Affirming" (17.8\%), and "Disengaged" $(13.3 \%), \chi^{2}(3, N=428)=12.30$, $p<.05$. Across both of these diagnostic categories, consistent patterns of between-cluster differences emerged. Specifically, members of the "Disengaged" and "Individualistic Affirming" clusters were over twice as likely to receive diagnoses for any lifetime and past-year affective disorder than members of the "Affirming" and Low Racial Sociability" clusters. In addition, chi-square analyses revealed significant differences between clusters with regard to diagnoses for alcohol abuse: "Affirming" (5.8\%), "Low Racial Socialization" (9.3\%), "Individualistic Affirming" (0\%), and "Disengaged" $(13.3 \%) \chi^{2}(3, N=428)=10.17, p<.05$. Specifically, members of the "Disengaged" cluster were over twice as likely to receive this diagnosis as compared to members of the "Individualistic Affirming" and "Affirming" clusters.

Summary of adjustment outcomes across all four measurement occasions.

Overall, one-way ANOVAs revealed between-cluster differences along a few of the adjustment outcomes measured in this study. Across the first three waves of measurement, a consistent pattern emerged in which youth from the "Affirming" cluster reported the highest levels of family pride and lowest levels of self-derogation. This finding supports existing evidence suggesting a positive relationship between positive racial attitudes and identification and indices of familial relationship quality and self- 
concept (Johnson, Shireman, \& Watson, 1987; McCreary, Slavin, Berry, 1996). In contrast, the "Disengaged" cluster consistently reported among the lowest levels of family pride. Despite failing to reach statistical significance in the Wave 2 analyses (i.e., $p<.067)$, youth in the "Disengaged" cluster also reported the highest levels of cultural mistrust at each of the first three occasions of measurement. However, one-way ANOVAs failed to reveal between-cluster differences on measures of substance use, depression, and delinquency across each of the initial three waves. Collectively, these results revealed continuous (i.e., consistent) patterns of adjustment such that, (a) group differences were identified for the same variables over time, and (b) the same cluster classifications were found to report the highest and lowest levels of adjustment for measures on which significant between-group differences were identified.

In addition, the trend of more salient levels of racial identity being associated with more adaptive adjustment outcomes continued as analyses conducted at the fourth wave of measurement revealed that youth from the "Affirming" cluster reported among the lowest levels of CESD-generated depression scores, CIDI-generated diagnoses for lifetime and past-year affective disorders, and consistently reported among the highest levels of trust for Black, Hispanic/Latino and White co-workers, while the "Disengaged" cluster reported the lowest levels for these measures. Considering all four waves, these findings reflected significant differentiation in key adjustment outcomes that were associated with early adolescents' and emerging adults' self-reported levels of racial/ethnic identity-salience. 
Research Question 4: Are there significant reciprocal cross-time influences between racial/ethnic identity constructs and patterns of psychosocial adjustment during adolescence?

To address the fourth and final research question of the current study, it was hypothesized that significant reciprocal cross-time relations between (a) early racial identity salience clusters and later adjustment outcomes and (b) early levels of adjustment and later racial identity salience clusters would emerge.

Early racial identity salience clusters as predictors of later adjustment outcomes

To investigate the predictive value that early racial identity clusters have upon later adjustment outcomes, hierarchical multiple regression (HMR) analyses were conducted for a set of conceptually relevant Wave 4 outcomes using the reduced Wave 3 identity cluster solution (as detailed earlier in Research Question 2). In step one of each regression analysis, gender and age were entered to control for the amount of variance accounted for by these demographic variables. Step two of each regression involved entering an adjustment indicator at Wave 3 that corresponded to the targeted outcome measures at Wave 4, essentially controlling for levels of earlier adjustment for each measure. In step three of each of the analyses, Wave 3 racial identity salience clusters were entered to determine whether these profiles accounted for a significant amount of the variance in later adjustment outcomes beyond that of the demographic variables and prior levels of adjustment. However, in order to investigate meaningful predictive relations, the categorical racial identity salience clusters were dummy-coded, such that the Affirming cluster was scored as $I$ and all other non-Affirming clusters were scored as 0 . Analyses that resulted in a significant F-value based upon the $R^{2}$ change, post-hoc t- 
tests were examined to evaluate univariate effects between each predictor and the Wave 4 outcome measured.

CESD Depression. In the overall model, the linear combination of predictors was significantly related to Wave 4 levels of depression, $F(4,267)=5.07, p<.05$. As shown in Table 15, the addition of the Wave 3 racial identity salience clusters to the model in Step 3 accounted for a significant increment to variance after controlling for age, gender and Wave 3 depression, in the prediction of Wave 4 CESD depression scores, $F(1,267)$ $=4.14, p<.01$. In this final model, post-hoc t-tests indicated significant relationships between Wave 3 CESD depression and Wave 4 CESD depression, $\beta=.22, t=3.72, p<$ .01 .

Personal Resources. The overall model indicated that the linear combination of predictors was significantly related to self-reported levels of personal resources reported at Wave $4, F(4,267)=3.51, p<.05$. As shown in Table 16 , levels of self-derogation at Wave 3 accounted for unique variance, after controlling for age and gender, to the prediction of Wave 4 levels of personal resources, $F(1,268)=8.66, p<.01$. In this model, post-hoc t-tests indicated a significant association between Wave 3 selfderogation and Wave 4 Personal resources, $\beta=-.18, t=-2.94, \mathrm{p}<.01$. However, in the final model, Wave 3 racial identity salience clusters were not significant predictors Wave 4 personal resources in this analysis, $\beta=.02, t=.30, p=\mathrm{NS}$.

Past-month alcohol use. In the overall model, the linear combination of predictors was significantly related to Wave 4 amounts of alcohol drank during the previous month, $F(4,239)=3.14, p<.05$. As shown in Table 17, levels of Wave 3 alcohol use during the previous month accounted for significant variance, after 
controlling for age and gender, to the prediction of Wave 4 past-month alcohol use, $F(1$, $240)=7.68, p<.01$. Post-hoc t-tests indicated a significant predictive relationship between Wave 3 past-month alcohol use and Wave 4 past-month alcohol use, $\beta=.18, t=$ $2.77, \mathrm{p}<.01$. However, in the final model, Wave 3 racial identity salience clusters were not significant predictors Wave 4 past-month alcohol use, $\beta=-.02, t=-.39, p=\mathrm{NS}$.

Past-month marijuana use. In the overall model, the linear combination of predictors was significantly related to Wave 4 past-month marijuana use, $F(4,262)=$ $3.06, p<.05$. As Table 18 illustrates, age and gender accounted for significant variance in the prediction of Wave 4 past-month marijuana usage, $F(2,264)=3.57, p<.05$ in the initial model. Follow-up t-tests indicated a significant predictive relationship between gender and Wave 4 past-month marijuana usage, $\beta=-.16, t=-2.62, \mathrm{p}<.01$. In addition, Wave 3 levels of past-month marijuana use accounted for a significant variance in the prediction of Wave 4 past-month marijuana usage, $F(1,263)=4.80, p<.05$. In this model, post-hoc t-tests indicated a significant predictive relationship between (a) gender and (b) Wave 3 past-month marijuana usage use and Wave 4 past-marijuana usage, $(\beta=$ $.15, t=-2.50, \mathrm{p}<.05$ and $(\beta=.13, t=2.19, \mathrm{p}<.05$, respectively). However, Wave 3 racial identity salience clusters were not significant predictors Wave 4 past-month marijuana use in this analysis, $\beta=.03, t=.50, p=\mathrm{NS}$.

Number of lifetime sexual partners. In the overall model, the linear combination of predictors was significantly related to Wave 4 number of lifetime partners $F(5,249)=$ $5.57, p<.01$. As shown in Table 19, age and gender accounted for significant variance in the prediction of the number of lifetime sexual partners reported at Wave $4, F(2,252)=$ $8.69, p<.01$, while post-hoc t-tests indicated significant relationships between gender 
and number of lifetime partners, $\beta=-.23, t=-3.74, \mathrm{p}<.01$. In addition, levels of minor and major deviance assessed at Wave 3 accounted for significant variance, after controlling for age and gender, to the prediction of numbers of lifetime sexual partners reported at Wave $4, F(2,250)=3.50, p<.05$. In this model, post-hoc t-tests indicated a significant predictive relationship between gender and number of lifetime sexual partners, $\beta=-.22, t=-3.48, \mathrm{p}<.01$. However, in the final model, Wave 3 racial identity salience clusters were not significant predictors Wave 4 numbers of lifetime sexual partners, $\beta=$ $.10, t=-1.17, p=\mathrm{NS}$.

Substance use co-occurring with sexual intercourse. In the overall model, the linear combination of predictors was significantly related to Wave 4 amounts of substance use occurring before or during sexual intercourse, $F(5,238)=4.46, p<.01$. As shown in Table 20, levels of minor and major deviance assessed at Wave 3 accounted for significant variance, after controlling for age and gender, to the prediction of the use of substances before or during sexual intercourse reported at Wave $4, F(2,239)=7.68, p$ $<.01$. Follow-up t-tests indicated a significant predictive relationship between levels of Wave 3 major deviance and Wave 4 use of substances before or during sexual intercourse, $\beta=.17, t=2.18, \mathrm{p}<.05$. However, in the final model, Wave 3 racial identity salience clusters were not significant predictors of Wave 4 substance use occurring before or during sexual intercourse in this analysis, $\beta=-.07, t=-1.06, p=$ NS. Proportions of episodes of sexual intercourse using a condom. In the overall model, the linear combination of predictors was significantly related to Wave 4 proportions of protected intercourse, $F(5,233)=3.61, p<.01$. As Table 21 illustrates, age and gender accounted for significant variance in the prediction of proportions of 
protected episodes of sexual intercourse as reported at Wave $4, F(2,236)=7.37, p<.01$. Follow-up $\mathrm{t}$-tests indicated significant relationships between the age, $\beta=.16, t=2.42, \mathrm{p}<$ .05 and gender, $\beta=-.16, t=-2.50, p<.05$, and Wave 4 indices of protected intercourse. However, in the final model, Wave 3 racial identity salience clusters were not significant predictors of Wave 4 substance use occurring before or during sexual intercourse in this analysis, $\beta=-.08, t=-1.22, p=\mathrm{NS}$.

No other HMR analyses revealed significant findings for the prediction of Wave 4 family pride, racial mistrust, past-year marijuana use, alcohol use before or during sexual intercourse, or numbers of lifetime psychiatric diagnoses. Tables illustrating test statistics for these measures can be found in the Appendix (shown as Tables 24-30). Early adjustment indices as predictors of later levels of racial identities

To determine the predictive value that early adjustment indices have upon later racial identities, exploratory HMR analyses were conducted for three separate racial identity scales at Wave 4 using Wave 3 adjustment indices. Specifically, the factors identified in the processes to construct the cluster solutions in the fourth wave (i.e., "Racial Identification and Pride", "Racial Sociability", "Racial Significance") were employed as independent indicators of Wave 4 levels of racial identity salience for the regression analyses (see Research Question 1 outlined in this chapter for detailed descriptions of scale items). In step one of each regression analysis, gender and age were entered to control for the amount of variance accounted for by these demographic variables. Step two of each regression involved entering Wave 3 racial identity salience clusters, after age and gender, essentially controlling for levels of earlier racial identity salience for each measure. In step three of each of the analyses, Wave 3 adjustment 
indices were entered to investigate whether these measures accounted for a significant amount of the variance in later levels of racial identity salience beyond that of the demographic variables and Wave 3 racial identity cluster solutions. These steps were repeated three times to predict levels of (a) "Racial Identification and Pride", (b) "Racial Sociability", and (c) "Racial Significance" for each adjustment measure investigated. For analyses that resulted in a significant F-value based upon the $R^{2}$ change, post-hoc t-tests were examined to evaluate univariate effects between each predictor and the Wave 4 racial identity salience outcome measure.

HMR analyses conducted for each Wave 3 adjustment measure in this study failed to yield significant findings for the "Racial Identification and Pride" and "Racial Sociability" scales, although tables illustrating test statistics for these measures can be found in the Appendix (shown as Tables 31-49). However, the following significant relations were detected with respect to indices of Wave 3 adjustment and Wave 4 levels of "Racial Significance".

Family Pride. In the overall model, the linear combination of predictors was significantly related to Wave 4 racial identity clusters, $F(5,233)=4.34, p<.05$. As Table 22 illustrates, after controlling for age and gender, indices of Wave 3 levels of family pride accounted for significant variance in the prediction of Wave 4 levels of "racial significance", $F(1,267)=13.80 p<.01$. Follow-up t-tests indicated significant relationships between gender, $\beta=.16, t=2.56, \mathrm{p}<.05$, and later levels of "racial significance". In addition, in the final model, levels of Wave 3 family pride accounted for significant variance, after controlling for the demographic variables of age and gender, as well as controlling for levels of Wave 3 racial identities, to the "racial 
significance" outcome measure, $F(1,266)=6.06, p<.05$. In the final model, post-hoc ttests indicated significant relationships between gender, $\beta=.14, t=2.32, \mathrm{p}<.05$ and Wave 3 family pride, $\beta=-.15, t=-2.46, p<.05$ and Wave 4 levels of "racial significance".

Self-Derogation. In the overall model, the linear combination of predictors was significantly related to Wave 4 racial identity clusters, $F(4,262)=2.43, p<.05$. As Table 23 illustrates, age and gender accounted for significant variance in the prediction of Wave 4 levels of "racial significance", $F(2,264)=4.41, p<.05$. Post-hoc t-tests indicated significant relationships between gender, $\beta=.18, t=2.86, \mathrm{p}<.01$ and Wave 4 levels of "racial significance". However, in the final model, Wave 3 levels of selfderogation were not significant predictors Wave 4 levels of "Racial Significance" in this analysis, $\beta=.04, t=.63, p=$ NS. Tables illustrating test statistics for all other nonsignificant measures with regard to predicting "Racial Significance" can be found in the Appendix (shown as Tables 43 - 47).

Summary of analyses of reciprocal cross-time relations

Overall, HMR analyses revealed a modest number of significant relations between Wave 3 racial identity profiles and Wave 4 adjustment indices. Specifically, final HMR models indicated significant predictive relationships between the linear combination of predictors at Wave 3 and the Wave 4 outcome measures of CESDassessed depression scores, personal resources, past-month alcohol use, past-month marijuana use, number of lifetime sexual partners, substance use co-occurring with sexual intercourse, and the percentage of protected episodes of sexual intercourse. Furthermore, only the outcome measures of CESD depression and proportions of 
episodes involving sexual intercourse using a condom were shown to be significantly predicted by earlier racial identity clusters, after controlling for demographic variables and earlier levels of comparable adjustment variables. In addition, exploratory HMR analyses investigating relations between levels of Wave 3 adjustment and Wave 4 racial identity profiles revealed few significant findings. Specifically, final HMR models indicated significant predictive relationships between the predictors of Wave 3 family pride and self-derogation and Wave 4 outcomes of racial identity salience clusters. Furthermore, the Wave 3 indicator of family pride was the only measure accounting for significant amounts of variance in the Wave 4 racial identity profiles after controlling for demographic variables and earlier levels of racial identity. 


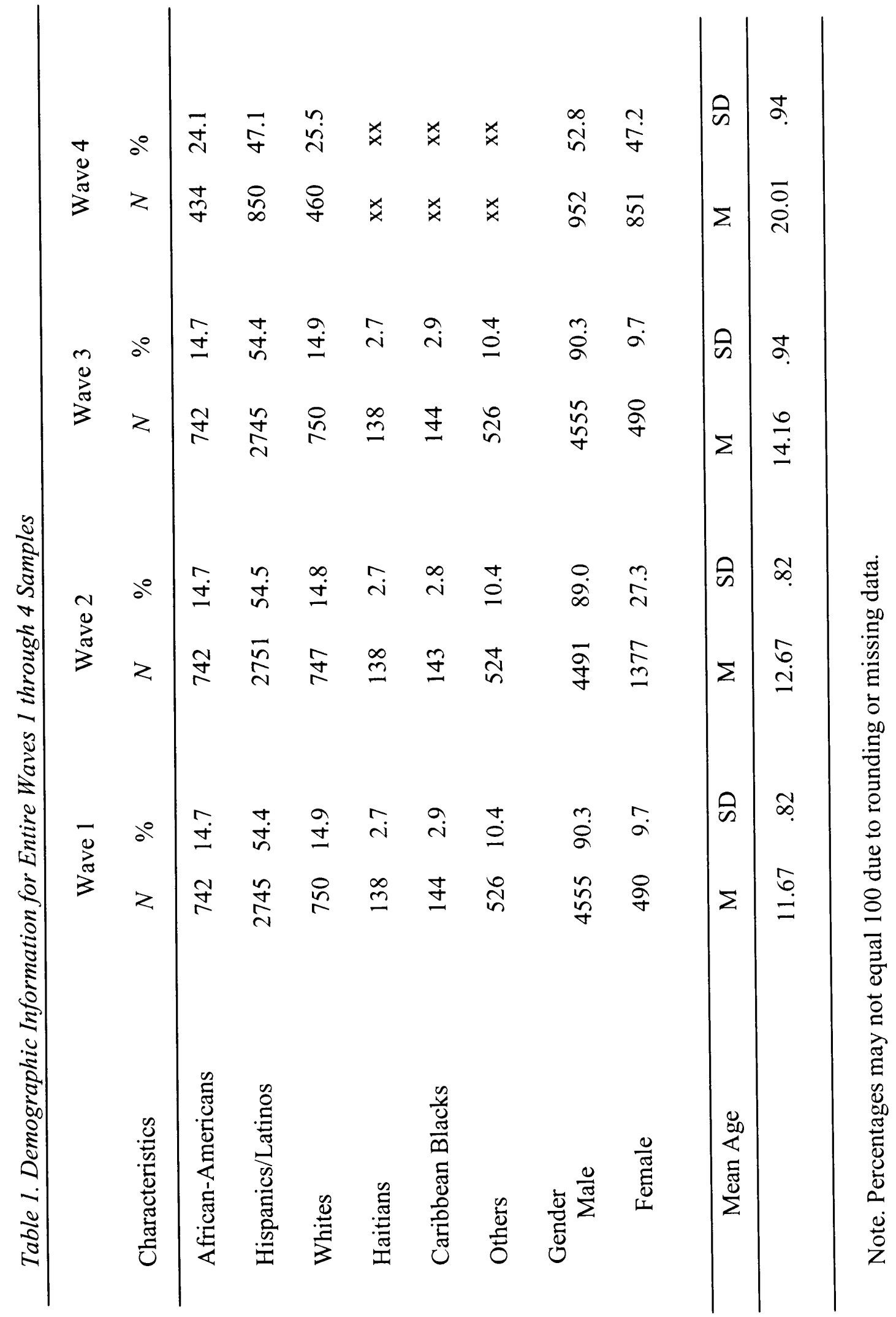




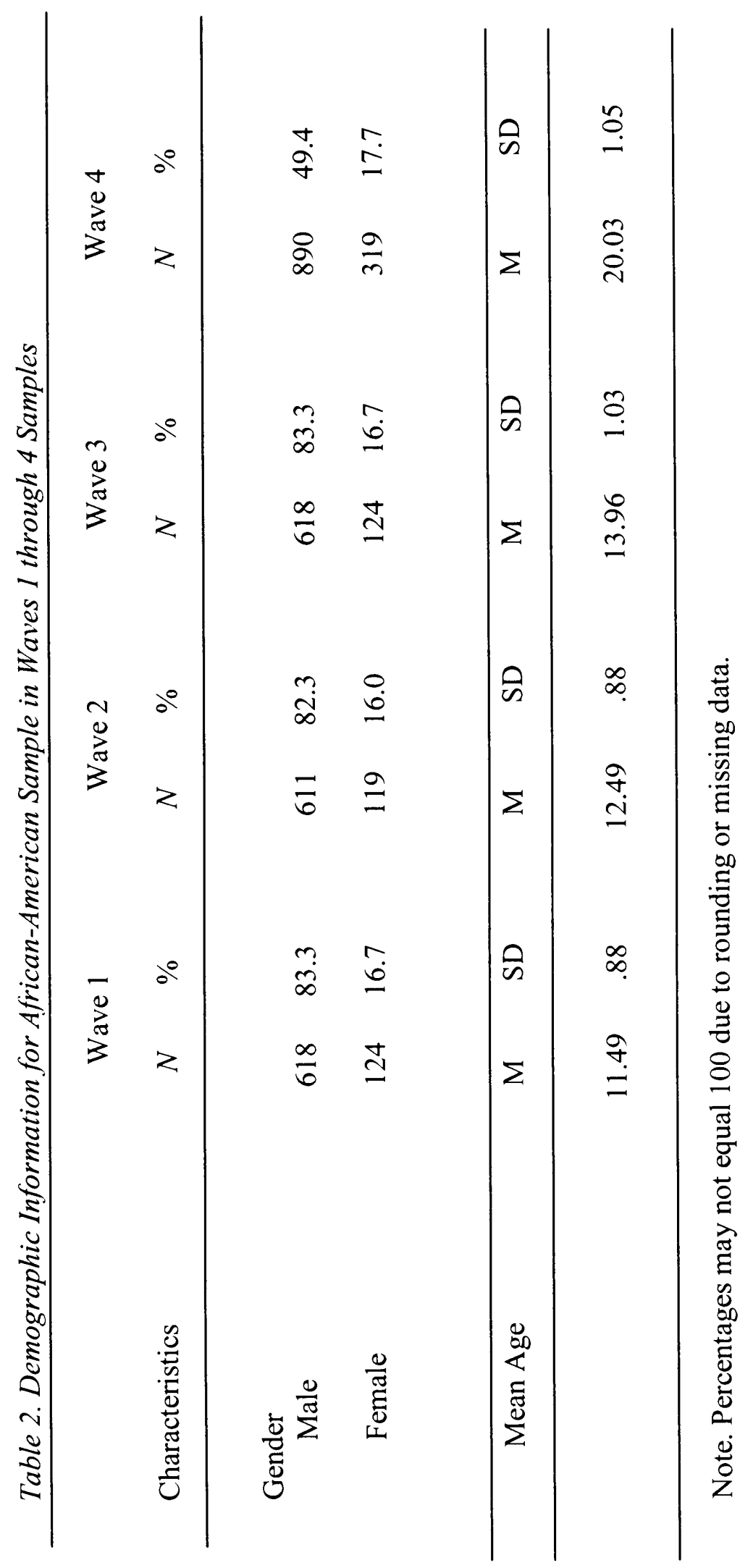




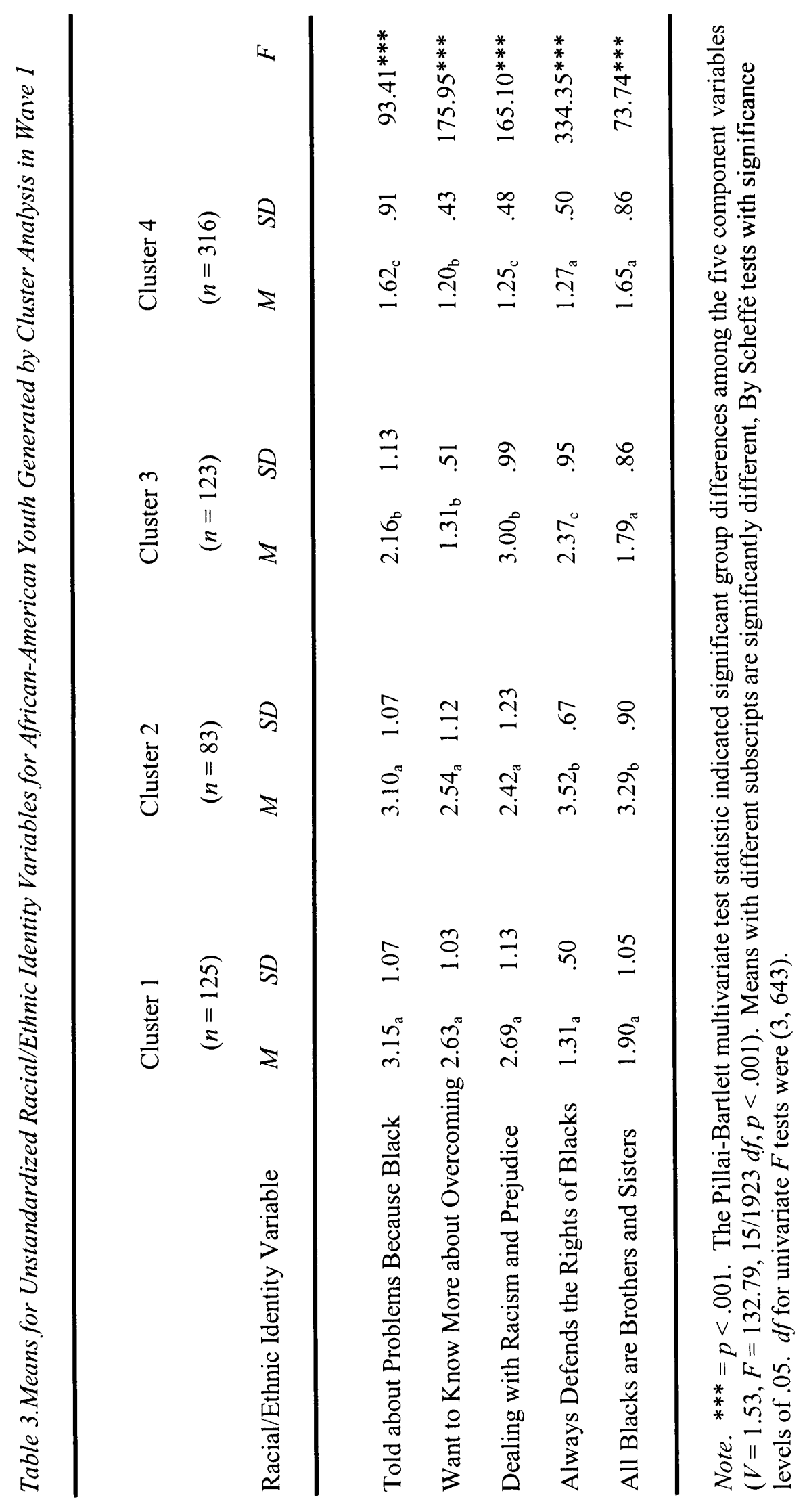




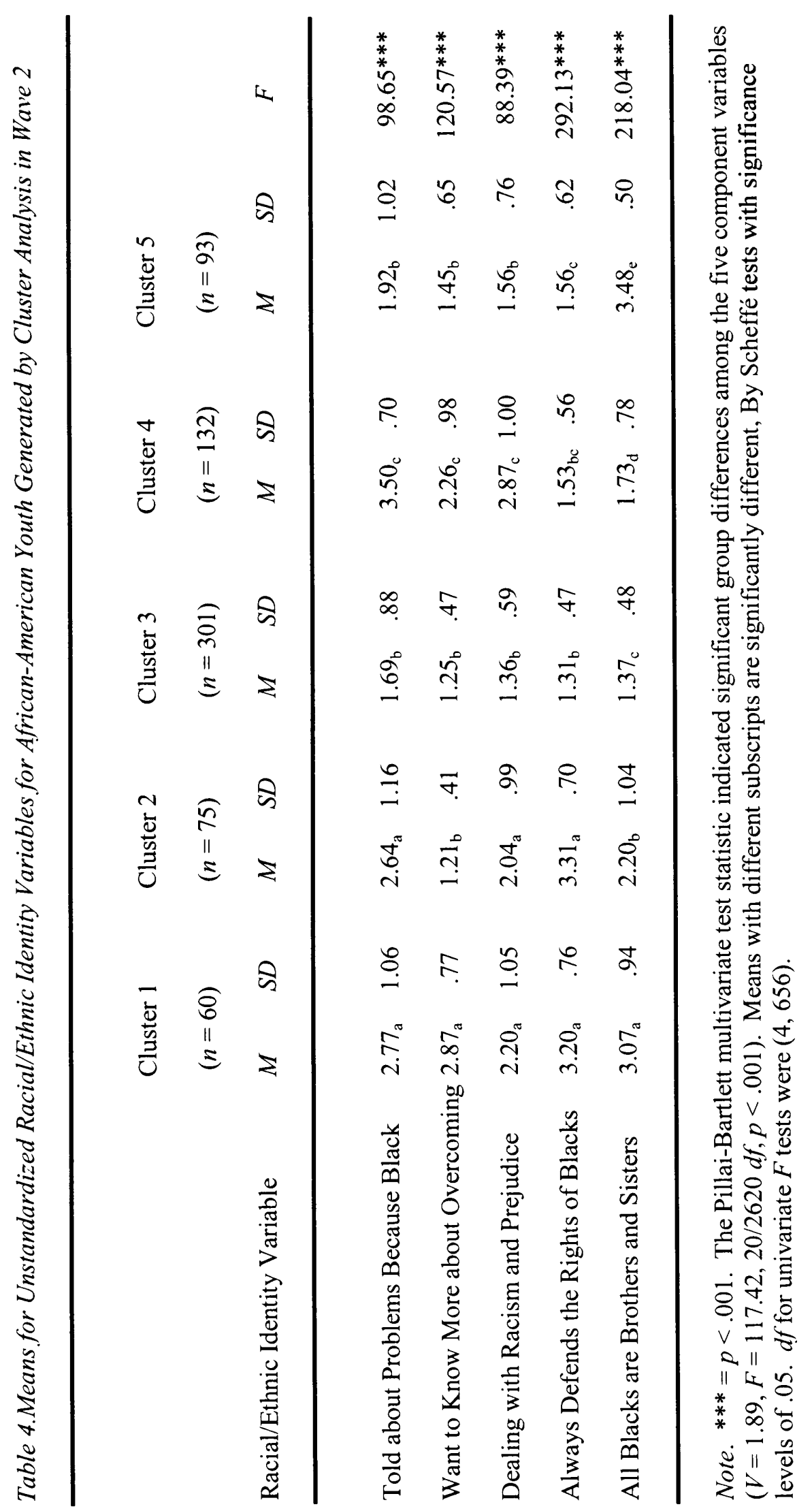




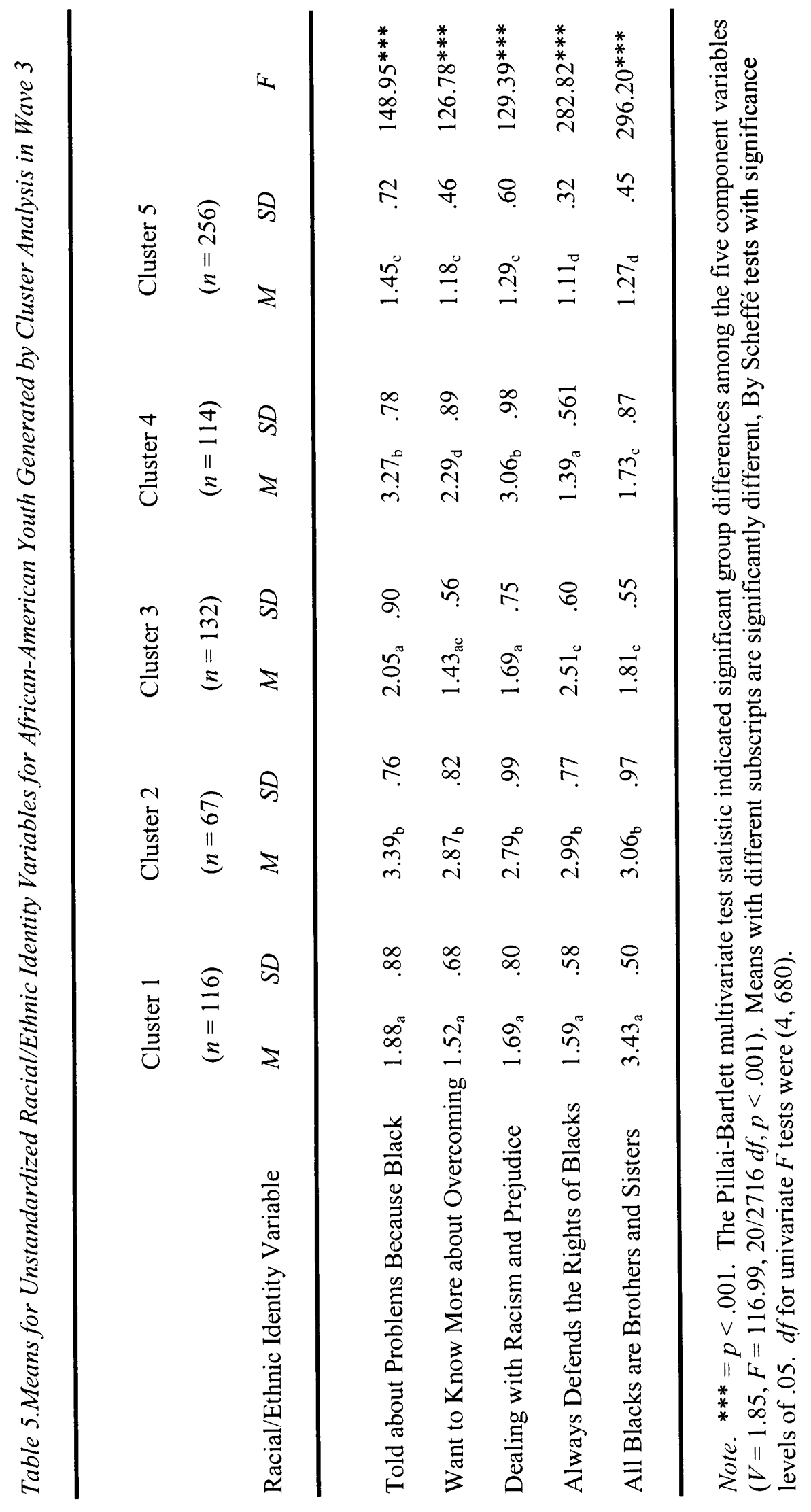


Table 6. Eigenvalues from Principal Factoring Method Employed for Racial Identity Salience Variables.

\begin{tabular}{cccc}
\hline Factor & Eigenvalue & Total Variance $\left({ }^{\circ} \circ\right)$ & Cumlative Variance $\left.{ }^{\circ}{ }^{\circ}\right)^{\circ}$ \\
\hline 1 & 4.09 & 40.90 & 40.90 \\
2 & 1.35 & 13.53 & 54.42 \\
\hline
\end{tabular}




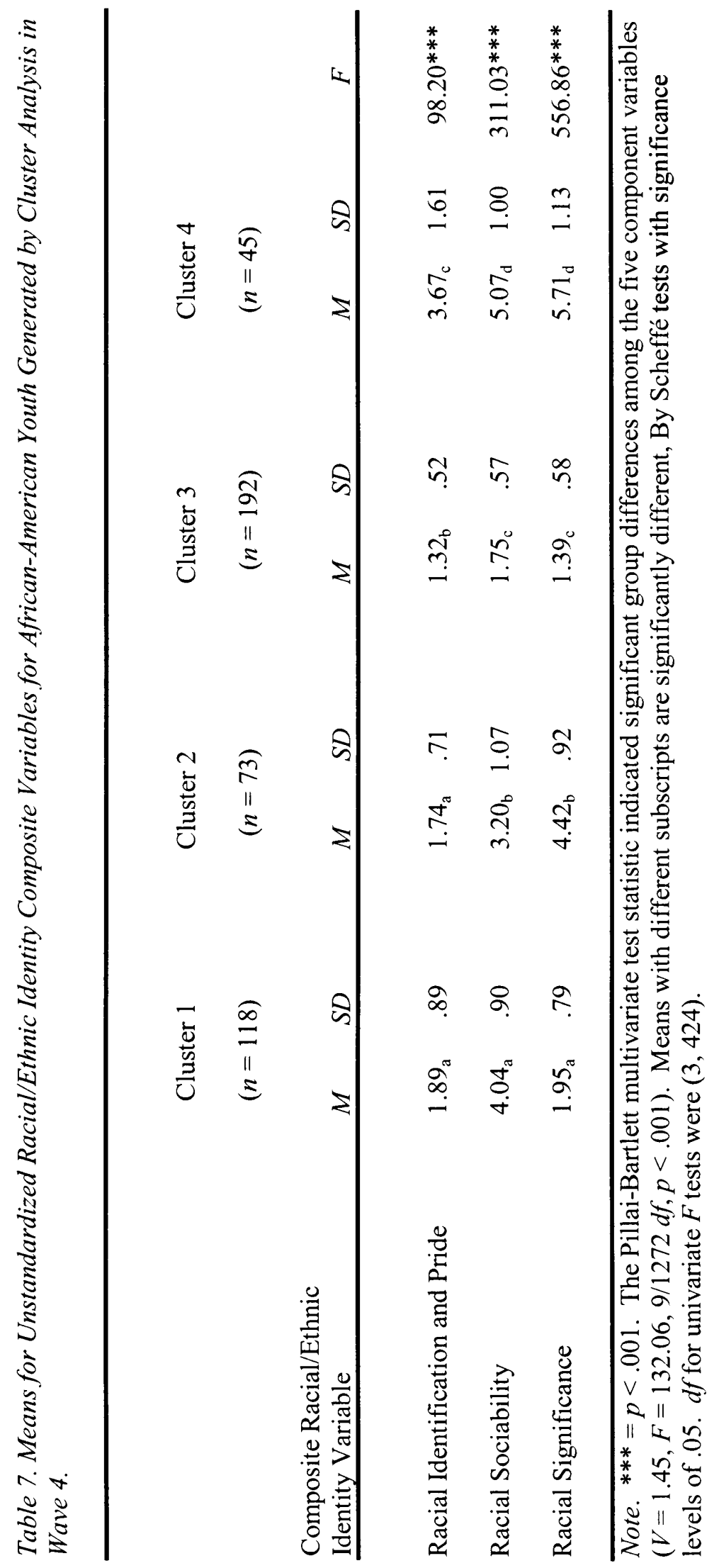




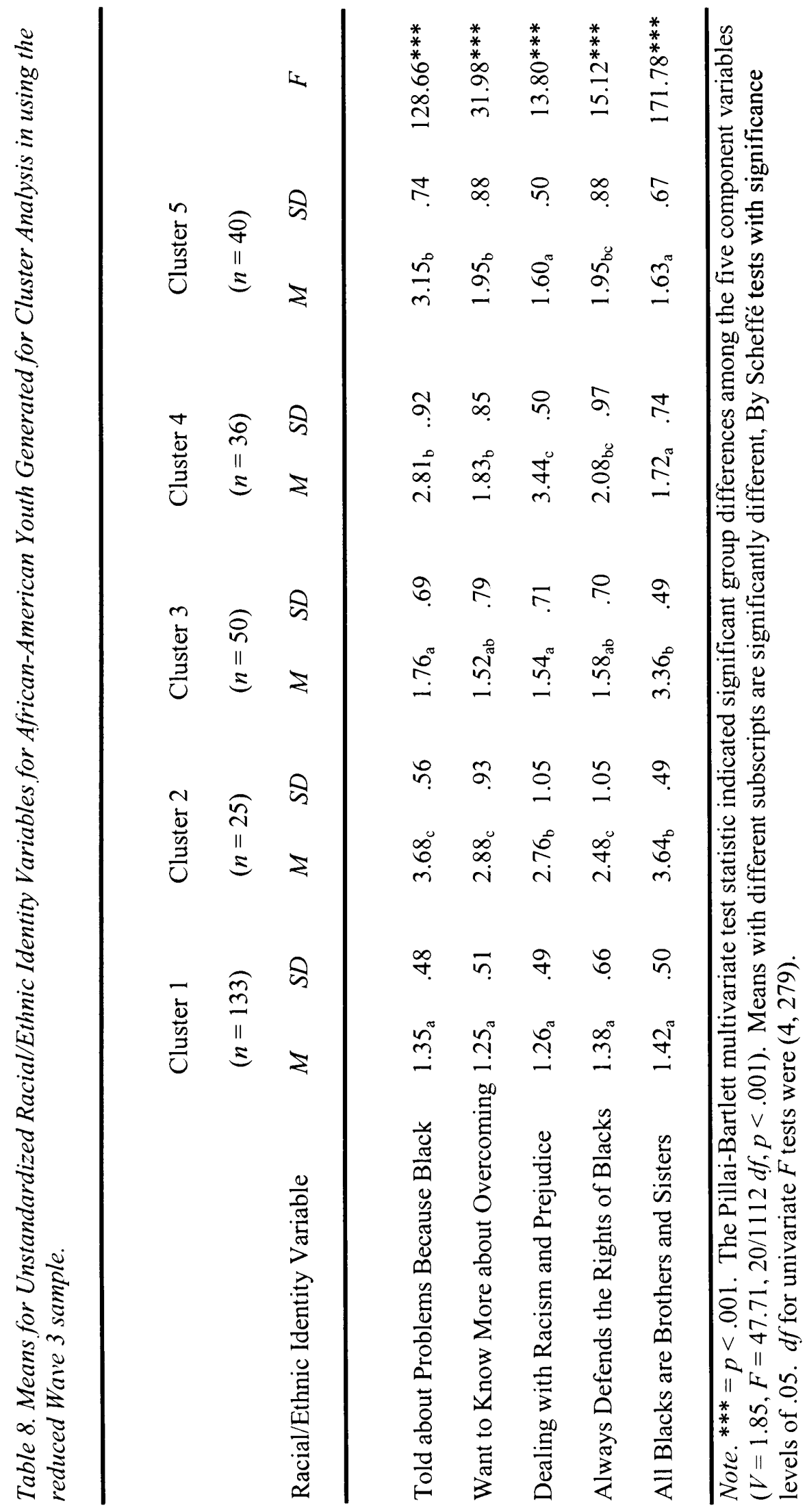




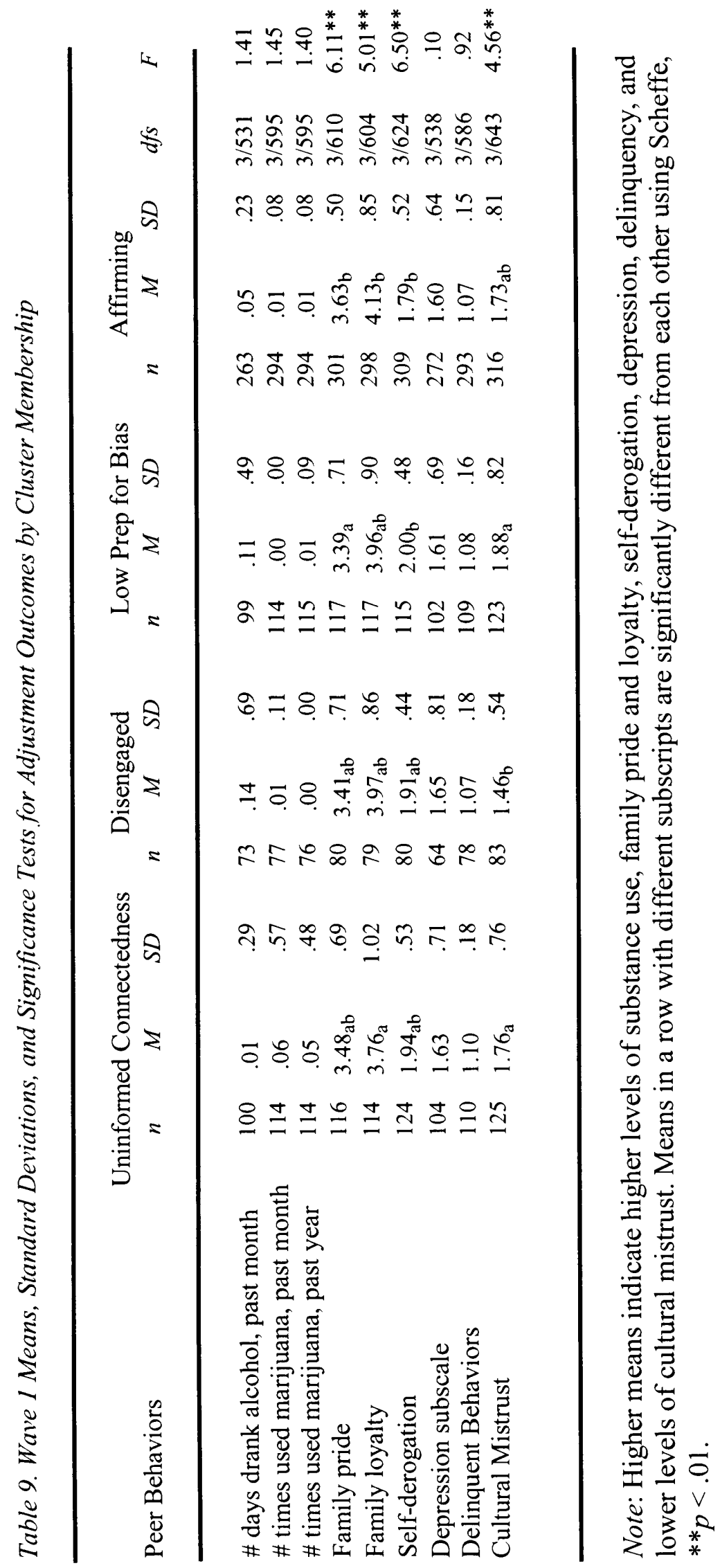


Table 10. Wave 2 Means, Standard Deviations, and Significance Tests for Adjustment Outcomes by Cluster Membership.

Adjustment Variables

Cluster

\# days drank alcohol, past month

Affirming

Non-Advocating

Low Preparation for Bias

Disengaged

Individualistic Affirming

\# times used marijuana, past month

Affirming

Non-Advocating

Low Preparation for Bias

Disengaged

Individualistic Affirming

\# times used marijuana, past year

Affirming

Non-Advocating

Low Preparation for Bias

Disengaged

Individualistic Affirming

Family pride

Affirming

Non-Advocating

Low Preparation for Bias

Disengaged

Individualistic Affirming

Family loyalty

Affirming

Non-Advocating

Low Preparation for Bias

Disengaged

Individualistic Affirming $n$

$M$

$M \quad S D$

$S D$

$d f s$

$F$

$4 / 538$

.88

$\begin{array}{ccr}247 & .15 & 1.29 \\ 67 & .07 & .26 \\ 101 & .15 & .65 \\ 47 & .40 & 1.53 \\ 81 & .09 & .28\end{array}$

289

75

121

56

89

.14

.13

.04

.00

.00

$4 / 625$

.21

2.35

1.15

.30

.00

.00

289

.02

.04

.12

.00

.01

$4 / 629$

$3.30 *$

291

$3.44_{\mathrm{a}}$

.58

74

$3.36_{\mathrm{ab}}$

.65

126

$3.33_{\mathrm{ab}}$

.64

56

$3.14_{\mathrm{b}}$

.72

87

$3.30_{\mathrm{ab}}$

.65

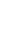

$\begin{array}{lll}57 & 3.56 & 1.02\end{array}$

$\begin{array}{lll}88 & 3.68 & .88\end{array}$

Table continues next page 
Table 10 (continued). Wave 2 Means, Standard Deviations, and Significance Tests for Adjustment Outcomes by Cluster Membership.

\begin{tabular}{|c|c|c|c|c|c|}
\hline $\begin{array}{c}\text { Adjustment Variables } \\
\text { Cluster }\end{array}$ & $n$ & $M$ & $S D$ & $d f s$ & $F$ \\
\hline Self-Derogation & & & & $4 / 635$ & $3.26^{*}$ \\
\hline Affirming & 293 & $1.79_{\mathrm{ab}}$ & .47 & & \\
\hline Non-Advocating & 72 & $1.81_{\mathrm{ab}}$ & .47 & & \\
\hline Low Preparation for Bias & 129 & $1.85_{\mathrm{ab}}$ & .48 & & \\
\hline Disengaged & 58 & $2.00_{\mathrm{a}}$ & .51 & & \\
\hline Individualistic Affirming & 88 & $1.72_{\mathrm{b}}$ & .46 & & \\
\hline Depression Subscale & & & & $4 / 615$ & 2.09 \\
\hline Affirming & 285 & 1.59 & .62 & & \\
\hline Non-Advocating & 72 & 1.72 & .85 & & \\
\hline Low Preparation for Bias & 120 & 1.77 & .86 & & \\
\hline Disengaged & 55 & 1.50 & .60 & & \\
\hline Individualistic Affirming & 88 & 1.69 & .74 & & \\
\hline Delinquent Behaviors & & & & $4 / 625$ & .20 \\
\hline Affirming & 287 & 1.09 & .18 & & \\
\hline Non-Advocating & 74 & 1.10 & .21 & & \\
\hline Low Preparation for Bias & 126 & 1.09 & .18 & & \\
\hline Disengaged & 56 & 1.11 & .22 & & \\
\hline Individualistic Affirming & 87 & 1.09 & .18 & & \\
\hline Cultural Mistrust & & & & $4 / 653$ & 2.21 \\
\hline Affirming & 301 & 1.83 & .86 & & \\
\hline Non-Advocating & 75 & 1.62 & .66 & & \\
\hline Low Preparation for Bias & 129 & 1.77 & .79 & & \\
\hline Disengaged & 60 & 1.61 & .73 & & \\
\hline Individualistic Affirming & 93 & 1.65 & .70 & & \\
\hline
\end{tabular}

Note: Higher means indicate higher levels of substance use, family pride and loyalty, self-derogation, depression, delinquency, and lower levels of cultural mistrust. Means in a row with different subscripts are significantly different from each other using Scheffe, $* p<.05$. 
Table 11. Wave 3 Means, Standard Deviations, and Significance Tests for Adjustment Outcomes by Cluster Membership.

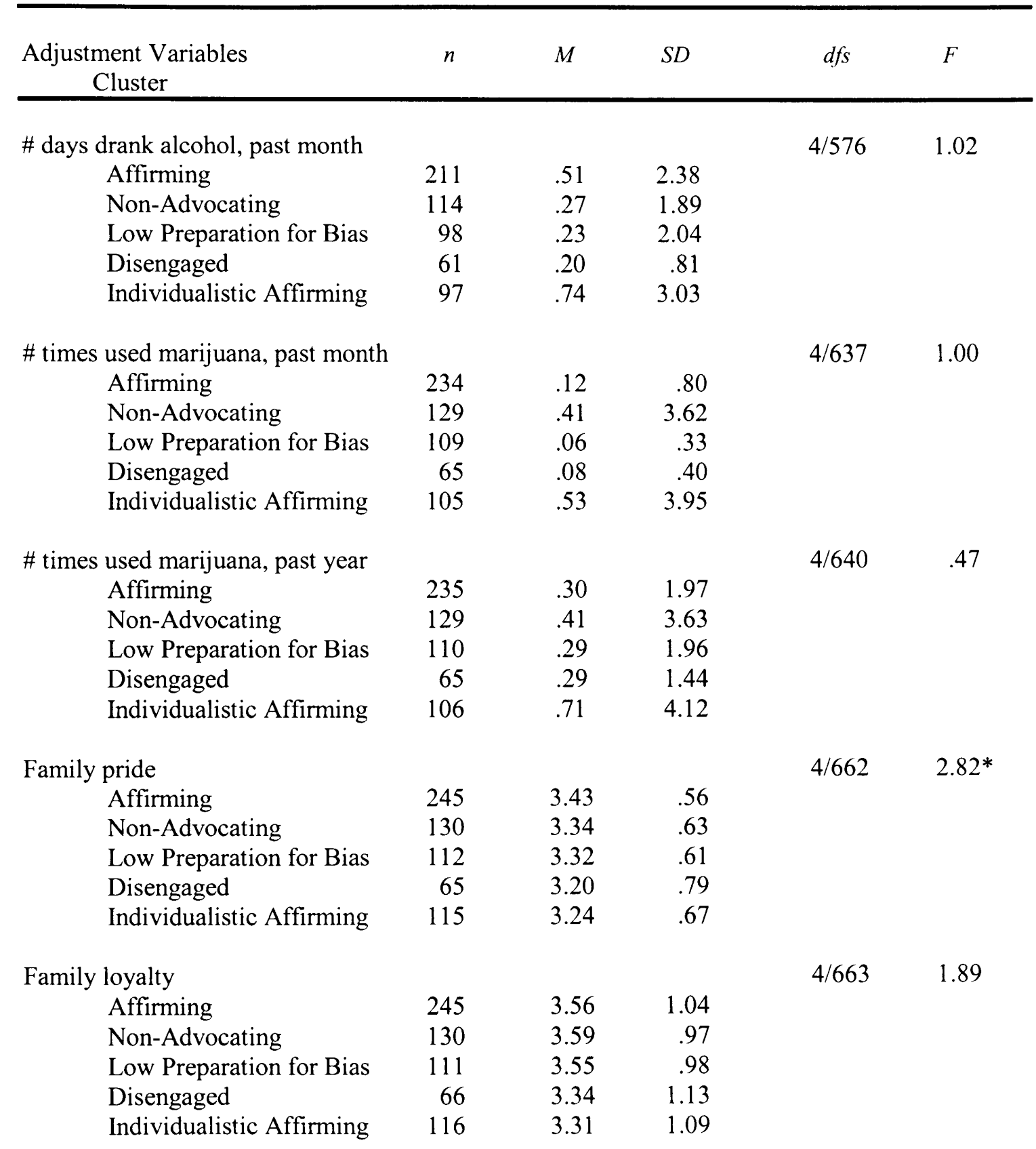

Table continues next page 
Table 11. (continued). Wave 3 Means, Standard Deviations, and Significance Tests for Adjustment Outcomes by Cluster Membership.

\begin{tabular}{|c|c|c|c|c|c|}
\hline $\begin{array}{l}\text { Adjustment Variables } \\
\text { Cluster } \\
\end{array}$ & $n$ & $M$ & $S D$ & $d f s$ & $F$ \\
\hline Self-Derogation & & & & $4 / 656$ & $3.80^{* *}$ \\
\hline Affirming & 245 & $1.68_{\mathrm{a}}$ & .45 & & \\
\hline Non-Advocating & 130 & $1.72_{\mathrm{ab}}$ & .53 & & \\
\hline Low Preparation for Bias & 111 & $1.84_{\mathrm{ab}}$ & .46 & & \\
\hline Disengaged & 64 & $1.90_{\mathrm{b}}$ & .47 & & \\
\hline Individualistic Affirming & 111 & $1.77_{\mathrm{ab}}$ & .53 & & \\
\hline Depression Subscale & & & & $4 / 639$ & .99 \\
\hline Affirming & 240 & 1.62 & .67 & & \\
\hline Non-Advocating & 129 & 1.53 & .66 & & \\
\hline Low Preparation for Bias & 105 & 1.62 & .79 & & \\
\hline Disengaged & 62 & 1.70 & .92 & & \\
\hline Individualistic Affirming & 108 & 1.70 & .74 & & \\
\hline Delinquent Behaviors & & & & $4 / 660$ & .36 \\
\hline Affirming & 244 & 1.08 & .15 & & \\
\hline Non-Advocating & 128 & 1.08 & .16 & & \\
\hline Low Preparation for Bias & 113 & 1.08 & .18 & & \\
\hline Disengaged & 64 & 1.10 & .19 & & \\
\hline Individualistic Affirming & 116 & 1.09 & .16 & & \\
\hline Cultural Mistrust & & & & $4 / 677$ & $3.66^{* *}$ \\
\hline Affirming & 253 & $1.86_{\mathrm{a}}$ & .88 & & \\
\hline Non-Advocating & 132 & $1.73_{\mathrm{ab}}$ & .76 & & \\
\hline Low Preparation for Bias & 114 & $1.74_{\mathrm{ab}}$ & .79 & & \\
\hline Disengaged & 67 & $1.47_{\mathrm{b}}$ & .63 & & \\
\hline Individualistic Affirming & 116 & $1.67_{\mathrm{ab}}$ & .72 & & \\
\hline
\end{tabular}

Note: Higher means indicate higher levels of substance use, family pride and loyalty, self-derogation, depression, delinquency, and lower levels of cultural mistrust. Means in a row with different subscripts are significantly different from each other using Scheffe, ${ }^{*} p<.05,{ }^{* *} p<.01$. 


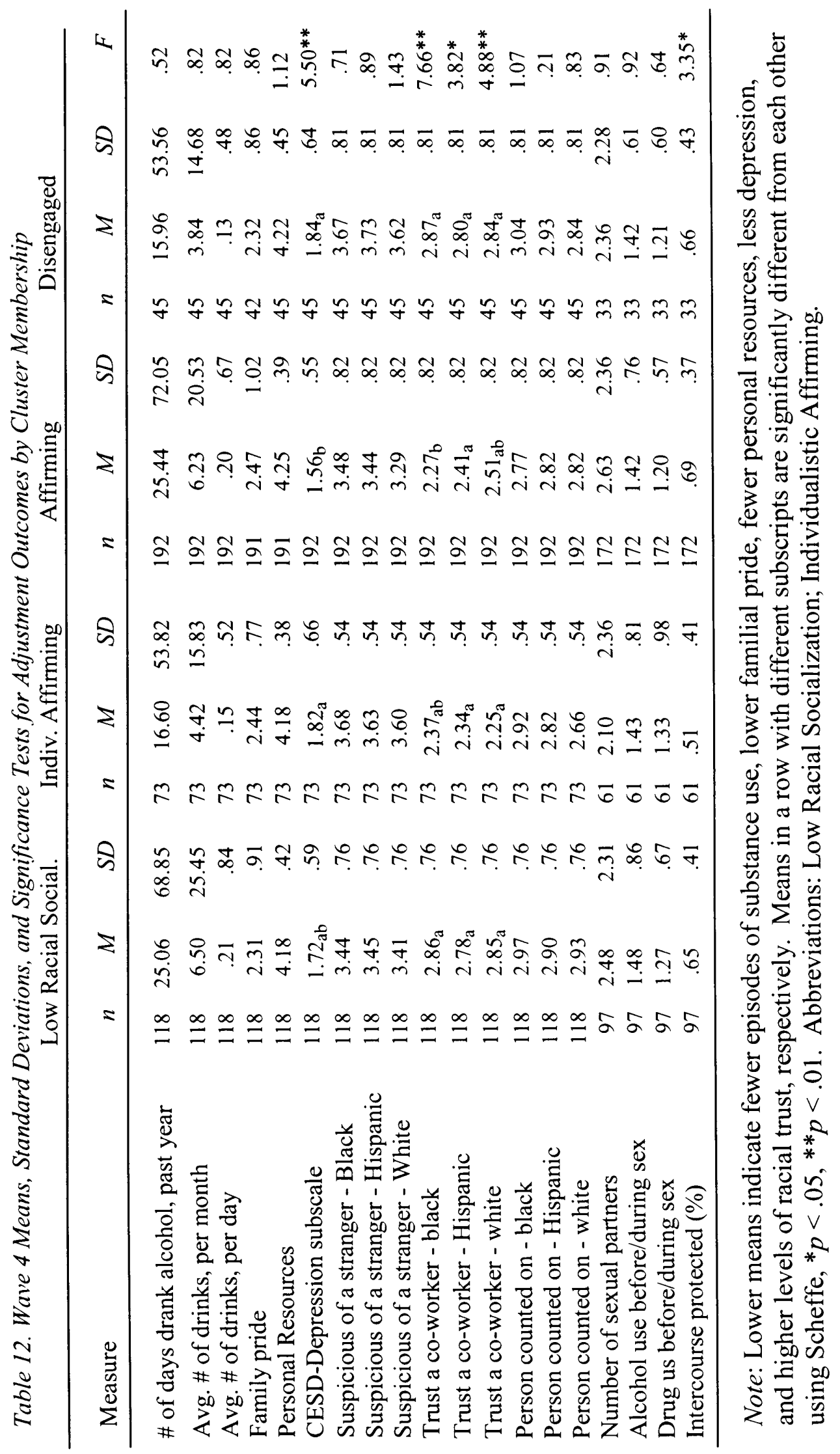




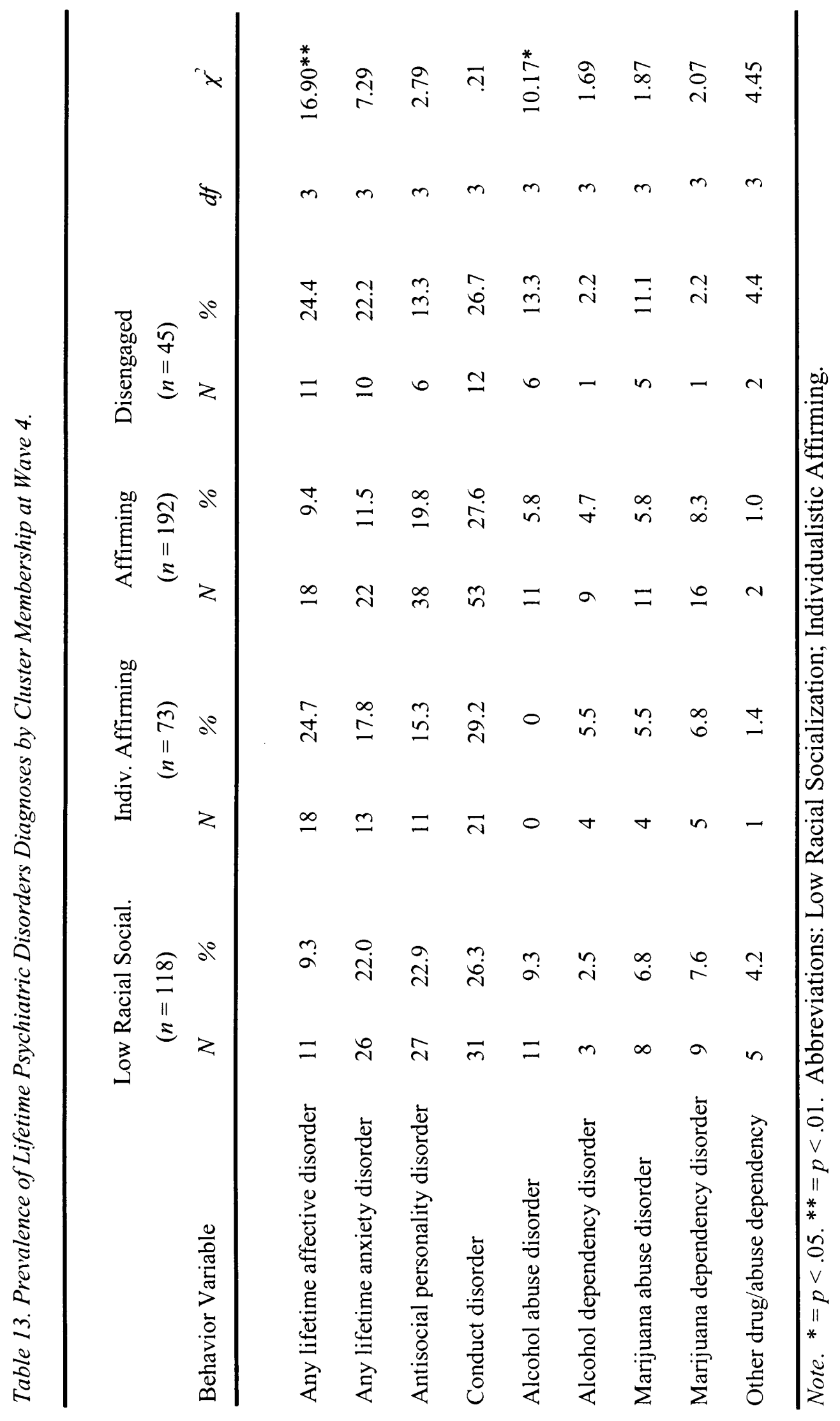




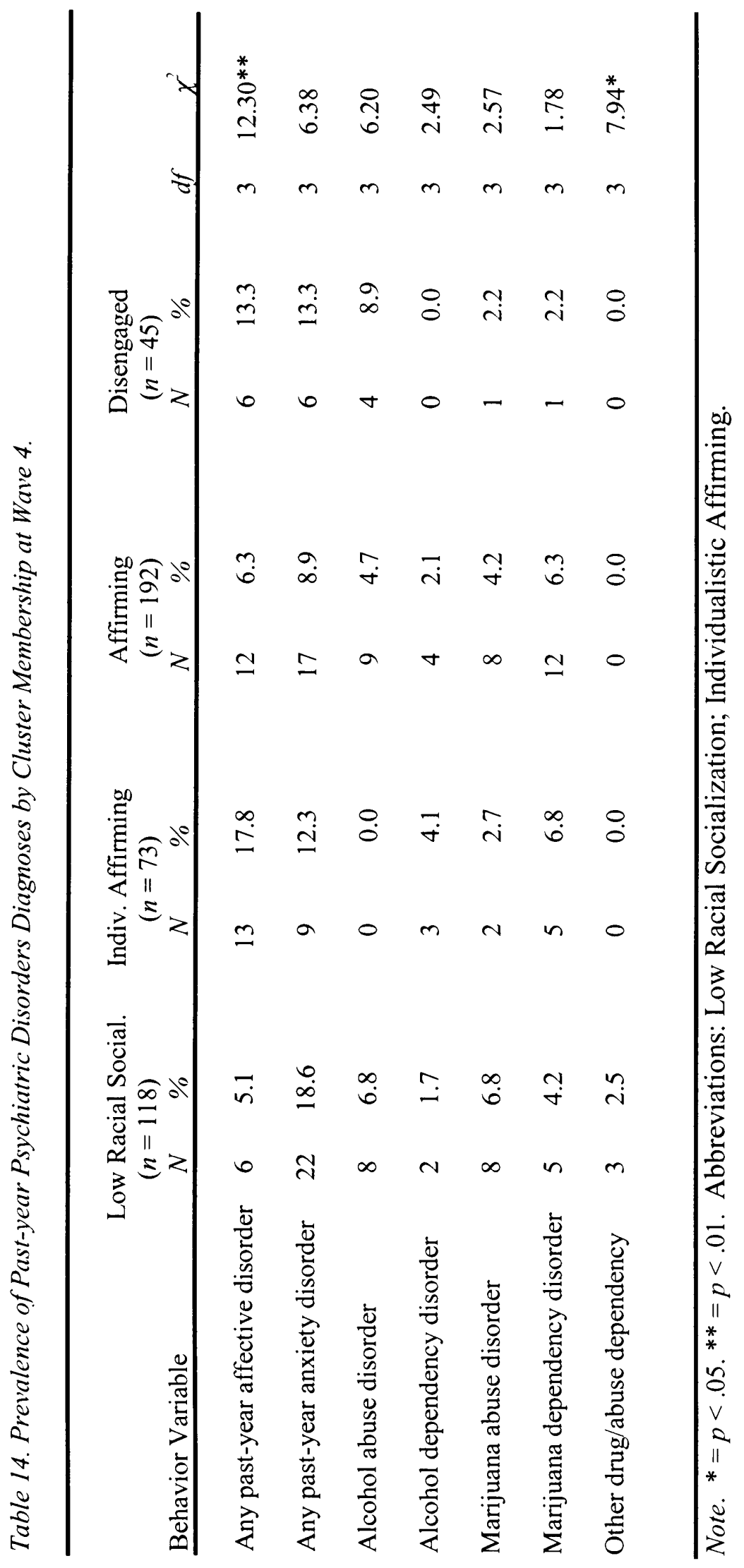


Table 15. Hierarchical Multiple Regression Model Predicting CESD Depression $(N=272)$

\begin{tabular}{|c|c|c|c|c|c|c|}
\hline & $B$ & $\beta$ & $R^{2}$ & $R^{2}$ Change & $F$ Change & $t$ \\
\hline Step 1 & & & .02 & .02 & 2.24 & \\
\hline Age & -.03 & -.05 & & & & -.78 \\
\hline Gender & .13 & .11 & & & & 1.81 \\
\hline Step 2 & & & .07 & .05 & $13.80^{*}$ & \\
\hline Age & .03 & -.05 & & & & -.84 \\
\hline Gender & .09 & .07 & & & & 1.22 \\
\hline W3 Depression & .16 & .22 & & & & $3.72 *$ \\
\hline Step 3 & & & .08 & .01 & $4.14 * *$ & \\
\hline Age & -.04 & -.05 & & & & -.81 \\
\hline Gender & .10 & .08 & & & & 1.33 \\
\hline W3 Depression & .16 & .22 & & & & $3.68^{*}$ \\
\hline W3 Racial Identity & & & & & & \\
\hline Clusters & -.09 & -.08 & & & & -1.33 \\
\hline
\end{tabular}

Note. Overall Significance, $F(4,267)=5.07 * .{ }^{*} p<.05,{ }^{* *} p<.01$. 
Table 16. Hierarchical Multiple Regression Model Predicting Personal Resources $(N=272)$

\begin{tabular}{|c|c|c|c|c|c|c|}
\hline & $B$ & $\beta$ & $R^{2}$ & $R^{2}$ Change & F Change & $t$ \\
\hline Step 1 & & & .01 & .01 & 2.58 & \\
\hline Age & .05 & .10 & & & & 1.63 \\
\hline Gender & .09 & .11 & & & & 1.86 \\
\hline Step 2 & & & .05 & .03 & $8.66^{* *}$ & \\
\hline Age & .05 & .10 & & & & 1.63 \\
\hline Gender & .08 & .10 & & & & 1.62 \\
\hline W3 Self-derogation & -.14 & -.18 & & & & $-2.94 * *$ \\
\hline Step 3 & & & .05 & .00 & .64 & \\
\hline Age & .05 & .10 & & & & 1.65 \\
\hline Gender & .08 & .10 & & & & 1.60 \\
\hline W3 Self-derogation & -.13 & -.17 & & & & $-2.81 * *$ \\
\hline $\begin{array}{l}\text { W3 Racial Identity } \\
\text { Clusters }\end{array}$ & .01 & .02 & & & & .30 \\
\hline
\end{tabular}

Note. Overall Significance, $F(4,267)=3.51 *{ }^{*} p<.05, * * p<.01$. 
Table 17. Hierarchical Multiple Regression Model Predicting Numbers of alcoholic drinks per month $(N=244)$.

\begin{tabular}{lcccccc}
\hline & $B$ & $\beta$ & $R^{2}$ & $R^{2}$ Change & F Change & $t$ \\
\hline Step 1 & & & & & & \\
Age & -2.72 & -.09 & .02 & .02 & 2.33 & \\
Gender & -5.19 & -.12 & & & & -1.49 \\
& & & & & & -1.85 \\
Step 2 & & & .05 & .03 & $7.68^{* *}$ & \\
Age & -2.55 & -.09 & & & & -1.41 \\
Gender & -4.93 & -.12 & & & & -1.78 \\
W3 \# drinks/month & 2.53 & .18 & & & & $2.77^{* *}$ \\
Step 3 & & & & & & \\
Age & -2.56 & -.09 & & & & -1.42 \\
Gender & -4.83 & -.11 & & & & -1.74 \\
W3 \# drinks/month & 2.59 & .18 & & & & $2.81^{* *}$ \\
W3 Racial Identity & & & & & \\
Clusters & -.99 & -.02 & & & -.39 \\
\hline
\end{tabular}

Note. Overall Significance, $F(4,239)=3.14 * .{ }^{*} p<.05,{ }^{* *} p<.01$ 
Table 18. Hierarchical Multiple Regression Model Predicting Number of times using marijuana during the past month $(N=267)$

\begin{tabular}{|c|c|c|c|c|c|c|}
\hline & $B$ & $\beta$ & $R^{2}$ & $R^{2}$ Change & F Change & $t$ \\
\hline Step 1 & & & .03 & .03 & $3.57^{*}$ & \\
\hline Age & .00 & .00 & & & & .03 \\
\hline Gender & -.60 & -.16 & & & & $-2.62 * *$ \\
\hline Step 2 & & & .04 & .02 & $4.80^{*}$ & \\
\hline Age & .03 & .01 & & & & .18 \\
\hline Gender & -.57 & -.15 & & & & $-2.50^{*}$ \\
\hline $\begin{array}{l}\text { W3 } \\
\text { marijuana/month }\end{array}$ & .26 & .13 & & & & $2.19 *$ \\
\hline Step 3 & & & .05 & .00 & .25 & \\
\hline Age & .03 & .01 & & & & .18 \\
\hline Gender & -.58 & -.16 & & & & $-2.52^{*}$ \\
\hline $\begin{array}{l}\text { W3 } \\
\text { marijuana/month }\end{array}$ & .26 & .13 & & & & $2.19^{*}$ \\
\hline $\begin{array}{l}\text { W3 Racial Identity } \\
\text { Clusters }\end{array}$ & .11 & .03 & & & & .50 \\
\hline
\end{tabular}

Note. Overall Significance, $F(4,262)=3.06 * .{ }^{*} p<.05,{ }^{* *} p<.01$. 
Table 19. Hierarchical Multiple Regression Model Predicting Number of lifetime sexual partners $(N=255)$.

\begin{tabular}{|c|c|c|c|c|c|c|}
\hline & $B$ & $\beta$ & $R^{2}$ & $R^{2}$ Change & F Change & $t$ \\
\hline Step 1 & & & .07 & .07 & $8.69 * *$ & \\
\hline Age & .21 & .07 & & & & 1.14 \\
\hline Gender & -1.09 & -.23 & & & & $-3.74 * *$ \\
\hline Step 2 & & & .09 & .03 & $3.50 *$ & \\
\hline Age & .25 & .08 & & & & 1.29 \\
\hline Gender & -1.01 & -.22 & & & & $-3.48 * *$ \\
\hline W3 Minor Deviance & 1.29 & .14 & & & & 1.79 \\
\hline W3 Major Deviance & .47 & .03 & & & & .40 \\
\hline Step 3 & & & .10 & .00 & 2.94 & \\
\hline Age & .24 & .08 & & & & 1.28 \\
\hline Gender & -.99 & -.21 & & & & $-3.39 * *$ \\
\hline W3 Minor Deviance & 1.43 & .15 & & & & 1.96 \\
\hline W3 Major Deviance & .34 & .02 & & & & .28 \\
\hline W3 Racial Identity & & & & & & \\
\hline Clusters & -.46 & -.10 & & & & -1.17 \\
\hline
\end{tabular}

Note. Overall Significance, $F(5,249)=5.57 * * .{ }^{*} p<.05,{ }^{* *} p<.01$. 
Table 20. Hierarchical Multiple Regression Model Predicting amounts of substance use before or during sexual intercourse $(N=244)$.

\begin{tabular}{|c|c|c|c|c|c|c|}
\hline & $B$ & $\beta$ & $R^{2}$ & $R^{2}$ Change & $F$ Change & $t$ \\
\hline Step 1 & & & .02 & .02 & 2.76 & \\
\hline Age & -.02 & -.02 & & & & -.31 \\
\hline Gender & -.22 & -.15 & & & & $-2.35^{*}$ \\
\hline Step 2 & & & .08 & .06 & $7.68^{* *}$ & \\
\hline Age & .25 & -.01 & & & & -.15 \\
\hline Gender & -.18 & -.12 & & & & -1.95 \\
\hline $\begin{array}{l}\text { W3 Minor } \\
\text { Deviance }\end{array}$ & .28 & .10 & & & & 1.22 \\
\hline $\begin{array}{l}\text { W3 Major } \\
\text { Deviance }\end{array}$ & .82 & .17 & & & & $2.18^{*}$ \\
\hline Step 3 & & & .09 & .00 & 1.12 & \\
\hline Age & -.01 & -.01 & & & & -.16 \\
\hline Gender & -.17 & -.12 & & & & $-1.85^{*}$ \\
\hline $\begin{array}{l}\text { W3 Minor } \\
\text { Deviance }\end{array}$ & .31 & .11 & & & & 1.36 \\
\hline $\begin{array}{l}\text { W3 Major } \\
\text { Deviance }\end{array}$ & .79 & .17 & & & & 2.09 \\
\hline $\begin{array}{l}\text { W3 Racial Identity } \\
\text { Clusters }\end{array}$ & -.09 & -.07 & & & & -1.06 \\
\hline
\end{tabular}

Note. Overall Significance, $F(5,238)=4.46^{* *} .{ }^{*} p<.05,{ }^{* *} p<.01$. 
Table 21. Hierarchical Multiple Regression Model Predicting percentage of episodes of protected sexual intercourse $(N=239)$.

\begin{tabular}{|c|c|c|c|c|c|c|}
\hline & $B$ & $\beta$ & $R^{2}$ & $R^{2}$ Change & F Change & $t$ \\
\hline Step 1 & & & .06 & .06 & $7.37 * *$ & \\
\hline Age & .08 & .16 & & & & $2.42 *$ \\
\hline Gender & -.13 & -.16 & & & & $-2.50 *$ \\
\hline Step 2 & & & .07 & .01 & .90 & \\
\hline Age & .08 & .16 & & & & $2.44 *$ \\
\hline Gender & -.13 & -.16 & & & & -2.50 \\
\hline W3 Minor Deviance & .12 & .08 & & & & .94 \\
\hline W3 Major Deviance & -.28 & -.11 & & & & -1.33 \\
\hline Step 3 & & & .09 & .02 & 1.50 & \\
\hline Age & .08 & .15 & & & & $2.37 *$ \\
\hline Gender & -.12 & -.15 & & & & $-2.32 *$ \\
\hline W3 Minor Deviance & .17 & .11 & & & & 1.30 \\
\hline W3 Major Deviance & -.33 & -.12 & & & & -1.54 \\
\hline W3 Racial Identity & & & & & & \\
\hline Clusters & -.06 & -.08 & & & & -1.22 \\
\hline
\end{tabular}

Note. Overall Significance, $F(5,233)=3.61 * * .{ }^{*} p<.05,{ }^{* *} p<.01$. 
Table 22. Hierarchical Multiple Regression Model Predicting Racial Significance by earlier levels of Family Pride $(N=271)$.

\begin{tabular}{|c|c|c|c|c|c|c|}
\hline & $B$ & $\beta$ & $R^{2}$ & $R^{2}$ Change & F Change & $t$ \\
\hline Step 1 & & & .02 & .02 & $3.33 *$ & \\
\hline Age & .14 & .06 & & & & .98 \\
\hline Gender & .54 & .16 & & & & $2.52 *$ \\
\hline Step 2 & & & .03 & .00 & .65 & \\
\hline Age & .14 & .06 & & & & .99 \\
\hline Gender & .55 & .16 & & & & $2.56^{*}$ \\
\hline W3 Racial Identity & & & & & & \\
\hline Clusters & .05 & .05 & & & & .80 \\
\hline Step 3 & & & .05 & .02 & $6.06^{*}$ & \\
\hline Age & .16 & .07 & & & & 1.16 \\
\hline Gender & .50 & .14 & & & & $2.32 *$ \\
\hline $\begin{array}{l}\text { W3 Racial Identity } \\
\text { Clusters }\end{array}$ & .05 & .04 & & & & .72 \\
\hline W3 Family Pride & -.42 & -.15 & & & & $-2.46^{*}$ \\
\hline
\end{tabular}

Note. Overall Significance, $F(4,266)=3.37 * .{ }^{*} p<.05$. 
Table 23. Hierarchical Multiple Regression Model Predicting Racial Significance by earlier levels of Self-Derogation $(N=266)$.

\begin{tabular}{|c|c|c|c|c|c|c|}
\hline & $B$ & $\beta$ & $R^{2}$ & $R^{2}$ Change & F Change & $t$ \\
\hline Step 1 & & & .03 & .03 & $4.41 *$ & \\
\hline Age & .19 & .08 & & & & 1.31 \\
\hline Gender & .63 & .18 & & & & $2.86 * *$ \\
\hline Step 2 & & & .03 & .00 & .55 & \\
\hline Age & .19 & .08 & & & & 1.30 \\
\hline Gender & .63 & .18 & & & & $2.89 * *$ \\
\hline $\begin{array}{l}\text { W3 Racial Identity } \\
\text { Clusters }\end{array}$ & .05 & .05 & & & & .74 \\
\hline Step 3 & & & .04 & .00 & .40 & \\
\hline Age & .19 & .08 & & & & 1.30 \\
\hline Gender & .64 & .18 & & & & $2.92 * *$ \\
\hline $\begin{array}{l}\text { W3 Racial Identity } \\
\text { Clusters }\end{array}$ & .05 & .04 & & & & .66 \\
\hline Self-Derogation & .13 & .04 & & & & .63 \\
\hline
\end{tabular}

Note. Overall Significance, $F(4,262)=2.43 *$. ${ }^{*} p<.05, * * p<.01$. 
Time 1
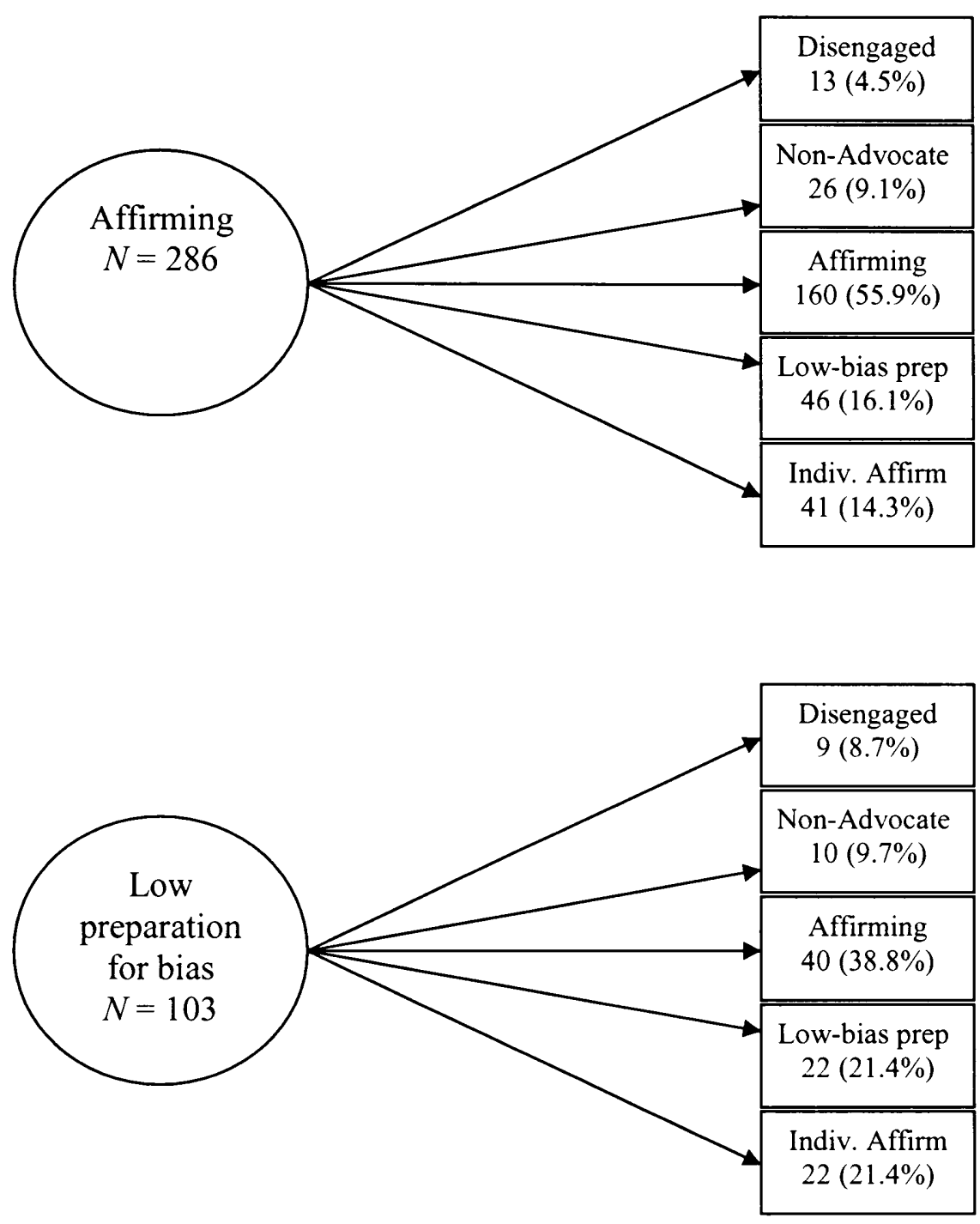

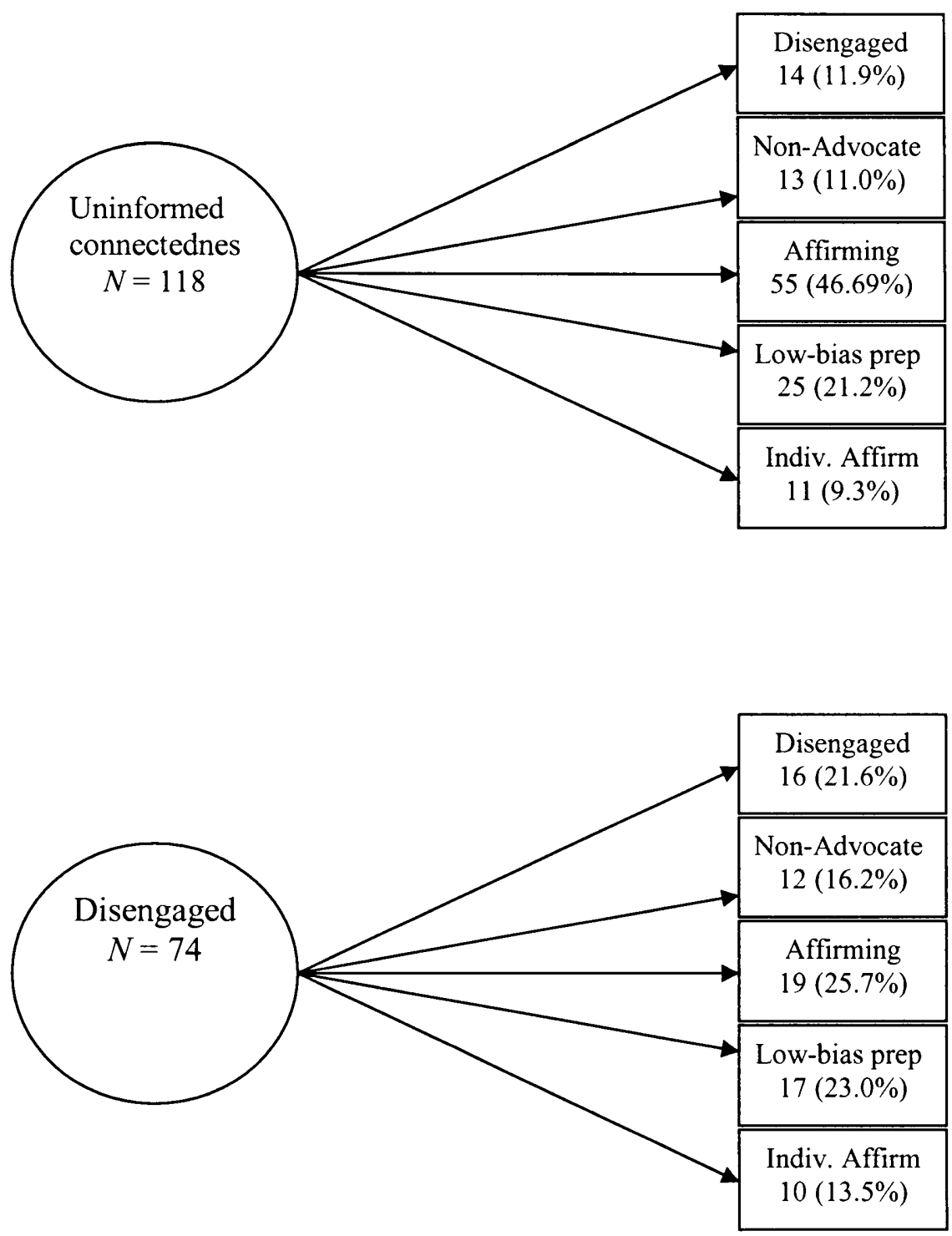
Time 2

Time 3
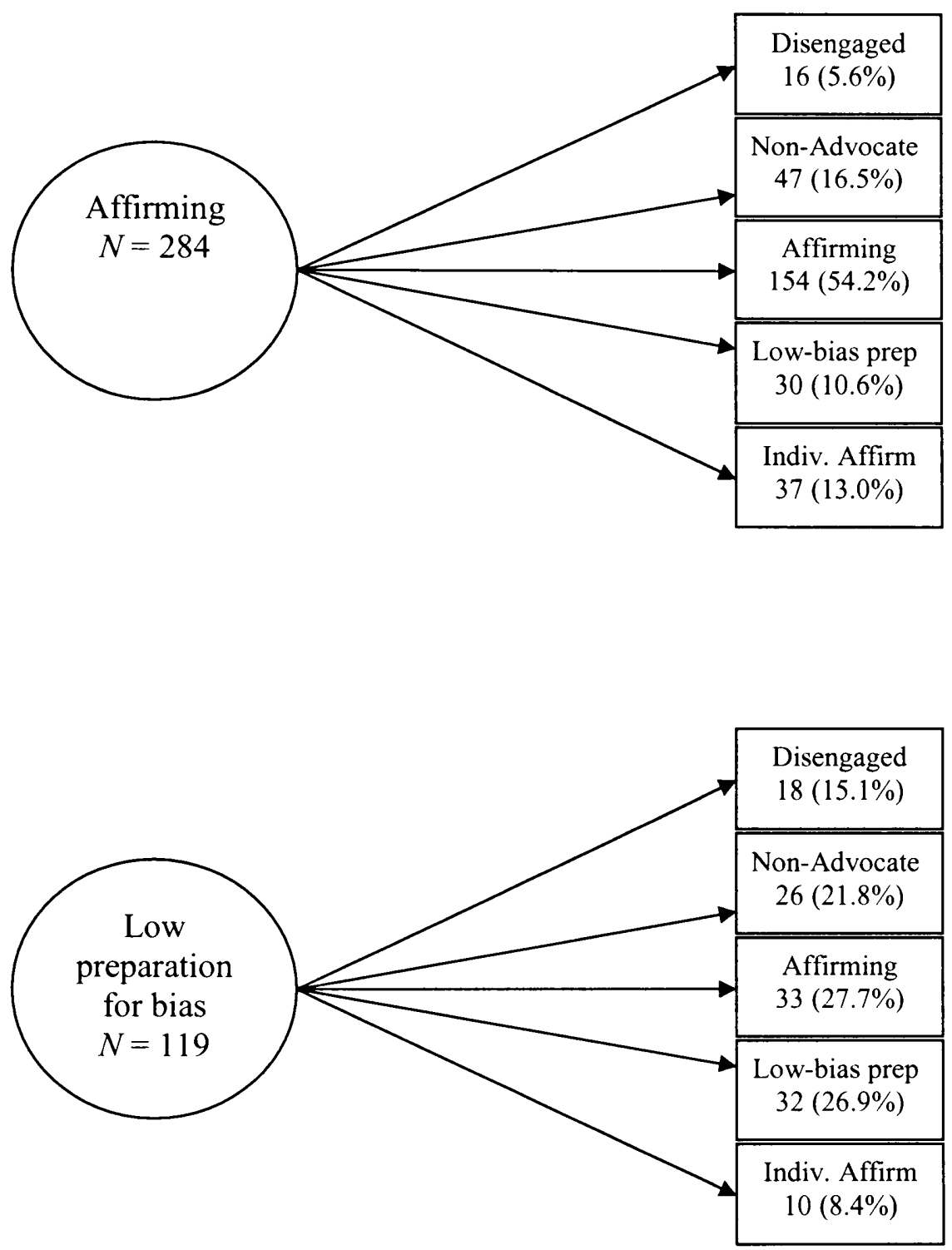


\section{Time 2}
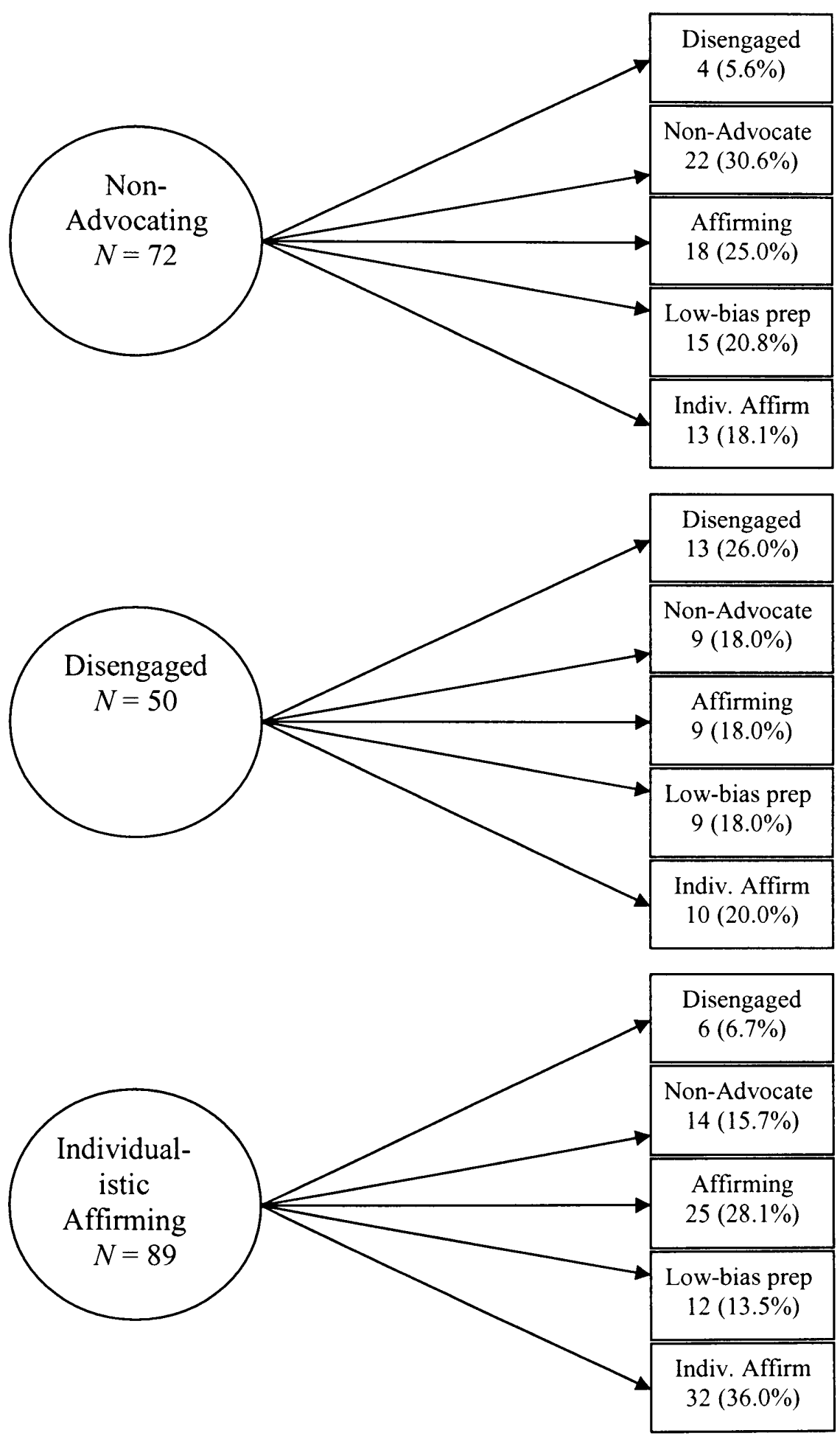
Figure 3. Shifts if Racial Identity Salience Cluster Profiles from Wave 3 to Wave 4.
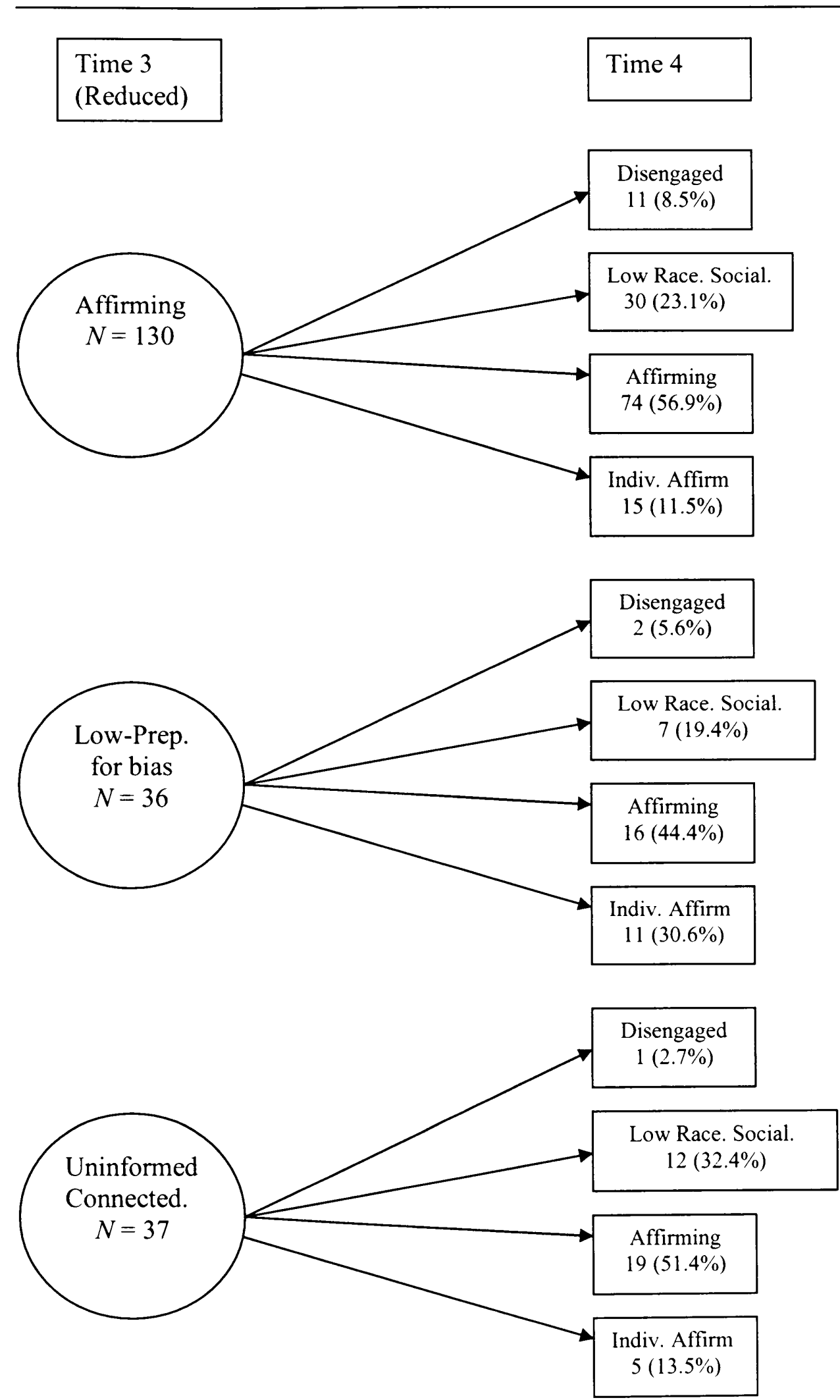

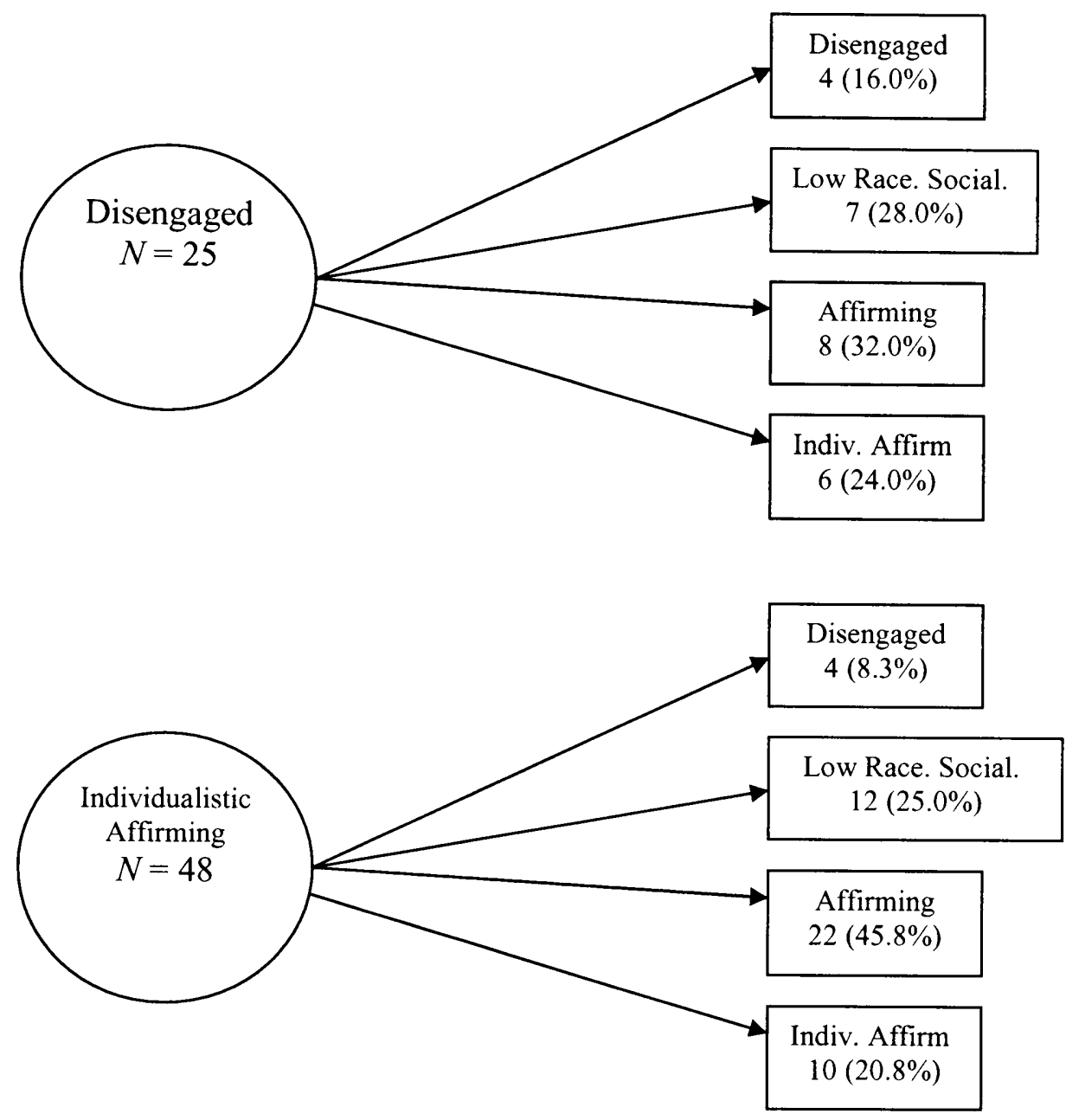

Note. Abbreviation: Low Racial Salience. 


\section{Chapter V. Discussion}

The purpose of this study was to examine key developmental patterns and adjustment outcomes associated with specific subgroups of African-American youth reporting distinct patterns of racial identity salience. The person-centered analytic approach used in this study offered a developmental and multidimensional characterization of racial identity salience among a community sample of AfricanAmerican youth. Specifically, utilizing two archived databases containing longitudinal follow-up data, this study investigated the underlying implications of racial identity salience at four different measurement occasions ranging from early adolescence to young adulthood. To address the specific research questions posed in this study, four separate groups of analyses were conducted to investigate (a) the existence of withingroup differences in levels of racial identity salience, (b) shifts from and to distinct racial identity cluster types between contiguous times of measurement, (c) adjustment variables associated with distinct racial identity cluster types within each time of measurement, and (d) predictive associations between racial identity clusters and adjustment outcomes. Taken together, results from the four sets of analyses illustrated the significance of racial identity as a meaningful developmental construct in the lives of these African-American youth. Furthermore, this study demonstrated the need to consider a range of domains of adjustment when investigating the salience of racial identity, as unique patterns of correlates were found across the different domains of adjustment investigated. Findings from this study were significant because they focus on adolescence, a developmental period that has been understudied in existing racial identity literature. 


\section{Summary of Key Findings}

Research question 1: Within-group differences in levels of racial identity salience

Using cluster analysis, the current study identified heterogeneous patterns in levels of racial identity salience manifested by the African-American youth at all four times of measurement. Therefore, the hypothesis that differentiated subgroups or clusters of youth manifesting distinct and meaningful patterns of racial identity salience would emerge across measurement occasions was supported. Specifically, at each time of measurement, "Affirming" and "Disengaged" clusters were identified from the cluster solutions, characterizing groups of youth reporting the highest and lowest levels of racial identity salience, respectively. Throughout the study, the "Affirming" cluster represented the largest proportions of youth, while the "Disengaged" cluster represented the smallest proportions of participants. Also consistent across each time of measurement was the emergence of clusters of youth manifesting differentiated and moderate levels of racial identity salience.

Research question 2: Continuity/Discontinuity of racial identity salience during adolescence

In the current study, cross-tabulation analyses revealed differential patterns in shifts in identity clusters between contiguous times of measurement. Therefore, the hypothesis that levels of racial identity salience would be discontinuous, (i.e., stronger or weaker) at key periods of adolescent development was supported. Specifically, when investigating cluster shifts occurring from Wave 1 to Wave 2, the largest proportion of youth in every cluster shifted to the "Affirming" cluster. This finding is consistent with existing literature suggesting that the progression through adolescence offers youth more 
race/ethnicity-based experiences, and thereby, is associated with incrementally higher levels of racial salience (Phinney, 1989; Quintana, 1998). In contrast, cross-tabulations investigating shifts in cluster membership from Wave 2 to Wave 3 indicated that for every Wave 2 cluster, the largest proportion of individuals remained in a comparable cluster at Wave 3 (with the exception of the "Low Preparation for Bias" cluster, which essentially retained only as many youth $(26.9 \%)$ at Wave 3 as the number $(27.7 \%)$ who shifted to the "Affirming" cluster). Also, in contrast with the findings regarding shifts from Wave 1 to Wave 2, findings regarding shifts from Wave 2 to Wave 3 suggest that levels of racial identity salience may become incrementally more stable as youth transition through early adolescence, and that these levels have unique associations with identities documented in young adulthood.

Research Question 3: Relations between cluster membership and adjustment outcomes Investigations of associations between racial identity salience profiles and key adjustment indices at each time of measurement revealed significant differences along several adjustment outcomes measured in this study. Therefore, the hypothesis that distinct patterns of cluster memberships would be associated with specific levels of adjustment, such that incrementally more salient racial identities would be associated with more adaptive outcomes was supported. Specifically, across the first three waves of the current study, a consistent pattern emerged in which youth from the "Affirming" cluster reported the highest levels of family pride and lowest levels of self-derogation. Utilizing data from an enhanced structured interview at Wave 4, the trend of more salient racial identities being associated with more adaptive adjustment persisted. In this fourth time of measurement, youth from the "Affirming" cluster reported among the lowest 
levels of CESD-assessed depression, CIDI-generated diagnoses for lifetime and past-year affective disorders, and were consistently among the highest levels of trust for black, Hispanic/Latino and white co-workers. In comparison, the "Disengaged" cluster reported the contrasting levels of these measures. Considering all four waves, the results of the current study revealed consistent patterns of adjustment such that, (a) group differences were related to the same variables over time, and (b) similar cluster classifications were associated with comparable levels of key adjustment measures.

Research Question 4: Cross-time influences between racial identity profiles and patterns of adjustment

Hierarchical Multiple Regression (HMR) analyses indicated few signficant crosstime relations between (a) early racial identity salience clusters and later adjustment outcomes and (b) early patterns of adjustment and later racial identity salience clusters. Given the exploratory nature of these analyses, no hypotheses were provided regarding the direction of findings. However, while final HMR models indicated significant predictive relationships between Wave 3 predictors (i.e., demographic variables, earlier levels of adjustment, and Wave 3 racial identity clusters) and several Wave 4 adjustment measures, only the outcome measures of CESD depression and proportions of episodes involving sexual intercourse using a condom were shown to be significantly predicted by earlier racial identity clusters, after controlling for demographic variables and earlier levels of comparable adjustment variables. In addition, exploratory HMR analyses investigating relations between levels of Wave 3 adjustment and Wave 4 racial identity salience variables revealed even fewer significant findings. Specifically, of the two final HMR models indicating significant predictive relationships between the predictors of 
Wave 3 outcomes (i.e., family pride and self-derogation) and Wave 4 racial identity salience variables, family pride was the only measure accounting for significant amounts of variance in the Wave 4 racial identity salience variables after controlling for demographic variables and earlier levels of racial identity salience. The lack of additional significant cross-time relations between identity profiles and adjustment may be due to underlying psychosocial factors not controlled for in the current study, which mediated relations between racial identity and adjustment outcomes over time.

Alternatively, measurement variations between the first three waves of data and the fourth wave may have limited the ability to detect significant relations.

Synthesis of Current Research and the Findings of this Study

Heterogeneity in Patterns of Racial Identity Salience

Taken together, the findings of the current study suggest the existence of significant heterogeneity in reports of racial identity salience in this community sample of African-American youth. While existing literatures exploring various aspects of racial identity have characterized the normative developmental processes by which AfricanAmericans construct their sense of who they are racially (e.g., Cross, 1971; Helms, 1986; 1991; Thomas, 1971), little research has highlighted the diversity of identities inherent among individuals from this racial group (Neville \& Lilly, 2000). However, related studies that have explored the expression of racial identity, awareness, and salience among African-American youth have suggested that these race-related constructs are developed within localized cultural and racial socialization contexts (Hughes, 2003). Furthermore, Celious and Oysterman (2001) suggested that the overarching meaning that one places on her or his race is contingent upon a constellation of factors, including 
socioeconomic status, gender, and physical characteristics. Therefore, the finding of distinct patterns of racial identity salience between subgroups of African-American youth in this study supports an emerging body of literature that has called for the awareness and exploration of within-group heterogeneity.

A clear overlap exists between the identity cluster solutions found in this study and traditional stage models of African-American racial identity development.

Fundamentally, the classifications of youth at each wave of measurement yielded a broad range of expressions of Black identity that are characteristic of Nigrescence Theory. For example, the "Affirming" pattern of racial identity salience detected in this study can be seen as corresponding to an "Internalized" or "Internalized-Commitment" level of racial identity in the Nigrescence model, as each characterizes individuals who view their racial identity as valuable and significant in their lives. The "Disengaged" pattern of racial identity salience documented in this study can be associated with a "Pre-Encounter" level of racial identity as characterized by Nigrescence, insofar that both labels describe identity types that exhibit indifference to issues central to Black culture (Cross \& Vandiver, 2001). Also, the intermediate and differentiated levels of racial identity attitudes found in this study also reflect transitional stages of the Nigrescence model (e.g. "Immersion-Emersion"), and are important indicators of key developmental stages of African-American identity process (Helms, 1990; Parham and Helms, 1981, 1985). Despite traditional applications of Nigrescence theory to young adult populations, the present findings suggest that progression through differentiated and incrementally more complex levels of Black identity occurs during adolescence as well. 
While the specific labels ascribed to the distinct clusters documented in this study may not comprehensively describe each individual member (von Eye \& Bergman, 2003), consideration of the broad patterns of racial identity salience captured by each cluster permits a meaningful characterization of typical members represented by these classifications or types. For example, individuals who endorsed "Affirming" levels of racial identity salience could be expected to have grown up in race-conscious families and communities wherein racial socialization messages reflected the importance of both a personal and collective Black identity for positive development (Stevenson, 1995; Thompson, 1994). Also, given Miami-Dade County's racially and ethnically diverse yet segregated communities (Vega \& Gil, 1993), it is plausible that for a large number of African-American youth, endorsement of a Black identity may simply reflect a normative self-actualization process by which these individuals manifest a sophisticated understanding of self in relation to others (Helms, 1990). This possibility may be validated by the consistent finding of "Affirming" patterns of racial identity salience to be the most populated at each measurement occasion of this study. In contrast, the "Disengaged" pattern of racial identity salience likely described youth who were nurtured in less race-salient environments, and in particular, those focusing on Black identity. Alternatively, these youth may not engage actively with aspects of their racial identity (i.e., advocating on behalf of Black people or actively seeking knowledge of Black history) because they do not relate notions of race to their overall self-concept (Plummer, 1995). Their lack of commitment to this specific racial classification may be the result of limited or negative interactions with other Black people, culture, and history, or 
alternatively, a personal rejection of these factors as positive representations of themselves (Rotterham-Borus \& Wyche, 1994).

The intermediate and somewhat transitional racial identity salience types "Uninformed Connectedness", "Low Preparation for Bias", and "Low Racial Sociability" each describe individuals who reported high levels of racial identity salience despite receiving little racially-relevant communications from family members regarding Black identity and social experiences. However, given that the present sample of youth were derived from diverse areas of Miami-Dade County (Biafora, et al., 1993; Vega \& Gil, 1993), differences between these intermediate levels of racial identity salience may be due to underlying contextual circumstances (e.g., race-related experiences, community demographics, and individual developmental histories). Thus, it is plausible that these factors moderated the content of racial socialization processes and messages, and in turn resulted in slightly different profiles of youth racial identity salience. Also, key differences in adolescent reference group orientation may have resulted in these similar, yet differentiated identity resolutions. For example, researchers have suggested that the range of Black adolescent racial identities may be linked to the inherent range in possible reference groups (i.e., Blacks Whites, both, neither) minority youth are referencing when responding to racial issues (Stevenson, 1995, Helms, 1990).

One of the most interesting clusters identified in the present study, "Individualistic Affiriming", likely represented individuals from families that manifested a mainstream orientation to processes of racial socialization, wherein these messages focused on personal competence, self-esteem, and hard work as a means of surviving in American society (Scott, 2003; Thornton, 1997). While this cluster included youth who 
embraced high levels of racial identity salience, these identities likely developed within a broader or humanistic notion of group connectedness, in which race is not a sole unifying characteristic. This position may be supported by the situational finding that youth from this cluster reported the highest levels of trust for White and Hispanic/Latino co-workers in comparison to members of other clusters. Another characteristic of the members of this cluster may be that these youth have begun to differentiate between subgroups of individuals who are identified as being Black (e.g., African-Americans, Haitians, Caribbean Blacks) - a particularly significant possibility given the demographic composition of South Florida. As a whole, the typical or central features characterizing the distinct typologies documented in this study can be drawn together with meaningful contextual factors that are likely to contribute to the different patterns of racial identity salience documented.

In addition, the different types of racial identity clusters found in this study can be viewed within the broader research conducted on identity formation. Specifically, as an expansion of Eriksonian psychosocial theory, Marcia's (1966) identity status model characterizing four unique identity statuses (i.e., Achieved, Moratorium, Foreclosed, and Diffused) can be used as a possible template for understanding the underlying identity exploration and commitment processes associated with youth that have expressed distinct levels of racial identity salience. With regards to studies investigating overall identity, researchers have typically associated an "Achieved" identity status with older adolescents and adults given their more mature psychosocial and cognitive processing capabilities, while younger adolescents are often associated with the "Foreclosed" and "Diffused statuses" (Archer, 1982; Archer \& Waterman, 1983). However, the findings of the 
current study suggest that this pattern may not describe key aspects of identity, and in particular, the racial identities of African-American youth. In support, existing research literature suggests that Black racial identities may be a largely separate entity from traditional identity formation processes. Specifically, Plummer $(1995,1996)$ held that some African-American parents begin to racially socialize their children during childhood in order to prepare them for growing up in predominately White society. Therefore, it is plausible that for some African-American youth, a clear commitment to an "Affirming" (or Achieved) identity could be attained within early adolescence. For example, the most common pattern of racial identity salience expressed at each time of measurement for the youth in this study (including during early adolescence) was the "Affirming" cluster, marked by high levels of personal relevance and commitment to this identity that are consistent with an "Achieved" identity status. Correspondingly, the least common pattern of racial identity salience documented across each wave of this study was represented by the "Disengaged" clusters, which conceptually overlap with the "Diffused" identity status with regards to a general disinterest in exploring or relating to race-related identities (Sankey \& Young, 1996).

\section{Continuity/Discontinuity in Patterns of Racial Identity Salience}

By looking at the identity cluster solutions identified in this study across time, evidence of incrementally more differentiated identities emerged. Specifically, there was a documented increase in the number of clusters identified as youth progressed from Wave 1 to Waves 2 and 3 (i.e., from four clusters to five clusters). This emergent fifth cluster suggests a developmental transition consistent with existing research iterature pointing to incremental increases in the complexity and differentiation in levels of racial 
identification (Cross, 1971; Cross \& Vandiver, 2001; Phinney, 1993). While existing studies exploring the stability of African-American racial identity, awareness, and salience over time have shown that these constructs have qualities of being both continuous and discontinous (Shelton \& Sellers, 2000; Stevenson, 1995), Parham (1989) asserted that specific levels of racial identity would fluctuate at different points during the lifespan in accordance with key developmental tasks. In support, the present findings provide empirical evidence for general discontinuity in levels of racial identity salience associated with progression through adolescence and into emerging adulthood.

Specifically, the general shift towards a more "Affirming" pattern of racial identity between the first two measurement occasions, followed by a period of identity maintenance (or leveling) between the second two measurement occasions may suggest underlying differences in the content and significance of racial socialization processes as youth grow older. For example, using an African-American adolescent sample, Stevenson (1995) suggested that adolescents' perceptions of parental racial socialization were in fact associated with the lowest and highest levels of racial identity among males, but not with the intermediate levels. Thus, messages regarding the importance of positive racial identities at an early developmental stage may be qualified by individuals' own race-related experiences at a later stage.

In addition, when considering shifts between the two most conceptually dissimilar clusters documented during early adolescence (i.e., from Wave 1 to 3 ), the largest proportion of youth in the Wave 1 "Disengaged" cluster moved to the "Affirming" cluster by the third occasion of measurement. In contrast, the lowest proportion of youth in any cluster in the Wave 1 "Affirming" cluster shifted to the "Disengaged" cluster by 
the third measurement occasion. This pattern was also documented, although it was not statistically significant, in descriptions of cluster shifts between the two most distal measurement occasions (i.e., Wave 3 to Wave 4). For the youth in this study, an affirming type of racial identity was (a) the most common type of racial identity within each developmental period, as well as (b) the most common single cluster to which individuals shifted as they progressed through this critical developmental transition.

These findings are consistent with Spencer's (1984) study that illustrated that due to increased social cognitions and experiences, a committed Black identity develops more completely as African-Americans grow older. Also, this finding of incrementally more engagement with one's racial identity documented in this study corresponded to Parham's and Williams' (1993) study of retrospective interviews of African-American adults, wherein participants were more likely to recall positive transformations in their identity during their lifetime than negative transformations. Furthermore, the shifts to and from the intermediate clusters that occurred between measurement occasions potentially can be seen as reflecting transitional identity processes related to the nonlinearity of Black identity development (Stevenson, 1995). Perhaps, the process-oriented development of racial identity salience results in a range of identity resolutions for African-American individuals, including recycling through different levels throughout the lifespan (Parham \& Williams, 1993). This possibility is similar to Erikson's (1968; 1980) notion that individuals may revisit earlier stages of aspects of their identity at different points in their lives.

The range of racial identities and the dynamic shifts occurring between them across developmental periods highlighted in this study point to the importance of viewing 
racial identity salience as a developmental construct (Holmbeck, Greenley, \& Franks, 2003). Doing so casts racial identity salience as a dynamic dimension of individuals' more fundamental self-concept. Moreover, as an underpinning concept of the identity formation literature, youth conceptualize themselves as being incrementally more independent and autonomous as they progress through adolescence. Therefore, older adolescents have a greater capacity to make a broader range of decisions regarding the manner in which they individualize and emphaize different aspects of their personal identities that do not threaten their overall self-concept. In support, Phinney (1993) suggested that while younger children tend to view aspects of who they are as being discrete and non-overlapping, the ability to consider the complexity and interconnectedness of different identities develops with age. Therefore, the differentiated patterns of racial identity salience documented in the present study can be associated with incrementally higher levels of complexity in the overall self-concepts of these youth. Accordingly, as research has shown that adolescence is a period of the lifespan that requires individuals to meet developmental challenges and continually renegotiate who they are, the longitudinal examination of shifts in identity clusters undertaken in this study contribute significantly to current understanding regarding racial identity formation in this stage. (Caspi \& Moffitt, 1991; French, Seidman, Allen, \& Aber, 2000; Graber, Lewinsohn, Seeley, \& Brooks-Gunn, 1997). Associations between Racial Identity Salience and Adjustment Outcomes

With respect to links between the distinct clusters of racial identity salience documented in this study and key adjustment outcomes, the present findings are both consistent with and add to existing literatures. Specifically, the finding that more 
"Affirming" levels of racial identity salience were associated with more adaptive levels of adjustment than were "Disengaged" identities was consistent with previous research suggesting that positive racial attitudes and identification are associated with incrementally more positive psychosocial outcomes (Johnson, Shireman, \& Watson, 1987; McCreary, Slavin, \& Berry, 1996; Neville \& Lilly, 2000). In addition, the clusters of youth representing intermediate levels of racial identity salience consistently showed moderate levels of psychosocial adjustment across each wave of measurement. These results provide tentative empirical support for the putative protective role of racial identity salience. Perhaps, by feeling incrementally more connected with a broader social group on the basis of race, these youth have both (a) a more positively reinforced global self-concept that may enhance adaptive adjustment in key domains and (b) greater opportunities to engage with others who share an affirming view of themselves. This potential explanation may be further supported by data regarding the "Disengaged" clusters consistently reporting among the lowest levels of family pride and among the highest levels of racial mistrust at each of the first three occasions of measurement. Also consistent with existing research, the lack of significant between-cluster findings in domains of early adolescent substance use may reflect general characterizations of African-American substance use being comparatively low during this particular developmental period (SAMHSA, 2004).

However, the current study did not investigate racial identity using traditional measures such as the Black Racial Identity Attitude Scale (Parham \& Helms, 1981) or the Multidimensional Inventory of Black Identity (Sellers, Rowley, Chavous, Shelton, \& Smith, 1997), but rather examined patterns of racial identity salience - an indicator of the 
extent to which an individual's race is a relevant feature of how they identity at specific points in time (Sellers, et al., 2003). Thus, the current findings regarding within-time adjustment outcomes adds to existing literature by moving beyond attempts to map direct relationships between broad racial identity stages and adjustment indices, toward understanding how specific elements of individuals' racial identity (i.e., levels of salience) are probabilistically linked to outcomes in specific domains. Moreover, investigating the salience of individuals' racial identity at distinct developmental periods, may allow for the identification and exploration of how (a) different levels of identity salience may moderate adjustment outcomes, and (b) racial identity may mediate relations between key psychosocial factors (e.g., peer networks, family relationships) and specific adjustment outcomes in future studies (Cicchetti \& Rogosch, 1996; Holmbeck, Greenley, \& Franks, 2003).

In addition, findings from the exploratory analyses conducted to investigate relations between (a) early racial identity salience clusters and later adjustment outcomes and (b) early levels of adjustment and later racial identity salience variables tentatively speak to the inherent complexity of operationalizing racial identity salience in a youth sample. Although Wave 4 levels of CESD depression and proportions of past-year episodes of sexual intercourse involving the use of a condom were predicted by Wave 3 patterns of racial identity salience, no clear pattern emerged regarding the prediction of later adjustment based upon earlier levels of identity variables. A potential explanation for the lack of significant findings may be that relationships between early levels of racial identity salience and later adjustment are mediated by a range of factors including familial and peer-group influences, developmental transitions (e.g., moving from middle 
school to high school), and levels of psychosocial competence. Therefore, meaningful associations between racial identities and adjustment variables occurring within times of measurement may be more likely to be identified than between measurement occasions. Yet, the lack of significant findings in from these explorations does not debase the point of conducting them. As Sellers et al. (1997) suggested, in spite of the substantial amount of research that has investigated aspects of Black racial identity, only a cursory amount is understood regarding the actual significance of this construct for the lives of AfricanAmerican individuals. Furthermore, attempts to draw conclusions with regard to the role that early racial identities play later in life are critical for comprehensively understanding this construct (Stevenson, 1995).

\section{Implications of Findings}

\section{Theoretical Implications}

Overall, the findings of this study both support and expand upon current racial identity theory and knowledge. Theoretically, the relational and multidimensional components of racial identity salience documented in this longitudinal study have critical implications for describing the process-oriented and person-in-context significance of this construct for individuals' lives (Bergman, 2001; Magnusson \& Stattin, 1998). With respect to their racial identity, considering the range of developmental levels that the African-American youth in this study manifested across distinct adolescent periods allows researchers to make incrementally more personalized and accurate inferences regarding likelihood of specific adjustment outcomes (Holmbeck, Greenley, \& Franks, 2003). Specifically, viewing racial identity as a developmental construct allows scholars to identify and explore how (a) different levels of racial identity may moderate 
adjustment outcomes, and racial identity may mediate relations between key psychosocial factors (e.g., family relationships, personal experiences) and specific adjustment outcomes (Resnicow et al., 1999). Integrating these dimensions within racial identity theory may restructure or expand existing notions of African-American racial identity development to include how changes in the person-centered relevance of this construct across time and context relate to overall adaptive development.

Furthermore, the use of the current adolescent sample expands knowledge of African-American racial identity by documenting its existence and function prior to adulthood - a consideration rarely investigated in traditional literatures (Resnicow et al., 1999). Clearly, racial identity salience is a meaningful construct in the lives of these youth, even among early adolescents, and is potentially a precursor for later identities and adjustment. Description of early racial identity salience types that are probabilistically associated with key adjustment outcomes enables researchers to characterize markers of meaningful developmental trajectories for distinct subgroups of youth. As a result, diverse individual or contextual features may be uncovered that support (a) many different racial identity-related developmental processes leading to similar adjustment outcomes (i.e., equifinality), and (b) common racial identity-related developmental processes leading to distinct adjustment outcomes (i.e., multifinality; Cicchetti \& Rogosch, 1996). For example, endorsing levels of racial identity salience consistent with either the "Uninformed Connectedness" or the "Low Preparation for Bias" identity patterns during early adolescence may both lead to similar notions of identity later in life.

In contrast, it may be that for some African-American youth, an early "Disengaged" pattern of racial identity salience is systematically related to maladjustment 
in young adulthood, while for others this is not the case. Hence, mapping the inherent spectrum of racial identities that relate to a broad range of developmental experiences may highlight the dynamic and interrelated features of the human ecology (e.g., biological, social, familial influences) and improve current detection and understanding of differences in psychosocial adjustment (Baltes, Lindenberger, \& Staudinger, 1998; Bergman, 2000; Elder, 1998). Adding these dimensions to existing racial identity theory enhances our ability to understand how dynamic developmental processes generate heterogeneity in the expression of racial identities and related patterns of adjustment outcomes among specific groups of African-American youth.

\section{Practice-Related Implications}

In addition to theoretical considerations, there are practice-related implications derived from the current study. Potentially, the most prominent practice-related domain that the proposed synthesis might inform is that of mental health counseling. Specifically, when working with African-American youth populations, considering links between adolescent levels of racial identity salience and ranges of developmental histories, adverse experiences, and access to social resources may help researchers and practitioners to identify and enhance desirable and process-oriented outcomes. (Cicchetti \& Rogosch 2002; Hargrow, 2001; Masten \& Coatsworth, 1998; Vinson \& Neimeyer, 2000). Furthermore, for counselors working with clients expressing diverse levels of racial identity salience, understanding not only how clients identify themselves racially, but also how a range of psychosocial influences have led to and maintain that sense of identity is critical for effective counseling (Brown, Parham, \& Yonker, 1996; Vinson \& Neimeyer, 2000). Within this context, accurate delineation of where clients begin 
psychologically and what they intend to address during the course of counseling needs to be informed coequally by developmental and adjustment outcome factors identified together by counselors and clients. Doing so may allow counselors to more fully engage clients on a client-centered level where the significance of racial identity can be characterized as it pertains to clients' own mental health issues.

Another practice-related domain which the present findings can inform involves prevention and treatment programs seeking to improve physical and mental health outcomes for individuals of diverse racial, ethnic, and cultural identities. Over the past decade, a number of physical and mental health disparities have been documented with respect to racial and ethnic minority groups. Given these health disparities, strategies directed at effectively treating members of these communities are vital (United States Department of Health and Human Services, 2001). For example, despite findings that rates of diabetes, syphilis, gonorrhea, and poor mental health are disproportionately higher among specific subgroups of African-Americans compared to similar groups of Whites, an emerging literature has illustrated significantly lower levels of availability, access, and use of health services in African-American communities (CDC, 2004a, b).

A potential shortcoming of existing health services may be that they fail to tap into identity-relevant ideologies of health for many minority individuals. For example, the help-seeking and treatment engagement behaviors required to access care may be dystonic with individuals' race-related social identities. To this end, efforts to identify and investigate racially/ethnically-specific factors that engage clients in accordance with the attitudes and values they possess and increase minority individuals' amenability to treatment may be effective treatment enhancement strategies. For example, substance 
use treatment programs incorporating cultural sensitivity and motivational components have demonstrated the ability to reduce risk for negative adjustment outcomes among minority clients (Longshore \& Grills, 2000; Resnicow, Soler, Braithwaite, Ahluwalia, \& Butler, 2000; Tubman, Wagner, Gil, \& Pate, 2002).

As this domain relates to the current study, recognition of the developmental processes associated with the documented racial identity salience profiles may help counselors devise plausible intervention strategies for working with African-American youth incrementally more vulnerable to negative adjustment outcomes (Kwan, 2001). For example, as "Affirming" patterns of racial identity salience were the most common throughout the study, the probability of working with African-American youth clients possessing high levels of racial identity salience should not be understated. Effective prevention/intervention programs designed for youth for whom an African-American identity is highly salient, may need to include the broader involvement and collaboration of family or peer-group members to which these youth manifest an internalized sense of connectedness (Cross \& Vandiver, 2001; Edberg, Wong, Woo, \& Doong, 2003; Neighbors, Braithwaite, \& Thompson, 1995). In addition, programs including AfricanAmerican counselors and staff may also have better success reducing identified problems, in as much as these personnel may be able to identify with individuals' developmental experiences, and in turn, redirect youth towards more positive health outcomes (Markstrom-Adams \& Spencer, 1994). However, for vulnerable youth who endorse intermediate levels of racial identity salience such as those profiles documented in the current study, universal prevention/intervention programs designed to focus intensively on broad race-related issues may not readily engage all members of this subgroup. 
Instead, programs selectively targeting members of this subgroup may be more effective if they are tailored to enhance specific aspects of individuals' identities, such as offering strategies for dealing with racism and prejudice or providing information regarding Black history and culture (Markstrom-Adams \& Spencer, 1994; Rotherham-Borus \& Wyche, 1994).

In addition, less prevalent racial identity profiles that emerged from this study involving associations between disengagement and collective notions of Black identity and incrementally more negative adjustment outcomes were consistent with existing research. Specifically, "Disengaged" and "Individualistic Affirming" levels of racial identity salience were shown to be associated with significantly greater likelihood of lifetime and past-year diagnoses of affective disorders. Furthermore, and in particular for youth endorsing "Disengaged" variables of identity patterns, high levels of CESDassessed depression and self-derogation were documented. In addition, the disproportionately high levels of lifetime alcohol abuse disorder found among the "Disengaged" cluster in young adulthood presents a critical target for intervention programs (CDC, 2002b), particular as substance use behaviors are associated with other significant health risk behaviors, including sexual risk behaviors.

Approaches for working effectively with this group of youth may need to incorporate strategies specifically directed at increasing involvement with AfricanAmerican community and cultural events and activities. Racial/ethnic pride and family/community empowerment themes have been shown to be effective methods of reducing symptoms related to key psychiatric disorders (CDC, 1999; Neighbors, Braithwaite, \& Thompson, 1995; Thomas \& Speight, 1999). However, the key 
conclusion of this study highlights the importance of acknowledging within-group heterogeneity in investigations of patterns of behaviors that may be related to levels of racial identity salience. For prevention/treatment strategies to be effective at retaining African-American youth and reducing negative health disparities associated with this vulnerable population, attention to this inherent heterogeneity is necessary.

\section{Study Limitations and Directions for Future Research}

Collectively, the results of the current study challenge notions of homogeneity in expressions of African-American racial identity. Based on these data, there is clear evidence that African-American youth display diverse patterns of racial identity salience across adolescence and into young adulthood. The four sets of systematic analyses conducted in this study offer a developmental glimpse at the role of racial identity salience in the lives of these minority youth. However, while incorporating levels of racial identity salience into broader domains of youth adjustment clarifies our understanding of the vulnerabilities unique to specific subgroups of African-American youth, the adjustment indices employed in this study were not exhaustive. For example, assessments of academic functioning, physical health, and community involvement were not investigated in this study as indices of psychosocial adjustment, and yet may be important for understanding developmental processes among African-American youth related to key developmental outcomes and tasks. Furthermore, although it was not the aim of this study to follow individual participants longitudinally, such investigations may offer additional and meaningful insights into the person-centered and process-oriented development of racial identity salience over time. 
As an emerging literature has called for an integration of racial identity research with the developmental lifespan perspective (Stevenson, 1995), future research charting comprehensively multiple developmental influences upon the racial identities of AfricanAmerican individuals and their association with key health and mental health outcomes over different periods of the lifespan is needed. Perhaps the overall significance of racial identity may not be readily evident until later in individuals' lives. As Burlingame (1999) suggested, additional research is needed to understand why despite developing in a challenging and oppressive social environment, African-American elders report a higher quality of life than their counterparts from other racial groups. It may be that the putative protective function of salient or internalized racial identities enhances individuals' experiences later in life.

In addition, beyond exploring descriptive profiles of cluster membership, this study did not conduct systematic analyses investigating gender effects. While the aim of this study was to document within-group heterogeneity in an understudied and potentially vulnerable minority population, it may be that patterns of racial identity salience are significantly different among males and females, underscoring the need for further calibration of intervention and prevention strategies to increase sensitivity to significant gender differences in developmental process and outcome. Also, concerning the sample employed in the current study, only the interviews of African-American youth who were born in the United States and lived in Miami-Dade County communities were investigated. The data investigated in the initial waves of this study were collected over a decade ago, deeming the present illustration of the significance of racial identity as bounded by potentially important cohort influences. Results from a more recent or 
currently ongoing study examining this construct may reveal a more updated picture of adolescent racial identity salience, and thereby, have a greater relevance to the lives of contemporary African-American youth.

In addition, future research might explore the replicability of these findings within other community-based youth samples as the findings of the current study may not generalize to samples of different racial or ethnic minority groups from other regions of the United States or to individuals from different countries. Perhaps there are specific contextual factors (e.g., racial composition of region, levels of access to sociopolitical resources) that differentially related to the construction of individuals' racial identity among youth from different locations that should be considered when working with those populations. Similarly, alternative racial identity resolutions may exist for AfricanAmerican youth than the types presented in this study. For example, researchers should not assume that similar identity patterns to those presented in this study would emerge within bi- or multi-racial populations (Spencer, Icard, Harachi, \& Oxford, 2000). Therefore future research exploring (a) the inherent range of possible identities and (b) the putative direction of relations between these identities and key adjustment outcomes is needed. This type of process-oriented research will expand current understanding of how racial identity salience and other race-related constructs are associated with general and racial/ethnic-specific aspects of minority youth adjustment. 
Aldenderfer, M. S. and Blashfield, R. K. (1984). Cluster Analysis, Sage Publications, London.

Arroyo, C. F., \& Zigler, E. (1995). Racial identity, academic achievement, and the psychological well-being of economically disadvantaged adolescents. Journal of Personality and Social Psychology, 69, 903-914.

Atkinson, D. R., Morten, G., \& Sue, D. W. (1998). A minority identity development model. In D. R. Atkinson, G. Morten, \& D. W. Sue (Eds.), Counseling American minorities (pp. 35-52). Dubuque, IA: W. C. Brown.

Baltes, P. B., \& Goulet, L. R. (1970). Status and issues of a life-span developmental psychology. In L. R. Goulet \& P. B. Baltes (Eds.), Life-span developmental psychology: Research and theory (pp. 4-21). New York: Academic Press.

Baltes, P. B., Lindenberger, U., \& Staudinger, U. M. (1998). Life-span theory in developmental psychology. In R. M. Lerner (Ed.), Theoretical models of human development. Volume 1 of the Handbook of child psychology, pp. 107-188. (5th ed.), Editor-in-Chief: William Damon. New York: Wiley.

Barbarin, O. (1993). Emotional and Social Development of African American Children. Journal of Black Psychology, 19, 381-391.

Bergman, L.R. (2000). The application of a person-oriented approach: Types and clusters. In L.R. Bergman, R.B., Cairns, \& L. Nilsson (Eds.), Developmental science and the holistic approach. Mahwah, NJ: Lawrence Erlbaum Associates.

Bergman, L. R. (2001). A person approach in research on adolescence: Some methodological challenges. In A. von Eye \& C. Schuster, Special Issue of the Journal of Adolescent Research, 16, 28-53.

Biafora, F. A., Warheit, G. J., Zimmerman, R. S., Gil, A. G., Apospori, E., \& Taylor, D.(1993). Racial mistrust and deviant behavior among ethnically diverse black adolescent boys, Journal of Applied Social Psychology, 23, 891-909.

Blumer, H. (1969). Symbolic interactionism. Perspective and method. Englewood Cliffs, NJ: Prentice-Hall.

Bowman, P. J., \& Howard, C. (1985). Race-related socialization, motivation, and academic achievement: A study of Black youths in three-generation families. Journal of the American Academy of Child Psychiatry, 24, 131-141. 
Boykin, A. W., \& Toms, F. D. (1985). Black child socialization: A cultural framework. In H. P. McAdoo \& J. L. McAdoo (Eds.), Black children: Social, educational, and parental environments (pp. 33-51). Newbury Park, CA: Sage.

Bronfenbrenner, U., \& Crouter, A. C. (1983). The evolution of environmental models in developmental research. In: W. Kessen (Hrsg.), Handbook of child psychology, vol. 1, History, theories, and methods, (4 ${ }^{\text {th }}$ edition). (357-414). New York: Wiley.

Bronfenbrenner, U., \& Morris, P. A. (1998). The ecology of developmental processes. In R. M. Lerner (Ed.), Theoretical models of human development. Volume 1 of the Handbook of child psychology, pp. 107-188. (5th ed.), Editor-in-Chief: William Damon. New York: Wiley.

Brookins, C. C., Anyabwile, T. M., \& Nacoste, R. (1996). Exploring the links between racial identity attitudes and psychological feelings of closeness in African American college students. Journal of Applied Social Psychology, 26, 243-264.

Brown, P. B., Parham, T. A., \& Yonker, R. (1996). Influence of a cross-cultural training course on racial identity attitudes of white women and men. Journal of Counseling \& Development, 74, 510-516.

Burlingame, V. S. (1999). Ethnogerocounseling: Counseling Ethnic Elders and Their Families. New York: Springer Publishing.

Cairns, R. B. (1998). The making of developmental psychology. In R. M. Lerner (Ed.), Theoretical models of human development. Volume 1 of the Handbook of child psychology, pp. 107-188. (5th ed.), Editor-in-Chief: William Damon. New York: Wiley.

Cairns, R. B. (2000). Developmental science: Three audacious implications. In L. R. Bergman, R. B. Cairns, L. G. Nilsson, \& L. Nystedt (Eds.), Developmental science and the holistic approach (pp. 49-62). Mahwah, NJ: Lawrence Erlbaum.

Carter, R. T. (1991). Racial identity attitudes and psychological functioning. Journal of Multicultural Counseling and Development, 19, 105-114.

Carter, R. T. (1996). Exploring the complexity of racial identity attitude measures. In G. R. Sodowsky \& J. Impara (Eds.), Multicultural assessment in counseling and clinical psychology (pp. 192-223). Lincoln, NE: Buros Institute of Mental Measurement.

Carter, R. T., DeSole, L., Sicalides, E. I., Glass, K., \& Tyler, F. R. (1997). Black racial identity and psychosocial competence: A preliminary study. Journal of Black Psychology, 23, 58-78. 
Carter, R.,\&Helms, J. (1990). White racial identity attitudes and cultural values. In J. E. Helms (Ed.), Black and White racial identity: Theory, research, and practice (pp. 105-118). Westport, CT: Greenwood.

Casas, J. M. (1984). Policy, training, and research in counseling psychology: The racail/ethnic minority perspective. In S. D. Brown and R. W. Lent (Eds.), Handbook of Counseling Psychology (pp. 758-931). New York: John Wiley \& Sons.

Caspi, A., \& Moffitt, T. (1991). The continuity of maladaptive behavior: From description to understanding in the study of antisocial behavior. In Manual of Developmental Psychopathology. Ed. D. Cicchetti and D. Cohen. New York: Wiley.

Celious, A. \& Oysterman, D. (2001). Race from the inside: An emerging heterogeneous race model. Journal of Social Issues, 57, 149-165.

Centers for Disease Control and Prevention. (2004a). Eliminate Disparities in Mental Health. Office of Minority Health. Online [http://www.cdc.gov/omh/AMH/factsheets/mental.htm] accessed September 8, 2004.

Centers for Disease Control and Prevention (2004b). National diabetes fact sheet: general information and national estimates on diabetes in the United States, 2003. Rev ed. Atlanta, GA: U.S. Department of Health and Human Services, Centers for Disease Control and Prevention.

Chavous, T. (2000). The relationships among racial identity, perceived ethnic fit, and organizational involvment for African-American students at a predominantly white university. Journal of Black Psychology, 26, 79-100.

Cicchetti, D., \& Rogosch, F. A. (1996). Editorial: Equifinality and multifinality in developmental psychopathology. Development and Psychopathology, 8, 597-600.

Cross, W. E., Jr. (1971). The Negro-to-Black conversion experience. Black World, 20, 13-27.

Cross, W. E., (1978). Models of psychological nigrescence: A literature review. Journal of Black Psychology, 5, 13-31.

Cross, W. E., Jr. (1991). Shades of Black: Diversity in African American Identity. Philadelphia: Temple University Press. 
Cross, W. E. (1994). Nigrescence theory: Historical and explanatory notes. Journal of Vocational Behavior, 44, 119-123.

Cross, W. E., Jr. (1995). The psychology of nigrescence: Revising the cross model. In J. G. Ponterotto, J. M. Casas, L. A. Suzuki, \& C. M. Alexander (Eds.), Handbook of multicultural counseling (pp. 93-122). Thousand Oaks, CA: Sage.

Cross, W. E., Parham, T. A., \& Helms, J. E. (1991). The stages of Black identity development: Nigresscence models. In R. L. Jones (Ed.), Black psychology $\left(3^{\text {rd }}\right.$ ed., pp 319-338). Berkeley, CA: Cobb \& Henry.

Cross, W. E., Jr., \& Vandiver, B. J. (2001).Nigrescence theory and measurement: Introducing the cross racial identity scale (CRIS). In J. G. Ponterotto, J. M. Casas, L. A. Suzuki, \& C. M. Alexander (Eds.), Handbook of multicultural counseling (2nd ed., pp. 371-393). Thousand Oaks, CA: Sage.

Csikszentmihalyi, M. (1996). Creativity: Flow and the psychology of discovery and invention. New York: HarperCollins.

Csikszentmihalyi, M., \& Rathunde, K. (1998). The development of the person: An experiential perspective on the ontogenesis of psychology complexity. In R. M. Lerner (Ed.), Theoretical models of human development. Volume 1 of the Handbook of child psychology, pp. 107-188. (5th ed.), Editor-in-Chief: William Damon. New York: Wiley.

Edberg, M. C., Wong, F. Y., Woo, V., \& Doong, T. (2003). Elimination of health disparities in racial/ethnic minority communities: Developing data indicators to assess the progress of community-based efforts. Evaluation and Program Planning: 26, 11-19.

Elder, G. H. (1998). The life course and human development. In R. M. Lerner (Ed.), Theoretical models of human development. Volume 1 of the Handbook of child psychology, pp. 107-188. (5th ed.), Editor-in-Chief: William Damon. New York: Wiley.

Erikson, E. H. (1959). Identity and the life cycle. Psychoogical Issues, 1, 1-171.

Erikson, E. H. (1968). Identity: Youth and crisis. New York: Norton.

Felix-Ortiz, M., Newcomb, M. D., \& Myers, H. (1994). A multidimensional measure of cultural identity for Latino and Latina adolescents. Hispanic Journal of Behavioral Sciences, 16, 99-115. 
Fisher, C., Jackson, J., \& Villarruel, F. (1998). The study of African American and Latin American children and youth. In W. Damon (Ed.-in-Chief) \& R. M. Lerner (Vol. Ed.), Handbook of Child Psychology: Vol. 1. Theoretical models of human development (5th ed.,pp. 1145-1208). New York: John Wiley \& Sons, Inc.

Fordham, S. \& Ogbu, J. (1986). Black student's success: Coping with the burden of "acting White." Urban Review, 18, 176-206.

French, S. E., Seidman, E. Allen, L. \& Aber, J. L. (2000). Racial/ethnic identity, congruence with the social context, and the transition to high school. Journal of Adolescent Research, 15, 587-602.

Gallagher, J. J. (1990). Editorial: The public and professional perception of the emotional status of gifted children. Journal for the Education of the Gifted, 13, 202-211.

Gandy, O. H. (2001). Racial identity, media use, and the social construction of risk among African Americans. Journal of Black Studies, 31, 600-618.

Gottlieb, G. Wahlsten, D., \& Lickliter, R. (1998). The significance of biology for human development: A developmental psychobiological systems view. In R. M. Lerner (Ed.), Theoretical models of human development. Volume 1 of the Handbook of child psychology, pp. 107-188. (5th ed.), Editor-in-Chief: William Damon. New York: Wiley.

Graber, J.A., Lewinsohn, P.M., Seeley, J.R., \& Brooks-Gunn, J. (1997). Is Psychopathology associated with the timing of pubertal development? Journal of the American Academy of Adolescent and Child Psychiatry, 36, 1768-1776.

Griffin, E. (1997). A first look at communication theory. New York: The McGraw-Hill Companies.

Grotevant, H. D. (1986). Assessment of identity development: Current issues and future directions. Journal of Adolescent Research, 1, 175-182.

Hall, R. E. (2001). Identity development across the lifespan: A biracial model. The Social Science Journal, 38, 119-123.

Hargrow, A. (2001). Racial identity development: The case of Mr. X, an African American. Journal of Mental Health Counseling, 23, 222-237.

Helms, J. E. (1984). Toward a theoretical explanation of he effects of race on counseling: A Black and White model. The Counseling Psychologist, 12, 153-165. 
Helms, J.E., (1985). Cultural identity in the treatment process. In P. Pedersen (Ed.), Handbook of Cross-cultural Counseling and Therapy, (pp. 239-247). Westport, CT: Greenwood Press

Helms, J. E. (1986). Expanding racial identity theory to cover counseling process. Journal of Counseling Psychology, 33, 62-64.

Helms, J. E. (1990). Black and white racial identity: Theory, research and practice. New York: Greenwood Press.

Helms, J. E. (1995). An update of Helms' White and people of color racial identity models. In J. G. Ponterotto, J. M. Casas, L. A. Suzuki, and C. M. Alexander (Eds.), Handbook of multicultural counseling (pp. 181-198). Thousand Oaks, CA: Sage.

Helms, J. E. \& Carter, R. T. (1990). Development of the White Racial Identity Attitudes Scale. In J. E. Helms (Ed.), Black and White racial identity: Theory, research, and practice (pp. 67-80). Westport, CT: Greenwood Press.

Hewitt, J. P. (1989). Dilemmas of the American Self. Philadelphia: Temple University Press.

Holmbeck, G. N., Greenley, R. N., \& Franks, E. (2003). Developmental issues and considerations in child and adolescents therapy: Research and practice. In A. E. Kazdin \& J. R. Weisz (Eds.). Evidence-based psychotherapics for children and adolescents (pp. 21-41). New York: Guilford.

Hughes, D. (2003). Correlates of African American and Latino Parents' Messages to Children About Ethnicity and Race: A Comparative Study of Racial Socialization. American Journal of Community Psychology, 31, 15-33.

Hughes, D. \& Chen, L. (1999). Parents' race-related messages to children: A developmental perspective. In C. Tamis-Lemonda \& L. Balter (eds.), Child Psychology: A handbook of contemporary issues. New York University Press.

Ianni, F. A. J. (1989). The search for structure: A report on American youth today. New York: The Free Press.

Jackson, C. L., \& Neville, H. A. (1998). Influence of racial identity attitudes on AfricanAmerican college students' vocational identity and hope. Journal of Vocational Behavior, 53, 97-113.

Janca, A., Robins, L., Cottler, L., \& Early, T. (1992). Clinical observations of CIDI assessments: An analysis of the CIDI field trial-Wave II at the St. Louis site. British Journal of Psychology, 160, 815-818. 
Johnson, D. J. (2001). Parental characteristics, racial stress, and racial socialization processes as predictors of racial coping in middle childhood. In Neal-Barnett (Ed.), Forging links: Clinical/developmental perspective of African American children (pp. 59-74). Westport, CT: Greenwood Press.

Johnson, P. R., Shireman, J. F., \& Watson, K. W. (1987). Transracial adoption and the development of Black identity at age eight. Child Welfare, 66, 45-55.

Jones, M. M. (1997). Prejudice and racism (2nd ed.). New York: McGraw-Hill.

Kalichman, S. C. (1998). Preventing AIDS: A sourcebook for behavioral interventions. Mahwah, NJ: Erlbaum.

Kando, T. M. (1977). Social interaction. Saint Louis: The C. V. Mosby Company.

Kent, P. \& Bhui, K. (2003). Editorial: Cultural identity and mental health. International Journal of Social Psychiatry, 49, 243-246.

Kerwin, K., \& Ponterotto, J. G. (1995). Biracial identity development. In J. G. Ponterotto, J. M. Casas, L. A. Suzuki, \& C. M. Alexander (Eds.), Handbook of multicultural counseling (pp. 199-217).Thousands Oaks, CA: Sage.

Kohatsu, E. L., \& Richardson, T. Q. (1996). Racial and ethnic identity assessment. In L. A. Suzuki, P. J. Meller, \& J. G. Ponterotto (Eds.), Handbook of multicultural assessment: clinical, psychological, and educational applications, (pp.611-650). San Francisco, CA: Josey-Bass Publishers.

Kroger, J. (2000). Identity development: Adolescence through adulthood. Thousand Oaks, CA: Sage Publications.

Kuhn, T. (1962) The structure of scientific revolutions. Chicago: University of Chicago Press.

Kwan, K. K. (2001). Models of Racial Identity Development: Delineation of Practice Implications. Journal of Mental Health Counseling, 23, 269-277.

Lambert, H. R. R. (2004). The underutilization of mental health services in an ethnically and racially diverse predominately low-income population: An investigation of worldview. Dissertation Abstracts International Section A: Humanities Social Sciences, 64(8-A), pp.2791.

Lazarus, R. S. \& Folkman, S. (1984). Stress, appraisal, and coping. New York: Springer. 
Lerner, R. M. (1998). Theories of human development: Contemporary perspectives. In R. M. Lerner (Ed.), Theoretical models of human development. Volume 1 of the Handbook of child psychology, pp. 107-188. (5th ed.), Editor-in-Chief: William Damon. New York: Wiley.

Lerner, R. M. \& Galambos, N. L. (1998). Adolescent development: Challenges and opportunities for research, programs, and policies. Annual Review of Psychology, $49,413-446$.

Lerner, R. M., Taylor, C. S., \& von Eye, A. (Eds.). (2002). Pathways to positive development among diverse youth. New directions for youth development: Theory, practice, and research. San Francisco: Jossey-Bass.

Lewis, C. C. (2000). Personal and cultural identity. Human Development, 43, 24-26.

Longshore, D., \& Grills, C. (2000). Motivating illegal drug use recovery: Evidence for a culturally congruent intervention. Journal of Black Psychology, 26, 288-301.

Luthar, S. S., \& Cicchetti, D. (2000). The construct of resilience: Implications for intervention and social policy. Development and Psychopathology, 12, 857-885.

Magnusson, D., \& Bergman, L. R. (1990). A pattern approach to the study of pathways from childhood to adulthood. In L. N. Robins \& M. Rutter (Eds.), Straight and devious pathways from childhood to adulthood (pp. 101-115). Cambridge, UK: Cambridge University Press.

Magnusson, D., \& Stattin, H. (1998). Person-context interaction theories. In R. M. Lerner (Ed.), Theoretical models of human development. Volume 1 of the Handbook of child psychology, pp. 107-188. (5th ed.), Editor-in-Chief: William Damon. New York: Wiley.

Marcia, J. E. (1966). Development and validation of ego ientity status. Journal of Personality and Social Psychology, 3, 551-558.

Marcia, J. E. (1980). Identity in adolescence. In J. Adelson (Ed.), Handbook of adolescent psychology (pp. 159-187). New York: Wiley.

Markstrom-Adams, C. \& Spencer, M. B. (1994). A model for identity intervention with minority adolescents. In S. Archer (Ed.), Interventions of adolescent identity development (pp. 62-83). Thousand Oaks, CA: Sage.

McCreary, M. L., Slavin, L.A., \& Berry, E. J. (1996). Predicting problem behavior and self-esteem among African American adolescents. Journal of Adolescent Research, 11, 216-234. 
McLoyd, V. C., \& Steinberg, L. (1998). Studying minority adolescents. Mahwah, NJ: Lawrence Erlbaum Associates

McRoy, R. G., \& Zurcher, L. A. Jr. (1983). Transracial and Inracial Adoptees: The adolescent years. Springfield, IL: Charles C. Thomas.

Mead, G. H. (1934). Mind, self and society. Chicago: University of Chicago Press.

Miller, D. B. (1999). Racial socialization and racial identity: Can they promote resiliency for African American Adolescents? Adolescence, 34, 493-501.

Miller, P. H. (2002). Theories of developmental psychology, (4 ${ }^{\text {th }}$ edition). New York: Worth Publishers.

Milliones, J. (1980). Construction of a Black consciousness measure: Psychotherapeutic implications. Psychotherapy: Theory, Research and Practice, 17, 175-182.

Moreland, C. \& Leach, M. M. The relationship between Black racial identity and moral development. Journal of Black Psychology, 27, 255-271.

Neighbors, H., Braithwaite, R., \& Thompson, E. (1995). Health promotion and African Americans: From personal empowerment to community action. American Journal of Health Promotion, 9, 281-287.

Neville, H. A., \& Lilly, R. L. (2000). The relationship between racial identity cluster profiles and psychological distress among African American college students. Journal of Multicultural Counseling and Development, 28, 194-207.

Ogbu, J. U. (1991). Minority coping responses and school experience. Journal of Psychohistory, 18, 433-456.

Overton, W. F. (1998). Developmental psychology: Philosophy, concepts, and methodology. In R. M. Lerner (Ed.), Theoretical models of human development. Volume 1 of the Handbook of child psychology, (pp. 107-188). (5th ed.), Editorin-Chief: William Damon. New York: Wiley.

Parham, T. A. (1989). Cycles of psychological nigrescence. The Counseling Psychologist, 17, 187-226.

Parham, T. A., \& Helms, J. E. (1981). The influence of Black students' racial identity attitudes on preference for counselor's race. Journal of Counseling Psychology, $28,250-258$. 
Parham, T. A. \& Helms, J. E. (1985). Relation of racial identity attitudes to selfactualization and affective states of Black students. Journal of Counseling Psychology, 32, 307-322.

Parham, T. A., \& Williams, P. (1993). The relationship of demographic and background factors to racial identity attitudes. Journal of Black Psychology, 19, 724.

Peters, M. F. (1985). Racial socialization of young Black children. In H. P. McAdoo \& J. L. McAdoo (Eds.), Black children: Social, educational, and parental environments (pp. 159-173). Newbury Park, CA: Sage.

Phinney, J. S. (1989). Stages of ethnic identity development in minority group adolescents. Journal of Early Adolescence, 9, 34-49.

Phinney, J. S. (1990). Ethnic identity in adolescents and adults: Review of research. Psychological Bulletin, 108, 499-514.

Phinney, J. S. (1992). The multigroup ethnic identity measure: A new scale for use with diverse groups. Journal of Adolescent Research, 7, 156-176.

Phinney, J. S. (1993). Multiple group idetntiies: Differentiation, conflict, and integration. In J. Kroger (Ed.), Discussions on Ego Identity (pp. 47-74). Lawrence Erlbaum Associates, New Jersey.

Phinney, J. S. (1996). Understanding ethnic diversity. American Behavioral Scientist, 40, 143-152.

Phinney, J. S. \& Chavira, V. (1995). Parental ethnic socialization and adolescent coping with problems related to ethnicity. Journal of Research on Adolescence, 5, 31-53.

Pinkerton, S. D., Holtgrave, D. R., Leviton, L. C., Wagstaff, D. A., Cecil, H., \& Abramson, P. R. (1998). Toward a standard sexual behavior data set for HIV prevention evaluation. American Journal of Health Behavior, 22, 259-266.

Plummer, D. L. (1995). Patterns of racial identity development of African American adolescent males and females. Journal of Black Psychology, 21, 168-180.

Plummer, D. L. (1996). Black racial identity attitudes and stages of the life span: An exploratory investigation. Journal of Black Psychology, 22, 169-181.

Pope, R. L. (1998). The relationship between psychosocial development and racial identity of Black college students. Journal of College Student Development, 39 , 273-282. 
Pope, R. L. (2000). The relationship between psychosocial development and racial identity of college students of color. Journal of College Student Development, 41, 302-312.

Pope-Davis, D. B., Liu, W. M., Ledesma-Jones, S. \& Nevitt, J. (2000). African American acculturation and Black racial identity: A preliminary investigation. Journal of Multicultural Counseling and Development, 28, 98-113.

Quintana, S. M. (1998). Development of children's understanding of ethnicity and race. Applied \& Preventive Psychology: Current Scientific Perspectives, 7, 27-45.

Resnicow, K., Soler, R., Ahluwalia, J. S., Butler, J., \& Braithwaite, R. L. (2000). Cultural sensitivity in substance use prevention. Journal of Community Psychology, 28, 271-290.

Rotheram, M. J. \& Phinney, J. S. (1987). Introduction: Definitions and perspectives in the study of children's ethnic socialization. In M. J. Rotheram \& J. S. Phinney (Eds.). Children's ethnicsocialization. (pp.10-31). London: Sage

Rotheram-Borus, M. J. \& Wyche, K. F. (1994). Ethnic differences in identity development in the United States. In S. Archer (Ed.), Interventions of adolescent identity development (pp. 62-83). Thousand Oaks, CA: Sage.

Sanders Thompson, V. L. (1994). Socialization to race and its relationship to racial identification among African Americans. Journal of Black Psychology, 20, 175188.

Sankey, A. M. \& Young, R.. A. (1996). Ego-identity status and narrative structure in retrospective accounts of parental career influence. Journal of Adolescence, 19, 141-153.

Sellers, R. M. (1993). A call to arms for researchers studying racial identity. Journal of Black Psychology, 19, 327-332.

Sellers, R.M., Caldwell, C.H., Schmeelk-Cone, K.H., Zimmerman, M.A. (2003). Racial identity, racial discrimination, perceived stress, and psychological distress among African American young adults. Journal of Health and Social Behavior, 44, 302317.

Sellers, R. M., Chavous, T. M., \& Cooke, D. Y. (1998). Racial ideology and racial centrality as predictors of African American college students' academic performance. Journal of Black Psychology, 24, 1998. 
Sellers, R. M., Rowley, S. A. J., Chavous, T. M., Shelton, J. N., \& Smith, M. A. (1997). Multidimensional inventory of Black Identity: A preliminary investigation of reliability and construct validity. Journal of Personality and Social Psychology, $73,805-815$.

Sellers, R. M., Smith, M. A., Shelton, J. N., Rowley, S., \& Chavous, T. M. (1998). The multidimensional model of racial identity: A reconceptualization of African American racial identity. Personality and Social Psychology Review, 2, 18-39.

Shelton, J. N., \& Sellers, R. M. (2000). Situational stability and variability in African American racial identity. Journal of Black Psychology, 26, 27-50.

Smith,E. P., Walker, K., Fields, L., Brookins, C. C., \& Seay, R. (1999) Ethnic identity and its relationship to self-esteem, perceived efficacy and prosocial attitudes in early adolescence. Journal of Adolescence, 22, 867-880

Spencer, M. B. (1982). Personal and group identity of Black children: An alternative synthesis. Genetic Psychology Monographs, 106, 59-84.

Spencer, M. S., Icard, L. D., Harachi, T. W., Catalano, R. F., \& Oxford, M. (2000). Ethnic identity among monoracial and multiracial early adolescents. Journal of Early Adolescence, 4, 365-383.

Spengler, P., \& Wittchen, H.-U. (1989). Procedural validity of standardized symptoms questions for the assessment of psychotic symptoms: A comparison of the CIDI with two clinical methods. Comprehensive Psychiatry, 29, 309-322.

Spitzer, R. L., Williams, J. B. W., Gibbon, M., \& First, M. B. (1990). Structured Clinical Interview for DSM-III-R: Patient Edition (SCID-P, Version 1.0). Washington, DC: American Psychiatric Press.

Steele, C. M. (1997). A threat in the air: How stereotypes shape the intellectual identities and performance of women and African-Americans. American Psychologist, 52, 613-629.

Steele, C. M., \& Aronson, J. (1995). Stereotype threat and the intellectual test performance of African Americans. Journal of Personality \& Social Psychology, 69, 797-811.

Stevenson, H. C. (1995). Relationship of adolescent perceptions of racial socialization to racial identity. Journal of Black Psychology, 21, 49-70.

Stevenson, H. C. (1997). Managing anger: Protective, proactive, or adaptive racial socialization identity profiles and African-American manhood development. Journal of Intervention and Prevention in the Community, 16, 35-61. 
Sue, D.W., Arredondo, P. \& McDavis, R.J. (1992). Multicultural Counseling Competencies: A Call to the Profession. Journal of Counseling \& Development, 70, 477486.

Taub, D. J., \& McEwen, M. K. (1992). The relationship of racial identity attitudes to autonomy and mature interpersonal relationships in Black and White undergraduate women. Journal of College Student Development, 33, 29-50.

Taylor, D. L., Biafora, F. A., \& Warheit, G. J.(1994). Racial mistrust and disposition to deviance among African American, Haitian, and other Caribbean island adolescent boys, Law and Human Behavior, 18, 291-303.

Taylor, John and R. Jay Turner. 2002. "Perceived Discrimination, Social Stress, and Depression in the Transition to Adulthood: Racial Contrasts." Social Psychology Quarterly, 65, 213-225.

Thomas, C. (1971). Boys no more. Beverly Hills, CA: Glencoe Press.

Thomas, A. J., \& Speight, S. L. (1999). Racial identity and racial socialization attitudes of African American parents. Journal of Black Psychology, 25, 152-170.

Tubman, J. G., Wagner, E. F., Gil A. G., \& Pate, K. N. (2002). Brief motivational intervention for substance-abusing delinquent adolescents: Guided self-change as a social work practice innovation. Health and Social Work, 27, 208-212.

Turner, R. J., and Gil, A. G. (2002). Psychiatric and substance use disorders in South Florida: Racial/ethnic and gender contrasts in a young adult cohort. Arch. Gen. Psychiatry 59: 43-50.

United States Department of Health and Human Services, 2001. HHS, ABC Radio Networks to launch education campaign to close African-American health gap. AFRICAN-AMERICAN HEALTH GAP. Online [http://www.hhs.gov/news/press/2001 pres/20011119.html] accessed August 7, 2004.

Vega, W. A. \& Gil, A. G. (1993). Drug use and ethnicity in early adolescence. Plenum Press, New York.

Vega, W. A., Zimmerman, R. S., Warheit, G. J., Apospori, E., \& Jackson, D. J. (1993). Risk factors for early substance use by adolescents in four racial/ethnic groups. American Journal of Public Health, 83, 185-189.

Vandiver, B. J. (2001). Psychological nigrescence revisited: Introduction and overview. Multicultural Counseling and Development, 29,14-19. 
Vandiver, B. J., Cross, W. E., Jr., Worrell, F. C., \& Fhagen-Smith, P. E. (2002). Validating the cross racial identity scale. Journal of Counseling Psychology, 49, 71-85.

Vinson, T. S., \& Neimeyer, G. J. (2000). The relationship between racial identity development and multicultural counseling competency. Journal of Multicultural Counseling and Development, 28, 177-191.

Von Eye, A. \& Bergman, L. R. (2003). Research strategies in developmental psychopathology: Dimensional identity and the person-oriented approach. Development and Psychopathology, 15, 553-580.

Wacker, H., Battegay, R., \& Schlosser, C. (1990). Using the CIDI-C in the general population. In C.N. Stefains, A.D. Rabavilas, \& C.R. Soldatos (Eds.), Psychiatry: $A$ world perspective (pp. 138-143). New York: Elsevier Science.

Washington, A. E., Napoles-Springer, A., Forte, D. A., Alexander, M., \& Perez-Stable, E.J. (2002). Establishing centers to address treatment effectiveness in diverse ethnic groups: The MEDTEP Experience. Ethnicity \& Health, 7, 231-42.

Wilson, J. W., \& Constantine, M. G. (1999). Racial identity attitudes, self-concept, and perceived family cohesion in Black College students. Journal of Black Studies, 29, 354-366.

Winston, R. B., \& Miller, T. K. (1987). Student development task and lifestyle inventory manual. Athens, GA: Student Development Associates.

Wittchen, H.-U., Robins, L.N., Cottler, L.B., Sartorious, N., Burke, J.D., \& Regier, D. (1991). Cross-cultural feasibility, reliability, and sources of variance in the Composite International Diagnostic Interview (CIDI). British Journal of Psychiatry, 159, 645-653. 
Appendix

Table 24. Hierarchical Multiple Regression Model Predicting Family Pride (N=275)

\begin{tabular}{|c|c|c|c|c|c|c|}
\hline & $B$ & $\beta$ & $R^{2}$ & $R^{2}$ Change & F Change & $t$ \\
\hline Step 1 & & & .00 & .00 & .47 & \\
\hline Age & -.05 & -.04 & & & & -.65 \\
\hline Gender & .08 & .04 & & & & .60 \\
\hline Step 2 & & & .01 & .00 & .48 & \\
\hline Age & -.06 & -.04 & & & & -.69 \\
\hline Gender & .08 & .04 & & & & .66 \\
\hline W3 Family Pride & .07 & .04 & & & & .69 \\
\hline Step 3 & & & .01 & .00 & .94 & \\
\hline Age & -.06 & -.04 & & & & -.69 \\
\hline Gender & .08 & .04 & & & & .69 \\
\hline W3 Family Pride & .06 & .04 & & & & .63 \\
\hline $\begin{array}{l}\text { W3 Racial Identity } \\
\text { Clusters }\end{array}$ & 11 & 06 & & & & 07 \\
\hline
\end{tabular}

Note. Overall Significance, $F(4,270)=.59$ 
Table 25. Hierarchical Multiple Regression Model Predicting Racial Mistrust of African-American co-workers $(N=281)$

\begin{tabular}{|c|c|c|c|c|c|c|}
\hline & $B$ & $\beta$ & $R^{2}$ & $R^{\prime}$ Change & $F$ Change & $t$ \\
\hline Step 1 & & & .01 & .01 & 2.01 & \\
\hline Age & -.07 & -.04 & & & & -.74 \\
\hline Gender & .26 & .10 & & & & 1.71 \\
\hline Step 2 & & & .02 & .00 & .68 & \\
\hline Age & -.07 & .04 & & & & -.65 \\
\hline Gender & .28 & .11 & & & & 1.82 \\
\hline W3 Racial Mistrust & .08 & .05 & & & & .82 \\
\hline Step 3 & & & .02 & .00 & 1.77 & \\
\hline Age & -.06 & -.04 & & & &.-64 \\
\hline Gender & .29 & .11 & & & & 1.86 \\
\hline W3 Racial Mistrust & .08 & .06 & & & & .91 \\
\hline $\begin{array}{l}\text { W3 Racial Identity } \\
\text { Clusters }\end{array}$ & -.19 & -.08 & & & & -1.33 \\
\hline
\end{tabular}

Note. Overall Significance, $F(4,276)=1.62$ 
Table 26. Hierarchical Multiple Regression Model Predicting Racial Mistrust of Hispanic Co-Workers $(N=281)$

\begin{tabular}{|c|c|c|c|c|c|c|}
\hline & $B$ & $\beta$ & $R^{2}$ & $R^{2}$ Change & F Change & $t$ \\
\hline Step I & & & .01 & .01 & .80 & \\
\hline Age & -.04 & -.02 & & & & -.40 \\
\hline Gender & .17 & .07 & & & & 1.11 \\
\hline Step 2 & & & .01 & .00 & .17 & \\
\hline Age & -.03 & -.02 & & & & -.36 \\
\hline Gender & .18 & .07 & & & & 1.16 \\
\hline W3 Racial Mistrust & .04 & .03 & & & & .41 \\
\hline Step 3 & & & .01 & .00 & .44 & \\
\hline Age & -.03 & .10 & & & & -.35 \\
\hline Gender & .18 & .07 & & & & 1.16 \\
\hline W3 Racial Mistrust & .04 & .03 & & & & .41 \\
\hline $\begin{array}{l}\text { W3 Racial Identity } \\
\text { Clusters }\end{array}$ & -.09 & -.04 & & & & -.66 \\
\hline
\end{tabular}

Note. Overall Significance, $F(4,276)=.55$ 
Table 27. Hierarchical Multiple Regression Model Predicting Racial Mistrust of White Co-Workers $(N=281)$

\begin{tabular}{|c|c|c|c|c|c|c|}
\hline & $B$ & $\beta$ & $R^{2}$ & $R^{2}$ Change & F Change & $t$ \\
\hline Step 1 & & & .01 & .01 & 1.72 & \\
\hline Age & -.17 & -.10 & & & & -1.70 \\
\hline Gender & .07 & .03 & & & & .45 \\
\hline Step 2 & & & .01 & .00 & .01 & \\
\hline Age & -.17 & -.10 & & & & -1.70 \\
\hline Gender & .07 & .03 & & & & 1.43 \\
\hline W3 Racial Mistrust & .01 & .00 & & & & -.07 \\
\hline Step 3 & & & .02 & .01 & 1.40 & \\
\hline Age & -.17 & -.10 & & & & -1.71 \\
\hline Gender & .06 & .02 & & & & .36 \\
\hline W3 Racial Mistrust & -.02 & -.01 & & & & -.22 \\
\hline $\begin{array}{l}\text { W3 Racial Identity } \\
\text { Clusters }\end{array}$ & .08 & .04 & & & & .58 \\
\hline
\end{tabular}

Note. Overall Significance, $F(4,276)=.94$ 
Table 28. Hierarchical Multiple Regression Model Predicting Number of times using marijuana during the past year $(N=268)$

\begin{tabular}{|c|c|c|c|c|c|c|}
\hline & $B$ & $\beta$ & $R^{2}$ & $R^{2}$ Change & F Change & $t$ \\
\hline Step 1 & & & .02 & .02 & 2.10 & \\
\hline Age & .12 & .05 & & & & .77 \\
\hline Gender & -.42 & -.11 & & & & -1.73 \\
\hline Step 2 & & & .03 & .01 & 3.06 & \\
\hline Age & .14 & .06 & & & & .93 \\
\hline Gender & -.38 & -.10 & & & & -1.61 \\
\hline W3 Marijuana/year & .13 & .11 & & & & 1.75 \\
\hline Step 3 & & & .03 & .00 & .14 & \\
\hline Age & .15 & .06 & & & & .94 \\
\hline Gender & -.39 & -.10 & & & & -1.63 \\
\hline W3 Marijuana/year & .14 & .11 & & & & 1.73 \\
\hline $\begin{array}{l}\text { W3 Racial Identity } \\
\text { Clusters }\end{array}$ & .08 & .02 & & & & .37 \\
\hline
\end{tabular}

Note. Overall Significance, $F(4,263)=1.85$ 
Table 29. Hierarchical Multiple Regression Model Predicting Amounts of alcohol use before or during sexual intercourse $(N=244)$

\begin{tabular}{lcccccc}
\hline & $B$ & $\beta$ & $R^{2}$ & $R^{2}$ Change & F Change & \multicolumn{1}{c}{$t$} \\
\hline Step 1 & & & & & & \\
Age & -.00 & -.02 & .01 & .01 & .77 & -.35 \\
Gender & -.13 & -.08 & & & & -1.23 \\
Step 2 & & & & & & \\
Age & -.01 & -.01 & & .02 & 2.27 & -.21 \\
Gender & -.10 & -.07 & & & & -1.01 \\
W3 Minor Deviance & .47 & .15 & & & & 1.85 \\
W3 Major Deviance & -.13 & -.03 & & & & -.32 \\
Step 3 & & & & & & \\
Age & -.01 & -.01 & & .00 & & -.21 \\
Gender & -.10 & -.07 & & & & -.98 \\
W3 Minor Deviance & .48 & .15 & & & & 1.85 \\
W3 Major Deviance & -.14 & -.13 & & & -.33 \\
W3 Racial Identity & & & & & \\
Clusters & -.02 & -.15 & & & -.23 \\
\hline
\end{tabular}

Note. Overall Significance, $F(5,238)=1.22$ 
Table 30. Hierarchical Multiple Regression Model Predicting Number of Lifetime Psychiatric Diagnoses $(N=284)$

\begin{tabular}{lcccccc}
\hline & $B$ & $\beta$ & $R^{2}$ & $R^{2}$ Change & F Change & $t$ \\
\hline Step 1 & & & & & & \\
Age & & & .03 & .03 & $3.70^{* *}$ & \\
Gender & -.05 & -.03 & & & & -.45 \\
& -.49 & -.16 & & & & $-2.72^{*}$ \\
Step 2 & & & & & & \\
Age & -.05 & -.03 & & .00 & .29 & -.45 \\
Gender & -.49 & -.16 & & & & $-2.69^{*}$ \\
W3 Racial Identity & & & & & & -.54 \\
Clusters & -.10 & -.03 & & & & \\
\hline
\end{tabular}

Note. Overall Significance, $F(3,280)=2.66 .{ }^{*} p<.05,{ }^{* *} p<.01$. 
Table 31. Hierarchical Multiple Regression Model Predicting Racial Identification and Pride by earlier levels of CESD Depression $(N=266)$

\begin{tabular}{|c|c|c|c|c|c|c|}
\hline & $B$ & $\beta$ & $R^{2}$ & $R^{2}$ Change & F Change & $t$ \\
\hline Step 1 & & & .01 & .01 & .72 & \\
\hline Age & .10 & .07 & & & & 1.16 \\
\hline Gender & -.01 & -.01 & & & & -.10 \\
\hline Step 2 & & & .01 & .00 & .03 & \\
\hline Age & .10 & .07 & & & & 1.15 \\
\hline Gender & -.01 & -.01 & & & & -.11 \\
\hline W3 Racial Identity & & & & & & \\
\hline Clusters & -.01 & -.01 & & & & -.17 \\
\hline Step 3 & & & .01 & .00 & .34 & \\
\hline Age & .10 & .07 & & & & 1.15 \\
\hline Gender & -.03 & -.01 & & & & -.20 \\
\hline W3 Racial Identity & & & & & & \\
\hline Clusters & -.01 & -.01 & & & & -.18 \\
\hline W3 Depression & .05 & .04 & & & & .58 \\
\hline
\end{tabular}

Note. Overall Significance, $F(4,261)=.45$ 
Table 32. Hierarchical Multiple Regression Model Predicting Racial Sociability by earlier levels of CESD Depression $(N=265)$

\begin{tabular}{|c|c|c|c|c|c|c|}
\hline & $B$ & $\beta$ & $R^{2}$ & $R^{2}$ Change & F Change & $t$ \\
\hline Step 1 & & & .00 & .00 & .51 & \\
\hline Age & .06 & .03 & & & & .49 \\
\hline Gender & .18 & .06 & & & & .96 \\
\hline Step 2 & & & .01 & .00 & .51 & \\
\hline Age & .06 & .03 & & & & .51 \\
\hline Gender & .18 & .06 & & & & .99 \\
\hline W3 Racial Identity & & & & & & \\
\hline Clusters & .04 & .04 & & & & .71 \\
\hline Step 3 & & & .01 & .00 & .05 & \\
\hline Age & .06 & .03 & & & & .51 \\
\hline Gender & .17 & .06 & & & & .93 \\
\hline $\begin{array}{l}\text { W3 Racial Identity } \\
\text { Clusters }\end{array}$ & .04 & .04 & & & & .71 \\
\hline W3 Depression & .02 & .01 & & & & .23 \\
\hline
\end{tabular}

Note. Overall Significance, $F(4,260)=.39$ 
Table 33. Hierarchical Multiple Regression Model Predicting Racial Identification and Pride by earlier levels of Family Pride $(N=271)$

\begin{tabular}{lcccccc}
\hline & $B$ & $\beta$ & $R^{2}$ & $R^{2}$ Change & $F$ Change & $t$ \\
\hline Step 1 & & & & & & \\
Age & .09 & .06 & & .00 & .51 & .98 \\
Gender & -.01 & -.01 & & & & -.09 \\
Step 2 & & & & & & \\
Age & .09 & .06 & & .00 & .21 & .97 \\
Gender & -.02 & -.01 & & & & -.11 \\
W3 Racial Identity & & & & & & -.45 \\
Clusters & .16 & -.03 & & & & \\
Step 3 & & & & & & \\
Age & .10 & .07 & & & & $-.44^{* *}$ \\
Gender & -.05 & -.02 & & & & -.10 \\
W3 Racial Identity & -.02 & -.03 & & & & -.53 \\
Clusters & & & & & & \\
W3 Family Pride & -.23 & -.13 & & & & \\
\hline
\end{tabular}

Note. Overall Significance, $F(4,266)=1.42 .{ }^{* *} p<.05$. 
Table 34. Hierarchical Multiple Regression Model Predicting Racial Sociability by earlier levels of Family Pride $(N=270)$

\begin{tabular}{|c|c|c|c|c|c|c|}
\hline & $B$ & $\beta$ & $R^{2}$ & $R^{2}$ Change & F Change & $t$ \\
\hline Step 1 & & & .01 & .01 & .88 & \\
\hline Age & .10 & .05 & & & & .80 \\
\hline Gender & .22 & .07 & & & & 1.18 \\
\hline Step 2 & & & .01 & .00 & .81 & \\
\hline Age & .10 & .05 & & & & .81 \\
\hline Gender & .23 & .08 & & & & 1.23 \\
\hline $\begin{array}{l}\text { W3 Racial Identity } \\
\text { Clusters }\end{array}$ & .05 & .06 & & & & .90 \\
\hline Step 3 & & & .02 & .01 & 2.49 & \\
\hline Age & .11 & .06 & & & & .91 \\
\hline Gender & .20 & .07 & & & & 1.06 \\
\hline $\begin{array}{l}\text { W3 Racial Identity } \\
\text { Clusters }\end{array}$ & .05 & .05 & & & & .85 \\
\hline W3 Family Pride & -.23 & -.10 & & & & -.158 \\
\hline
\end{tabular}

Note. Overall Significance, $F(4,265)=1.27$ 
Table 35. Hierarchical Multiple Regression Model Predicting Racial Identification and Pride by earlier levels of Racial Mistrust $(N=275)$

\begin{tabular}{|c|c|c|c|c|c|c|}
\hline & $B$ & $\beta$ & $R^{2}$ & $R^{2}$ Change & F Change & $t$ \\
\hline Step 1 & & & .00 & .00 & .57 & \\
\hline Age & .10 & .07 & & & & 1.07 \\
\hline Gender & .02 & .01 & & & & .11 \\
\hline Step 2 & & & .01 & .00 & .26 & \\
\hline Age & .10 & .07 & & & & 1.06 \\
\hline Gender & .01 & .01 & & & & .09 \\
\hline W3 Racial Identity & & & & & & \\
\hline Clusters & -.02 & -.03 & & & & -.51 \\
\hline Step 3 & & & .01 & .00 & .00 & \\
\hline Age & .10 & .07 & & & & 1.05 \\
\hline Gender & .01 & .01 & & & & .09 \\
\hline $\begin{array}{l}\text { W3 Racial Identity } \\
\text { Clusters }\end{array}$ & -.02 & -.03 & & & & -.51 \\
\hline W3 Racial Mistrust & .00 & .00 & & & & .00 \\
\hline
\end{tabular}

Note. Overall Significance, $F(4,270)=.35$ 
Table 36. Hierarchical Multiple Regression Model Predicting Racial Sociability by earlier levels of Racial Mistrust ( $N=274)$

\begin{tabular}{|c|c|c|c|c|c|c|}
\hline & $B$ & $\beta$ & $R^{2}$ & $R^{2}$ Change & $F$ Change & $t$ \\
\hline Step 1 & & & .01 & .01 & .78 & \\
\hline Age & .09 & .05 & & & & .73 \\
\hline Gender & .21 & .07 & & & & 1.13 \\
\hline Step 2 & & & .01 & .00 & .48 & \\
\hline Age & .09 & .05 & & & & .73 \\
\hline Gender & .21 & .07 & & & & 1.15 \\
\hline W3 Racial Identity & & & & & & \\
\hline Clusters & .04 & .04 & & & & .69 \\
\hline Step 3 & & & .01 & .00 & .05 & \\
\hline Age & .08 & .04 & & & & .70 \\
\hline Gender & .21 & .07 & & & & 1.10 \\
\hline $\begin{array}{l}\text { W3 Racial Identity } \\
\text { Clusters }\end{array}$ & .04 & .04 & & & & .66 \\
\hline W3 Racial Mistrust & -.02 & -.01 & & & & -.22 \\
\hline
\end{tabular}

Note. Overall Significance, $F(4,269)=.52$ 
Table 37. Hierarchical Multiple Regression Model Predicting Racial Identification and Pride by earlier levels of Self-Derogation $(N=267)$

$B \quad \beta \quad R^{2} \quad R^{2}$ Change $F$ Change

Step 1

Age

Gender

$.12 \quad .08$

$.04 \quad .02$

Step 2

Age

Gender

W3 Racial Identity

Clusters

$.12 \quad .08$

$.04 \quad .02$

$-.03 \quad-.04$

.01

.01

.01

.82

Step 3

Age

Gender

W3 Racial Identity

Clusters

Self-Derogation
$.05 \quad .02$

$-.03 \quad-.04$

.01

.00

1.41
$.12 \quad .08$
1.28

.29

.00

1.28

.27

$-.56$

1.30

.36

$-.70$

1.19

Note. Overall Significance, $F(4,262)=.84$ 
Table 38. Hierarchical Multiple Regression Model Predicting Racial Sociability by earlier levels of Self-Derogation $(N=266)$

\begin{tabular}{|c|c|c|c|c|c|c|}
\hline & $B$ & $\beta$ & $R^{2}$ & $R^{2}$ Change & $F$ Change & $t$ \\
\hline Step 1 & & & .01 & .01 & .86 & \\
\hline Age & .08 & .04 & & & & .63 \\
\hline Gender & .24 & .08 & & & & 1.25 \\
\hline Step 2 & & & .01 & .00 & .33 & \\
\hline Age & .08 & .04 & & & & .63 \\
\hline Gender & .24 & .08 & & & & 1.27 \\
\hline W3 Racial Identity & & & & & & \\
\hline Clusters & .03 & .04 & & & & .57 \\
\hline Step 3 & & & .01 & .00 & .35 & \\
\hline Age & .08 & .04 & & & & .63 \\
\hline Gender & .25 & .08 & & & & 1.31 \\
\hline $\begin{array}{l}\text { W3 Racial Identity } \\
\text { Clusters }\end{array}$ & .03 & .03 & & & & .50 \\
\hline Self-Derogation & .10 & .04 & & & & .59 \\
\hline
\end{tabular}

Note. Overall Significance, $F(4,261)=.60$ 
Table 39. Hierarchical Multiple Regression Model Predicting Racial Identification and Pride by earlier levels of Past-Month Alcohol Use $(N=237)$

\begin{tabular}{|c|c|c|c|c|c|c|}
\hline & $B$ & $\beta$ & $R^{2}$ & $R^{2}$ Change & F Change & $t$ \\
\hline Step 1 & & & .01 & .01 & .10 & \\
\hline Age & .14 & .09 & & & & 1.41 \\
\hline Gender & .03 & .02 & & & & .26 \\
\hline Step 2 & & & .01 & .00 & .32 & \\
\hline Age & .14 & .09 & & & & 1.41 \\
\hline Gender & .04 & .02 & & & & .23 \\
\hline W3 Racial Identity & & & & & & \\
\hline Clusters & -.03 & -.04 & & & & -.56 \\
\hline Step 3 & & & .01 & .00 & .01 & \\
\hline Age & .14 & .10 & & & & 1.41 \\
\hline Gender & .03 & .02 & & & & .23 \\
\hline $\begin{array}{l}\text { W3 Racial Identity } \\
\text { Clusters }\end{array}$ & -.03 & -.04 & & & & -.55 \\
\hline $\begin{array}{l}\text { Alcohol use past } \\
\text { month }\end{array}$ & .01 & .01 & & & & .11 \\
\hline
\end{tabular}

Note. Overall Significance, $F(4,232)=.58$ 
Table 40. Hierarchical Multiple Regression Model Predicting Racial Sociability by earlier levels of Past-Month Alcohol Use $(N=236)$

$\begin{array}{llllll}B & \beta & R^{2} & R^{2} \text { Change } & \text { F Change } & t\end{array}$

Step 1

.01

.01

1.19

Age .12

.06

$.29 \quad .10$

1.44

Gender

.10

Step 2

Age

.12

.01

.00

.28

Gender

.29

.06

.88

1.45

W3 Racial Identity

Clusters

$.03 \quad .04$

.53

Step 3

Age

$.11 \quad .06$

.01

.00

.20

Gender

W3 Racial Identity

$.03 \quad .03$

Clusters

Alcohol use past

$-.03$

$-.03$ month

Note. Overall Significance, $F(4,231)=.71$ 
Table 41. Hierarchical Multiple Regression Model Predicting Racial Identification and Pride by earlier levels of Past-Month Marijuana use $(N=260)$

\begin{tabular}{|c|c|c|c|c|c|c|}
\hline & $B$ & $\beta$ & $R^{2}$ & $R^{2}$ Change & F Change & $t$ \\
\hline Step 1 & & & .01 & .01 & .76 & \\
\hline Age & .11 & .08 & & & & 1.22 \\
\hline Gender & .00 & .00 & & & & .01 \\
\hline Step 2 & & & .01 & .00 & .10 & \\
\hline Age & .11 & .08 & & & & 1.21 \\
\hline Gender & .00 & .00 & & & & -.01 \\
\hline $\begin{array}{l}\text { W3 Racial Identity } \\
\text { Clusters }\end{array}$ & -.01 & -.02 & & & & -.32 \\
\hline Step 3 & & & .01 & .00 & .01 & \\
\hline Age & .11 & .08 & & & & 1.20 \\
\hline Gender & .00 & .00 & & & & -.01 \\
\hline $\begin{array}{l}\text { W3 Racial Identity } \\
\text { Clusters }\end{array}$ & -.01 & -.02 & & & & -.32 \\
\hline $\begin{array}{l}\text { Marijuana use past } \\
\text { month }\end{array}$ & -.01 & -.01 & & & & -.11 \\
\hline
\end{tabular}

Note. Overall Significance, $F(4,255)=.41$ 
Table 42. Hierarchical Multiple Regression Model Predicting Racial Sociability by earlier levels of Past-Month Marijuana Use $(N=259)$

\begin{tabular}{|c|c|c|c|c|c|c|}
\hline & $B$ & $\beta$ & $R^{2}$ & $R^{2}$ Change & F Change & $t$ \\
\hline Step 1 & & & .01 & .01 & .81 & \\
\hline Age & .11 & .06 & & & & .92 \\
\hline Gender & .19 & .07 & & & & 1.04 \\
\hline Step 2 & & & .01 & .00 & .56 & \\
\hline Age & .11 & .06 & & & & .93 \\
\hline Gender & .20 & .07 & & & & 1.07 \\
\hline $\begin{array}{l}\text { W3 Racial Identity } \\
\text { Clusters }\end{array}$ & .04 & .05 & & & & .75 \\
\hline Step 3 & & & .01 & .00 & .09 & \\
\hline Age & .11 & .06 & & & & .90 \\
\hline Gender & .20 & .07 & & & & 1.04 \\
\hline $\begin{array}{l}\text { W3 Racial Identity } \\
\text { Clusters }\end{array}$ & .04 & .05 & & & & .75 \\
\hline $\begin{array}{l}\text { Marijuana use past } \\
\text { month }\end{array}$ & -.03 & -.02 & & & & -.31 \\
\hline
\end{tabular}

Note. Overall Significance, $F(4,254)=.57$ 
Table 43. Hierarchical Multiple Regression Model Predicting Racial Identification and Pride by earlier levels of Deviant Behaviors $(N=272)$

\begin{tabular}{|c|c|c|c|c|c|c|}
\hline & $B$ & $\beta$ & $R^{2}$ & $R^{2}$ Change & F Change & $t$ \\
\hline Step 1 & & & .01 & .01 & .62 & \\
\hline Age & .10 & .07 & & & & 1.11 \\
\hline Gender & .03 & .01 & & & & .22 \\
\hline Step 2 & & & .01 & .00 & .03 & \\
\hline Age & .10 & .07 & & & & 1.10 \\
\hline Gender & .03 & .01 & & & & .21 \\
\hline $\begin{array}{l}\text { W3 Racial Identity } \\
\text { Clusters }\end{array}$ & -.01 & -.01 & & & & -.16 \\
\hline Step 3 & & & .01 & .00 & .12 & \\
\hline Age & .10 & .07 & & & & 1.10 \\
\hline Gender & .03 & .01 & & & & .19 \\
\hline $\begin{array}{l}\text { W3 Racial Identity } \\
\text { Clusters }\end{array}$ & .00 & -.01 & & & & -.08 \\
\hline Minor Deviance & .14 & .35 & & & & .40 \\
\hline Major Deviance & -.25 & .55 & & & & -.46 \\
\hline
\end{tabular}

Note. Overall Significance, $F(5,266)=.30$ 
Table 44. Hierarchical Multiple Regression Model Predicting Racial Sociability by earlier levels of Deviant Behaviors $(N=271)$

Step 1

Age

Gender

Step 2

Age

Gender

W3 Racial Identity

Clusters
B .08

\section{$\beta$} .08

$.18 \quad .06$

.01

$.19 \quad .06$

$.05 \quad .06$

.00
F Change

.58

.00 .65

.96

.00

.86

1.01

.93

Step 3

Age

$.08 \quad .04$
.18

Gender

$.18 \quad .06$

.00

.25

.01

W3 Racial Identity

$.06 \quad .06$

Clusters

Minor Deviance

$.20 \quad .03$

Major Deviance

$\begin{array}{ll}-.52 & -.06\end{array}$

Note. Overall Significance, $F(5,365)=.50$ 
Table 45. Hierarchical Multiple Regression Model Predicting Racial Significance by earlier levels of CESD Depression $(N=266)$

\begin{tabular}{|c|c|c|c|c|c|c|}
\hline & $B$ & $\beta$ & $R^{2}$ & $R^{2}$ Change & F Change & $t$ \\
\hline Step 1 & & & .02 & .02 & $3.10^{* *}$ & \\
\hline Age & .13 & .06 & & & & .94 \\
\hline Gender & .53 & .15 & & & & $2.43 * *$ \\
\hline Step 2 & & & .03 & .00 & .54 & \\
\hline Age & .14 & .06 & & & & .96 \\
\hline Gender & .54 & .15 & & & & $2.46^{* *}$ \\
\hline W3 Racial Identity & & & & & & \\
\hline Clusters & .05 & .05 & & & & .73 \\
\hline Step 3 & & & .03 & .00 & .34 & \\
\hline Age & .14 & .06 & & & & .96 \\
\hline Gender & .52 & .15 & & & & $2.32^{* *}$ \\
\hline $\begin{array}{l}\text { W3 Racial Identity } \\
\text { Clusters }\end{array}$ & .05 & .04 & & & & .72 \\
\hline W3 Depression & .08 & .04 & & & & .58 \\
\hline
\end{tabular}

Note. Overall Significance, $F(4,261)=1.76 .^{* *} p<.05$. 
Table 46. Hierarchical Multiple Regression Model Predicting Racial Significance by earlier levels of Racial Mistrust $(N=275)$

\begin{tabular}{lcccccc}
\hline & $B$ & $\beta$ & $R^{2}$ & $R^{2}$ Change & F Change & $t$ \\
\hline Step 1 & & & & & & \\
Age & .15 & .06 & .03 & .03 & $3.91^{* *}$ & \\
Gender & .58 & .17 & & & & 1.06 \\
Step 2 & & & .03 & .00 & .63 & \\
Age & .15 & .07 & & & & $1.73^{*}$ \\
Gender & .59 & .17 & & & & $2.76^{*}$ \\
W3 Racial Identity & & & & & & \\
Clusters & .05 & .05 & & & & .79 \\
Step 3 & & & & & & \\
Age & .14 & .06 & & .00 & & .98 \\
Gender & .56 & .16 & & & & .69 \\
W3 Racial Identity & .05 & .04 & & & & \\
Clusters & & & & & & \\
W3 Racial Mistrust & -.10 & -.05 & & & & \\
\hline
\end{tabular}

Note. Overall Significance, $F(4,270)=2.26 .{ }^{*} p<.01,{ }^{* *} p<.05$. 
Table 47. A Hierarchical Multiple Regression Model Predicting Racial Significance by earlier levels of Past-Month Alcohol use $(N=237)$

\begin{tabular}{|c|c|c|c|c|c|c|}
\hline & $B$ & $\beta$ & $R^{2}$ & $R^{2}$ Change & F Change & $t$ \\
\hline Step 1 & & & .02 & .02 & 2.75 & \\
\hline Age & .16 & .07 & & & & 1.07 \\
\hline Gender & .54 & .15 & & & & 2.28 \\
\hline Step 2 & & & .02 & .00 & .33 & \\
\hline Age & .54 & .07 & & & & 1.06 \\
\hline Gender & .08 & .15 & & & & 2.30 \\
\hline $\begin{array}{l}\text { W3 Racial Identity } \\
\text { Clusters }\end{array}$ & .04 & .04 & & & & .58 \\
\hline Step 3 & & & .03 & .00 & .20 & \\
\hline Age & .16 & .07 & & & & 1.04 \\
\hline Gender & .54 & .15 & & & & 2.27 \\
\hline $\begin{array}{l}\text { W3 Racial Identity } \\
\text { Clusters }\end{array}$ & .04 & .04 & & & & .53 \\
\hline $\begin{array}{l}\text { Alcohol use past } \\
\text { month }\end{array}$ & -.04 & -.03 & & & & -.45 \\
\hline
\end{tabular}

Note. Overall Significance, $F(4,232)=1.50$ 
Table 48. Hierarchical Multiple Regression Model Predicting Racial Significance by earlier levels of Past-Month Marijuana Use $(N=260)$

\begin{tabular}{|c|c|c|c|c|c|c|}
\hline & $B$ & $\beta$ & $R^{2}$ & $R^{2}$ Change & $F$ Change & $t$ \\
\hline Step 1 & & & .02 & .02 & 2.73 & \\
\hline Age & .17 & .08 & & & & 1.19 \\
\hline Gender & .48 & .14 & & & & $2.19 * *$ \\
\hline Step 2 & & & .02 & .00 & .60 & \\
\hline Age & .17 & .08 & & & & 1.20 \\
\hline Gender & .49 & .14 & & & & $2.22 * *$ \\
\hline $\begin{array}{l}\text { W3 Racial Identity } \\
\text { Clusters }\end{array}$ & .05 & .05 & & & & .77 \\
\hline Step 3 & & & .03 & .01 & 2.67 & \\
\hline Age & .19 & .08 & & & & 1.31 \\
\hline Gender & .51 & .15 & & & & $2.33 * *$ \\
\hline $\begin{array}{l}\text { W3 Racial Identity } \\
\text { Clusters }\end{array}$ & .05 & .05 & & & & .77 \\
\hline $\begin{array}{l}\text { Marijuana use past } \\
\text { month }\end{array}$ & .18 & .10 & & & & 1.64 \\
\hline
\end{tabular}

Note. Overall Significance, $F(4,255)=2.19 .{ }^{* *} p<.05$. 
Table 49. Hierarchical Multiple Regression Model Predicting Racial Significance by earlier levels of Deviant Behaviors $(N=272)$

\begin{tabular}{|c|c|c|c|c|c|c|}
\hline & $B$ & $\beta$ & $R^{2}$ & $R^{2}$ Change & F Change & $t$ \\
\hline Step 1 & & & .03 & .03 & $3.67^{* *}$ & \\
\hline Age & .14 & .06 & & & & .10 \\
\hline Gender & .56 & .16 & & & & $2.65^{*}$ \\
\hline Step 2 & & & .03 & .00 & .94 & \\
\hline Age & .14 & .06 & & & & 1.02 \\
\hline Gender & .57 & .17 & & & & $2.70^{*}$ \\
\hline $\begin{array}{l}\text { W3 Racial Identity } \\
\text { Clusters }\end{array}$ & .06 & .06 & & & & .97 \\
\hline Step 3 & & & .04 & .00 & .73 & \\
\hline Age & .13 & .06 & & & & .92 \\
\hline Gender & .55 & .16 & & & & $2.56^{* *}$ \\
\hline $\begin{array}{l}\text { W3 Racial Identity } \\
\text { Clusters }\end{array}$ & .05 & .05 & & & & .76 \\
\hline Minor Deviance & -57 & -.08 & & & & -1.06 \\
\hline Major Deviance & .18 & .02 & & & & .20 \\
\hline
\end{tabular}

Note. Overall Significance, $F(5,266)=1.94 .{ }^{*} p<.01,{ }^{* *} p<.05$. 
April 10, 1976

1998

2000

2002

$2003-2004$

2004

2004 - present
Born, Lincoln, Nebraska

B.A., Psychology

University of North Carolina at Chapel Hill

Chapel Hill, North Carolina

McKnight Doctoral Fellowship

Florida International University

Miami, Florida

M.S., Psychology

Florida International University

Miami, Florida

Research Interviewer - GAPS program

Community-Based Intervention Research Group.

Miami, Florida

American Psychological Association Minority Substance Abuse Research Fellowship.

Florida International University

Miami, Florida

Doctoral Candidate

Florida International University

Miami, Florida

\section{PUBLICATIONS AND PRESENTATIONS}

Burrow, A. L., Tubman, J. G., \& Finley, G. E. (2004). Adolescent adjustment in a nationally collected sample: Identifying group difference by adoption status, adoption subtype, developmental stage and gender. Journal of Adolescence, 27, 367-282..

Burrow, A. L., \& Finley, G. E. (2004). Transracial, same-race adoptions and the need for multiple measures of adolescent adjustment. American Journal of Orthopsychiatry74, 577-583. 
Burrow, A. L., Burrow, J. L., \& Burrow, B. J. (2003). Transracial adoption: The black white controversy. In E. Farmer, J. Rojewski, and B. Farmer (Eds.), Diversity in America: Visions of the future.

Burrow, A. L., Tubman, J. G., \& Montgomery, M. J. (Submitted, October 2004). Racial Identity: Towards an Integrated Developmental Psychological Literature. Identity: An International Journal of Theory and Research.

Burrow, A. L., Tubman, J. G., \& Gil, A. G. (Submitted, November 2004). Within-Group Heterogeneity in Expressions of Sexual Risk Behaviors among African-American Youth. Journal of Community Psychology.

Finley, G. E., Burrow, A. L., Heller, H. (Submitted, October 2004). Adolescents' Perceptions of Closeness to Fathers and Mothers by Adoptive Status. American Journal of Orthopsychiatry.

Burrow, A. L., Finley, G. E., \& Heller, H. (2003, November). Adoptive and biological children: Who feels closest to father and who to mother? 2003 National Conference on Family Relations Annual Conference, Vancouver, BC.

Burrow, A. L., Tubman, J. G., \& Finley, G. E. (2004, March) Adolescent adjustment: identifying group differences by adoption status, adoption subtype, developmental stage and gender. Society for Research on Adolescence, Tenth Biennial Meeting, Baltimore, MD.

Burrow, A. L. \& Finley, G. E. (2004, March). The transracial adoption outcome controversy in the context of multiple measures of adolescent adjustment. Society for Research on Adolescence, Tenth Biennial Meeting, Baltimore, MD.

Burrow, A. L., Tubman, J. G., \& Gil, A. G. (2004, June). Within-group heterogeneity in expressions of sexual risk behaviors among African-American youth. Research Society on Alcoholism. Twenty-sixth Annual RSA Scientific Meeting, Vancouver, Canada.

Burrow, A. L., Des Rosiers, S. E, Tubman, J. G., \& Gil, A. G. (Accepted, November 2004). Multivariate patterns of African-American substance use during early adolescence. Society for Research on Child Development, Atlanta, GA.

Des Rosiers, S. E., Burrow, A. L., Tubman, J. G., \& Gil, A. G. (Accepted, November, 2004). Cumulative Alcohol and Other Drug Use: A Descriptive Study of AfricanAmerican Early Adolescents. Society for Research on Child Development, Atlanta, GA.

Within-Group Heterogeneity in Expressions of Sexual Risk Behaviors among AfricanAmerican Youth. (2005). Black Identity Series. Florida International University, Miami, FL. 